\title{
PLOIDY MANIPULATION FOR GENETIC IMPROVEMENT IN SOME MEDITERRANEAN FRUIT CROPS
}

PhD CANDIDATE

GIUSEPPE CIMÒ
PhD COORDINATOR

PROF.SSA MARIAANTONIETTA GERMANÀ
SUPERVISOR

PROF.SSA MARIA ANTONIETTA GERMANÀ
CO SUPERVISOR

DRA. MARIA LUISA BADENES 


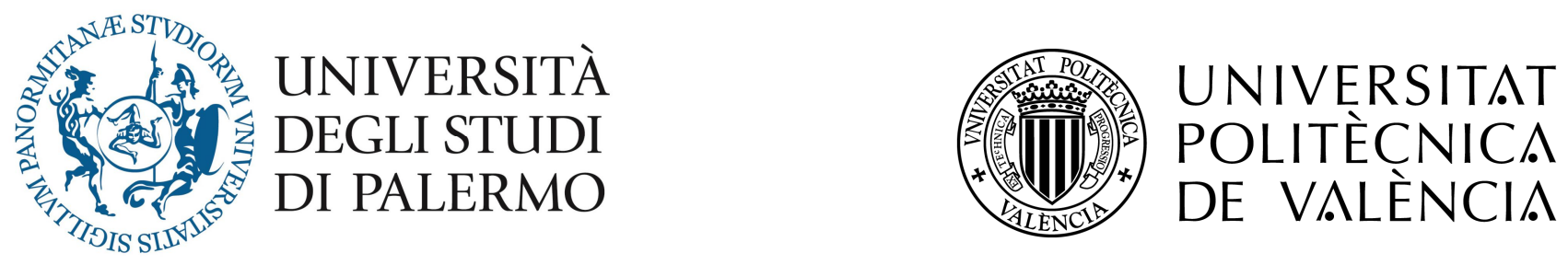

Dottorato Internazionale in 'Frutticoltura Mediterranea'

Dipartimento di Scienze Agrarie e Forestali

AGR/03 - Arboricoltura generale e Coltivazioni arboree

\section{PLOIDY MANIPULATION FOR GENETIC IMPROVEMENT IN SOME MEDITERRANEAN FRUIT CROPS}

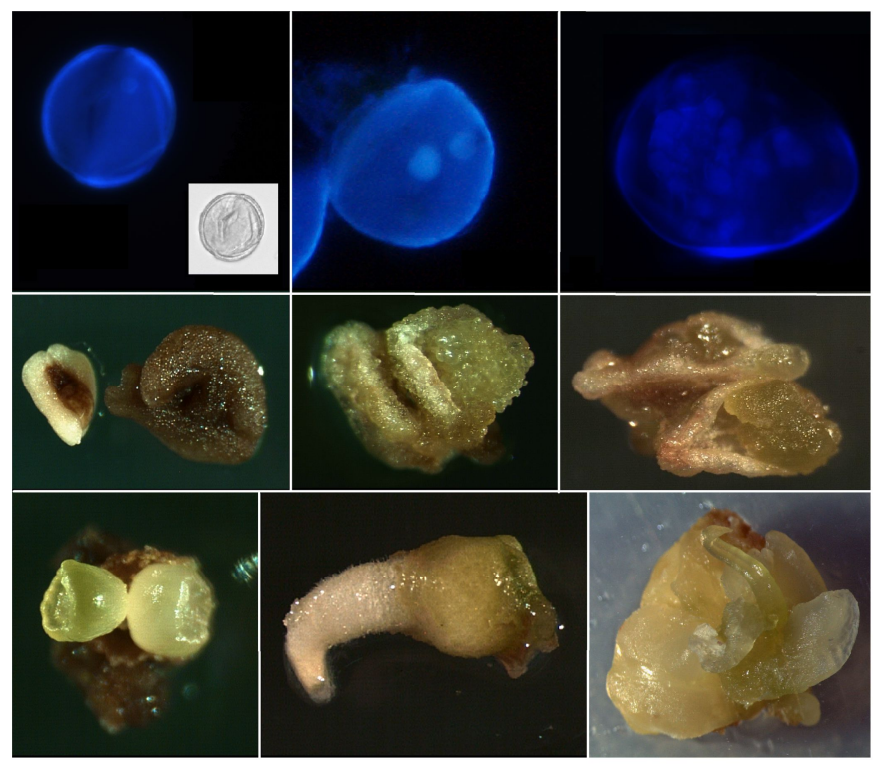

PhD CANDIDATE

GIUSEPPE CIMÒ

Goseme conor

SUPERVISOR

PROF.SSA MARIA ANTONIETTA GERMANÀ

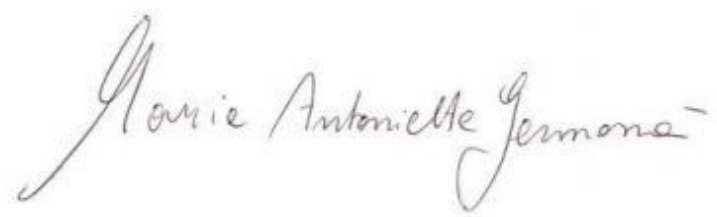

PhD COORDINATOR

PROF.SSA MARIAANTONIETTA GERMANÀ

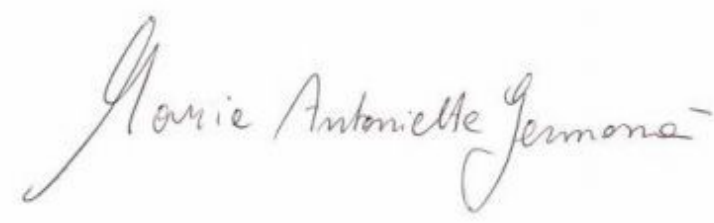

CO SUPERVISOR

DRA. MARIA LUISA BADENES

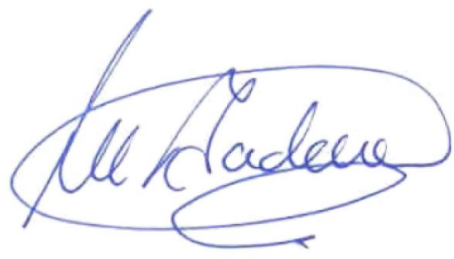





\section{ACKNOWLEDGMENTS}

I am extremely grateful to my supervisor, Prof. Maria Antonietta Germanà, for giving me her trust, for her patience, understanding and affection, for her expert guidance, time and dedication in my training and planning, development and completion of this thesis.

I would like to thank all the staff and colleagues of the 'Università degli Studi di Palermo' for their technical assistance, help and cooperation during my research work.

I would like to express my sincere gratitude to my co-supervisor, Dra Marisa Badenes, for making me feel part of her team, for all her efforts, support, constant encouragement and useful suggestions.

I am thankful to Mar Naval for her guidance, patience and persistence during my invaluable experience at the 'Instituto Valenciano de Investigaciones Agrarias' (IVIA).

I would like to thank all the working group of the 'Fruit Tree Breeding Department' of the IVIA for their cooperation, hospitality and friendship, and to the 'Tissue Culture' group, especially to Pablo Aleza, for his help and disinterested advice.

I am grateful to Manuel Agustí, Carmina Reig, Carlos Mesejo and all the working group of the 'Instituto Agroforestal Mediterráneo' (IAM) for kindly welcoming and supporting me during my stay at the 'Universitat Politècnica de València' (UPV).

I am thankful to Jose M. Seguí-Simarro and all the group of the 'Instituto para la Conservación y la Mejora de la Agrodiversidad Valenciana' (COMAV) for their dedication in my training and improvement on the isolated microspores in vitro culture techniques.

Special thanks to all my friends and to all the amazing people I have met during these years, who have supported me and led me thus far.

Many thanks to my family for having always encouraged and supported me in all my choices and for their great endurance during my long stay away from them.

To Ana Luisa, for all the love you gave me, for being always remained at my side, for your endless and invaluable presence. All this would not be possible without you...

Todo llega para el que sabe esperar. (Henry Longfellow Wadsworth) 



\section{CONTENTS}

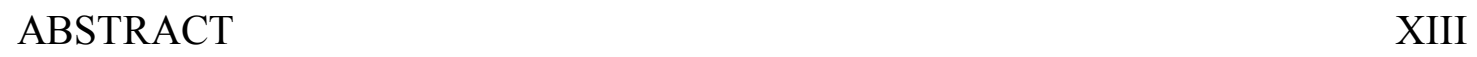

RIASSUNTO XV X

RESUMEN XVII

RESUM XIX

INTRODUCTION 1

1. PLANT BREEDING AND GENETIC RESOURCES 1

1.1 Plant genetic resources 1

1.2 Plant breeding 2

1.3 Breeding objectives and approaches: the case of some Mediterranean fruit trees

1.3.1 Almond (Prunus dulcis Mill.) 4

1.3.2 Mandarin (Citrus reticulata Blanco) 7

1.3.3 Loquat (Eriobotrya japonica (Thunb.) Lindl.) 10

2. HAPLOIDS AND DOUBLED HAPLOIDS IN BREEDING 12

2.1 The importance of Hs and DHs in plant breeding 13

2.2 Status of art of Hs and DHs technology 15

2.3 Methods to obtain Hs and DHs 16

2.4 Characterization of Hs and DHs 21

3. POLYPLOIDS IN BREEDING 22

3.1 Definition and types of polyploids 22

3.2 Modes of origin of polyploids 23

3.2.1 Natural polyploids 24

3.2.2 Artificial polyploids 25

3.3 Polyploidy detection 26

3.4 Application of polyploidy in plant breeding 26

$\begin{array}{ll}3.5 \text { Polyploidy in fruit trees } & 28\end{array}$

$\begin{array}{ll}\text { OBJECTIVES } & 31\end{array}$ 
ALMOND ANTHER CULTURE

Chapter 1 - Microspore embryogenesis induced through in vitro anther culture of almond (Prunus dulcis Mill.)

1.1 Abstract

1.2 Materials and methods

1.2.1 Plant material

1.2.2 Bud size and microspore stage correlation

1.2.3 Flower bud sterilization and anther culture

1.2.4 Experimental design

1.2.5 Characterization of regenerants 43

1.3 Results and discussion 44

1.4 Conclusions $\quad 52$

Chapter 2 - Application of different BAP concentrations for in vitro callus induction in almond (Prunus dulcis Mill.) anther culture

2.1 Abstract

2.2 Materials and methods

2.2.1 Plant material

2.2.2 Bud size and microspore stage correlation

2.2.3 Flower bud sterilization and anther culture $\quad 54$

2.2.4 Experimental design $\quad 54$

2.3 Results and discussion $\quad 56$

$\begin{array}{ll}2.4 \text { Conclusions } & 61\end{array}$

MANDARIN ISOLATED MICROSPORE CULTURE 63

Chapter 3 - Gametic embryogenesis through isolated microspore culture in 65 $\begin{array}{ll}\text { mandarin (Citrus reticulata Blanco), 'Mandarino Tardivo di Ciaculli' } & 65 \\ \text { 3.1 Abstract } & 65\end{array}$

3.2 Material and methods 65

3.2.1 Plant material and pollen developmental stage 65

3.2.2 Microspore isolation and culture 66

3.2.3 Evaluation of the microspore response 66

$\begin{array}{ll}\text { 3.2.4 Allelic pattern detection by SSR analysis } & 67\end{array}$ 
3.4 Conclusions $\quad 72$

$\begin{array}{ll} & 73\end{array}$

Chapter 4 - Morphogenic callus induction through in vitro anther culture of loquat (Eriobotrya japonica (Thunb.) Lindl.)

4.1 Abstract $\quad 75$

4.2 Materials and methods $\quad 75$

4.2.1 Plant material 75

4.2.2 Bud size and microspore stage correlation $\quad 76$

4.2.3 Flower bud sterilization and anther culture $\quad 77$

$\begin{array}{ll}\text { 4.2.4 Culture media } & 77\end{array}$

4.2.5 Data collection and statistical analysis $\quad 77$

$\begin{array}{ll}\text { 4.2.6 Ploidy Analysis } & 78\end{array}$

4.3 Results and discussion $\quad 79$

$\begin{array}{ll}4.4 \text { Conclusions } & 84\end{array}$

Chapter 5 - Induced mutagenesis using colchicine for polyploids production in loquat (Eriobotrya japonica (Thunb.) Lindl.), cultivars Cardona and Magdal 5.1 Abstract

5.2 Material and Methods $\quad 85$

5.2.1 Plant Material 85

5.2.2 Seeds treatment 86

5.2.3 Determination of ploidy level $\quad 87$

$\begin{array}{ll}\text { 5.2.4 Statical analysis } & 87\end{array}$

5.3 Results and Discussion $\quad 87$

5.3.1 Survival rate $\quad 87$

5.3.2 Flow cytometric analysis $\quad 89$

$\begin{array}{ll}5.4 \text { Conclusions } & 92\end{array}$

$\begin{array}{ll}\text { DISCUSSION } & 93\end{array}$

$\begin{array}{lr}\text { CONCLUSIONS } & 99\end{array}$ 
REFERENCES

LIST OF PAPERS AND WORKS 


\section{FIGURES INDEX}

Fig. I.1 The different androgenic routes (Seguí-Simarro 2010 - modified)

Fig. I.2 Polyploids formation (Comai 2005 - modified)

Fig. 1.1 a Phenological stages of flower buds selected in relation to the microspore developmental stage $*$ (best stage $=$ vacuolated stage); $\mathbf{b}$ Anther of 'Ferragnes' containing vacuolated microspore; c Uninucleated-vacuolated microspore; d Microspore with two nuclei of equal size (symmetrical nucleus division) of 'Filippo Ceo'; e Multinucleated microspore of 'Filippo Ceo'

Fig. 1.2 a Not developed (left) and swollen (right) anthers of 'Filippo Ceo' after three months in culture; b Anther with friable white callus; c Anther with hard green callus; d Early embryos of 'Filippo Ceo' coming out from the anther; e Embryo of 'Filippo Ceo' developing the root axis; $\mathbf{f}$ Abnormal embryos of 'Lauranne' (Bars represent in a, b, c: $1 \mathrm{~mm}$, in d: $0.75 \mathrm{~mm}$, in e: $1.5 \mathrm{~mm}$, in $\mathrm{f:} 1$ $\mathrm{cm})$

Fig. 1.3 Characterization of anther culture regenerants. Microsatellite analysis: Pherograms of the microsatellite markers EPPCU-5990 profiles of the mother plant (top) and two 'Filippo Ceo' regenerants. The mother plant is heterozygous and carries two alleles, the regenerants show only one of the mother plant alleles. The presence of alternative alleles from the mother plant has been considered as support for the gametic origin of regenerants

Fig. 1.4 Characterization of anther culture regenerants. Microsatellite analysis: Pherograms of the microsatellite markers UDAP-468 profiles of the mother plant (top) and two 'Filippo Ceo' regenerants. The mother plant is heterozygous and carries two alleles, the regenerants show only one of the mother plant alleles. The presence of alternative alleles from the mother plant has been considered as support for the gametic origin of regenerants

Fig. 2.1 a Polarized-uninucleate microspore; b Bicellular pollen grains containing two different nuclei (asymmetrical division); c Microspore with two nuclei similar in size and chromatin condensation (symmetrical division) of 'Vayrò'; d Trinucleated microspore of 'Vayrò' (Bars represent $20 \mu \mathrm{m}$ )

Fig. 2.2 a Anther with friable callus of 'Planeta'; b Hard callus of 'Tarraco' after three months of culture (Bars represent $0.5 \mathrm{~cm}$ )

Fig. 3.1 a Phenological stages of flower bud of MTC selected in relation to the microspore developmental stage (best stage $=$ vacuolate stage); b Uninucleatevacuolate microspore of MTC; c Multinucleated structure of MTC (Bars represent $10 \mu \mathrm{m})$ 
Fig. 3.2 a Miscrospore-derived calli and globular embryo of MTC; b Heartshaped embryo of MTC (Bars represent $150 \mu \mathrm{m}$ )

Fig. 3.3 Amplicons of the SSR loci CCSM147 (at left) and Ci08C05 (at right) in embryo (top) and in the parental genotype (bottom) of MTC. Values above each peak represent the allele size $(b p)$. The allelic pattern of the embryo shows a single allele, shared with the parental genotype

Fig. 4.1 a Phenological stages of flower buds selected in relation to the microspore developmental stage *(best stage $=$ polarized uninucleated stage); $\mathbf{b}$ Flower bud containing anthers with the correct microspore stage; c Uninucleated-vacuolated microspore (Bars represent in a: $3 \mathrm{~mm}$, in b: $10 \mu \mathrm{m}$ )

Fig. 4.2 a Microspore with two equal nuclei (symmetrical division) of 'Peluche'; b Bicellular pollen grains (asymmetrical division) of 'Algerie' (Bars represent $25 \mu \mathrm{m}$ )

Fig. 4.3 a Anther producing white and friable callus after one month of culture; b Morphogenic callus showing organized tissues of 'Zaozhong-6' after three months of culture (Bars represent in a: $2 \mathrm{~mm}$, in b: $5 \mathrm{~mm}$ )

Fig. 5.1 Loquat seedlings growing in pots under natural photoperiod and greenhouse conditions

Fig. 5.2 Flow cytometry histogram of 'Magdal' plants obtained from ungerminated seeds treated with colchicine $(0.5 \%)$. a Diploid control plant $(2 x), \mathbf{b}$ Triploid plant $(3 \mathrm{x})$

Fig. 5.3 Flow cytometry histogram of 'Cardona' plants obtained from ungerminated seeds treated with colchicine $(0.5 \%)$. a Diploid control plant (2x), b Triploid plant (3x), c Tetraploid plant (4x) 


\section{TABLES INDEX}

Table 1.1 Media composition (in $\mathrm{g} \mathrm{L}^{-1}$ or $\mathrm{mg} \mathrm{L}^{-1}$ )

Table 1.2 Microspore developmental responses of the seven almond genotypes after one month of culture

Table 1.3 In vitro anther culture response of the seven almond genotypes after three months of culture

Table 2.1 Media composition (in $\mathrm{g} \mathrm{L}^{-1}$ or $\mathrm{mg} \mathrm{L}^{-1}$ )

Table 2.2 In vitro anther culture response of the eight almond cultivars tested after three months of culture

Table 3.1 Media composition (in $\mathrm{g} \mathrm{L}^{-1}$ or $\mathrm{mg} \mathrm{L}^{-1}$ )

Table 3.2 In vitro isolated microspore culture response after 10 months of culture

Table 3.3 Allelic pattern in parental genotype and embryo. Allele size in bp

Table 4.1 Media composition (in $\mathrm{g} \mathrm{L}^{-1}$ or $\mathrm{mg} \mathrm{L}^{-1}$ )

Table 4.2 Anthers culture responses to the seven genotypes tested

Table 4.3 Anthers culture responses to the four culture media tested three months after culture

Table 5.1 Effect of colchicine treatment and time of exposure on loquat ungerminated seed (Exp. 1)

Table 5.2 Effect of colchicine treatment and time of exposure on loquat ungerminated seed (Exp. 2) 



\section{ACRONYMS}

2,4-D 2,4-Dichlorophenoxyacetic acid

AA Androgenic anther

AFLP Amplified Fragment Length Polymorphism

AND Asymmetrical Nucleus Division

ANOVA Analysis of Variance

BAP 6-Benzylaminopurine

CREC Citrus Research and Education Center

CTV Citrus Tristeza Virus

DAPI

4,6- Diamidino-2-Phenylindole

$\mathrm{DH}$ Doubled Haploid

EDM Embryo Differentiation Medium

FAO Food and Agriculture Organization

GA3 Gibberellic Acid

GSI

$\mathrm{H}$ Gametophytic Self-Incompatibility

IAEA International Atomic Energy Agency

IBA Indole-3-Butyric Acid

IP Intellectual Property

IVIA Instituto Valenciano de Investigaciones Agrarias

KIN Kinetin

MAS Marker-Assisted Selection

MC Morphogenic Calli

MS Murashige and Skoog

mT meta-Topolin

NAA 1-Naphthalene Acetic Acid

OM Organogenic Medium

PCR Polymerase Chain Reaction

RAPD Random Amplified Polymorphic DNA

RT Room Temperature

SCAR Sequence Characterized Amplified Regions

SND Symmetrical Nucleus Division

SSR Simple Sequence Repeat

TDZ Thidiazuron

UNIPA Università degli Studi di Palermo

USDA United States Department of Agriculture

ZEA Zeatin 



\section{ABSTRACT}

Plant breeding is focused on selection of new genotypes with improved traits. Conventional methods based on hybridization and those based on biotechnology (somatic hybridization, genetic transformation, ploidy manipulation, etc.) are used to create novel genetic variations. Biotechnology provides powerful tools for plant breeding, for instance, haploid technology allows achievement of homozygous lines from heterozygous parents in one step, which reduces significantly the time required by conventional methods. Concerning woody species, characterized by selfincompatibility, long juvenile period and high degree of heterozygosity, this technique is the only way to get homozygous lines. Haploid plants are of great interest for breeding and genomic studies, being used in mutation research, genetic analysis, genome mapping and gene transfer. Gametic embryogenesis, based on cellular totipotency, produces an embryo from an immature gamete, by switching its developmental pathway from gametophytic to sporophytic.

This research is focused on inducing gametic embryogenesis in two important Mediterranean fruit crops: almond (Prunus dulcis Mill.) via in vitro anther culture and mandarin (Citrus reticulata Blanco) via isolation and microspore culture. Also ploidy manipulation was applied to loquat (Eriobotrya japonica (Thunb.) Lindl.) for getting genotypes whit different ploidy levels. The experiments were carried out through years 2014, 2015 and 2016 at the 'Università degli Studi di Palermo' (UNIPA) as well as at the 'Instituto Valenciano de Investigaciones Agrarias' (IVIA).

Regarding the almond anther culture, formation of calli and production of embryos was achieved through the direct embryogenesis route. On then other hand, early embryo regeneration is reported, for the first time, from isolated microspore culture of mandarin, 'Mandarino Tardivo di Ciaculli'.

Our results report the evidence of gametic embryogenesis and the production of homozygous regenerants in almond and mandarin, two species extremely recalcitrant to microspore embryogenesis. However, the results are affected by many factors that need further studies to better understand the embryogenic development and to increase the rate of embryo achievement. 
Moreover, another biotechnological tool (ploidy manipulation) was also applied for implementing the IVIA loquat breeding program. Polyploid plants are of great interest in this species, due to its potential for producing seedless genotypes via direct use of triploids or crosses between tetra and diploids. Aimed at obtaining new loquat genotypes, with different ploidy levels (polyploids), colchicine was applied to seeds before germination, to induce chromosome duplication. A total of three triploids $(3 \mathrm{x})$ and one tetraploid $(4 \mathrm{x})$ were obtained. 


\section{RIASSUNTO}

Il miglioramento genetico ha come obiettivo la selezione di nuovi genotipi con caratteristiche superiori. Metodi convenzionali basati sull'ibridazione e metodi biotecnologici (ibridazione somatica, trasformazione genetica, manipolazione della ploidia, etc.) vengono utilizzati per creare nuova variabilità. Le biotecnologie forniscono potenti strumenti per il miglioramento genetico, per esempio, l'ottenimento di aploidi permette di ottenere linee omozigoti da parentali eterozigoti in un solo atto, riducendo in modo significativo il tempo necessario rispetto ai metodi convenzionali. Per quanto riguarda le specie legnose, caratterizzate spesso da auto-incompatibilità, lungo periodo giovanile ed alta eterozigosi, questa è l'unica tecnica per ottenere linee omozigoti. Le piante aploidi rivestono un elevato interesse per studi di genomica, per mutazioni, analisi genetica, mappatura genetica e trasformazione genetica.

Questa ricerca ha avuto come obiettivo l'induzione di embriogenesi gametica in due importanti specie mediterranee: il mandorlo (Prunus dulcis Mill), tramite coltura in vitro di antere, ed il mandarino (Citrus reticulata Blanco), mediante coltura di microspore isolate. Inoltre, sono stati condotti esperimenti per indurre duplicazione cromosomica in nespolo (Eriobotrya japonica (Thunb.) Lindl.) al fine di ottenere genotipi con diversi livelli di ploidia. Gli esperimenti sono stati condotti nel 2014, 2015 e 2016 presso l'Università degli Studi di Palermo (UNIPA) e l'Instituto Valenciano de Investigaciones Agrarias (IVIA).

Per quanto riguarda la coltura di antere di mandorlo, è stata ottenuta la formazione di calli e la produzione di embrioni omozigoti tramite embriogenesi diretta. Inoltre, la rigenerazione di embrioni è stata ottenuta, per la prima volta, anche a partire da microspore isolate di 'Mandarino Tardivo di Ciaculli'.

I risultati ottenuti hanno consentito di indurre con successo l'embriogenesi gametica con produzione di rigeneranti omozigoti in mandorlo e mandarino, due specie estremamente recalcitranti a questa tecnica.

Inoltre, un altro strumento biotecnologico (la manipolazione della ploidia) è stato applicato con l'obiettivo di implementare il programma di miglioramento genetico del nespolo dell'IVIA. 
Le piante poliploidi hanno un elevato interesse per questa specie, in quanto potrebbero consentire la produzione di genotipi apireni, attraverso la diretta utilizzazione di triploidi o tramite ibridazione tra tetra e diploidi. Con l'obiettivo di ottenere nuovi genotipi con diversi livelli di ploidia (poliploidi), è stata applicata una soluzione di colchicina su semi non germinati di nespolo al fine di indurre duplicazione cromosomica. Un totale di tre triploidi $(3 \mathrm{x})$ ed un tetraploide $(4 \mathrm{x})$ sono stati così ottenuti. 


\section{RESUMEN}

La mejora genética tiene como objetivo la selección de nuevos genotipos con mejores características. Los métodos de mejora convencional basados en hibridaciones y aquellos basados en Biotecnología (hibridación somática, transformación genética, manipulación de la ploidía, etc.) se utilizan para obtener nueva variación genética. La Biotecnología proporciona herramientas poderosas en mejora genética, por ejemplo, la obtención de haploides permite obtener líneas homocigotas en un solo paso, disminuyendo significativamente el tiempo requerido usando métodos convencionales. Respecto a especies leñosas, caracterizadas por autoincompatibilidad floral, largo período juvenil y alto grado de heterocigosidad, esta técnica es el único método de obtención de líneas homocigotas. Los genotipos haploides tienen un alto interés en estudios genómicos, siendo utilizados en estudios de mutaciones, análisis genéticos, mapeo genético y transferencia genética.

Este estudio tiene como objetivo la inducción de embriogénesis gamética en dos especies mediterráneas muy importantes: el almendro (Prunus dulcis Mill.) por medio de cultivo in vitro de anteras y el mandarino (Citrus reticulata Blanco) por medio de aislamiento de microesporas. Además, se ha estudiado la obtención de poliploides en níspero (Eriobotrya japonica (Thunb.) Lindl.) con el objetivo de obtener genotipos con diversos niveles de ploidía. Los experimentos se llevaron a cabo en los años 2014, 2015 y 2016 en la 'Università degli Studi di Palermo' (UNIPA) y en el 'Instituto Valenciano de Investigaciones Agrarias' (IVIA).

Respecto al cultivo de anteras en almendro, la formación de callos y producción de embriones se obtuvo mediante embriogénesis directa. Por otro lado, se ha conseguido regenerar por primera vez embriones a partir de microesporas aisladas en el cultivar de mandarino 'Mandarino Tardivo di Ciaculli'.

Los resultados obtenidos muestran que la embriogénesis gamética y la regeneración de embriones homocigótos en almendro y mandarino, dos especies extremadamente recalcitrantes para la embriogenésis a partir de microesporas, es posible. Sin embargo, los resultados se ven afectados por muchos factores que necesitan estudios adicionales para comprender mejor el desarrollo embriogénico y para aumentar la tasa de obtención del embriones. 
Además, otra herramienta biotecnológica (manipulación de la ploidía) se aplicó con el objetivo de implementar el programa de mejora de níspero del IVIA. Las plantas poliploides en esta especie tienen un alto interés, pues podrían permitir la obtención de frutos sin semilla, por medio de la obtención directa de triploides o mediante cruzamiento entre tetraploides y diploides. Con el objetivo de obtener nuevos genotipos de níspero con diferentes niveles de ploidía (poliploides), se aplicó colchicina a semillas sin germinar con el fin de inducir la duplicación cromosómica y se obtuvieron 3 triploides $(3 \mathrm{x})$ y un tetraploide $(4 \mathrm{x})$. 


\section{RESUM}

La millora genètica té com objectiu la selecció de nous genotips amb millors característiques. Els mètodes de millora convencional basats en hibridacions i aquells basats en Biotecnologia (hibridació somàtica, transformació genètica, manipulació de la ploïdia, etc.) s'utilitzen per aconseguir nova variació genètica. La Biotecnologia proporciona eines poderoses en millora genètica, per exemple, l'obtenció d'haploides permet obtenir línies homozigòtiques en un sol pas, disminuint significativament el temps requerit usant mètodes convencionals. Pel que fa a espècies llenyoses, caracteritzades per autoincompatibilitat floral, llarg període juvenil i alt grau d'heterozigosi, aquesta tècnica és l'únic mètode d'obtenció de línies homozigòtiques. Els genotips haploides tenen un alt interès en estudis genòmics, sent utilitzats en estudis de mutacions, anàlisis genètics, mapatge genètic $i$ transferència genètica.

Aquest estudi té com objectiu la inducció d'embriogènesi gamètica en dos espècies mediterrànies molt importants: l'ametller (Prunus dulcis Mill.) a través del cultiu in vitro d'anteres i el mandariner (Citrus reticulata Blanco) per mitjà d'aillament de micròspores. A més a més, s'ha estudiat l'obtenció de poliploides en nespra (Eriobotrya japonica (Thunb.) Lindl.) Amb l'objectiu d'aconseguir genotips amb diversos nivells de ploïdia. Els experiments es van dur a terme en els anys 2014, 2015 i 2016 a la 'Università degli Studi di Palermo' (UNIPA) i a 'l'Institut Valencià d'Investigacions Agràries' (IVIA).

Respecte al cultiu d'anteres en ametller, la formació de calls i producció d'embrions es va obtenir mitjançant embriogènesi directa. D'altra banda, s'ha aconseguit per primera vegada la regeneració d'embrions a partir de micròspores aillades en el conrear de mandariner 'Mandarino Tardivo di Ciaculli'.

Els resultats obtinguts mostren que l'embriogènesi gamètica i la regeneració d'embrions homozigotics en ametller i mandariner, dues espècies extremadament recalcitrants per l'embriogènesi a partir de micròspores, és possible. No obstant això, els resultats es veuen afectats per molts factors que necessiten estudis addicionals per entendre millor el desenvolupament embriogènic i per augmentar la taxa d'obtenció dels embrions.

A més, una altra eina biotecnològica (manipulació de la ploïdia) es va aplicar amb l'objectiu d'implementar el programa de millora de nespra de l'IVIA. 
Les plantes poliploides en aquesta espècie tenen un alt interès, ja que podrien permetre l'obtenció de fruits sense llavor, per mitjà de l'obtenció directa de triploides o mitjançant encreuament entre tetraploides i diploides. Amb l'objectiu d'aconseguir nous genotips de nespra amb diferents nivells de ploïdia (poliploides), es va aplicar colquicina a llavors sense germinar per tal d'induir la duplicació cromosòmica i es van obtenir 3 triploides (3x) i un tetraploide $(4 \mathrm{x})$. 


\section{INTRODUCTION}

\section{PLANT BREEDING AND GENETIC RESOURCES}

\subsection{Plant genetic resources}

Plant genetic resources represent the basis for agricultural development and, at the same time, a very important pool of genetic variability that acts as a buffer against environmental changes. Genetic diversity may be derived from breeding populations (either naturally occurring or synthetic), from spontaneous crosses, intra and interspecific, natural or induced mutations, plant material from the introduction of transgenic events, natural introgression and changes in chromosome form and number, or combinations of all mentioned sources (Moose and Mumm 2008).

Introduction of crops in different environments needs new cultivars adapted to the new conditions. Genetic variability provides the tools for adaptability to a range of environments (Hayward et al. 2012).

The prospect of dwindling plant genetic diversity, coupled with increased demands on plant resources, has propelled them into the centre of global discussions on the environment and sustainable development. The need to utilize and conserve these resources as a safeguard against an unpredictable future is well recognized (Hoban et al. 2013; Prescott-Allen and Prescott-Allen 2013; Henry 2014). Indeed, from an agricultural utilitarian standpoint, natural genetic resources can be considered limited and perishable (Hernández 1999). They provide the raw material (genes) which, when used and combined in the right way, can produce new and better plant varieties. In fact, the greatest value that new varieties produce for humanity lies fundamentally in the genes they contain, that are not only the source of features like disease resistance, nutritional quality and adaptability to adverse environmental conditions, but also those which, although unrecognized at present, may someday be considered invaluable. These genes are dispersed throughout local cultivars and natural plant populations that have been selected over thousands of years by nature and farmers as they are an irreplaceable source (Roa et al. 2016). 
In recent years, the replacement of local varieties by imported ones, the settlement of new lands, the changes in cultivation methods and the appearance of new technologies, have been causing a rapid and extreme plant genetic erosion (Ahuja and Jain 2015). This affects both cultivated species and many wild ones that might have a direct, indirect or potential agricultural use. The erosion of these resources could lead to the extinction of valuable material which has not yet been exploited. The road to a continuous increase in the production and quality of food lies through the protection and efficient utilization of plant genetic resources; this requires their conservation, evaluation, documentation and exchange (Hawkes et al. 2012; Crisson and Visser 2014; Pandey et al. 2014). Thousands of years of selection performed by farmers and nature, have produced local varieties and genotypes adapted to the different places and to cultivation practices which were determined by the climate and other environmental factors (Roa et al. 2016). Today, the spectrum of valuable variation is enormous and this visible variation conceals an even greater genetic diversity. Up to now, the primitive varieties and related wild populations have been a fruitful, sometimes the sole, source of genes for pest and disease resistance, adaptations to difficult environments and other agricultural traits, such as the dwarf type in rice, wheat and other grains, that have contributed to the Green Revolution in many parts of the world (Everson and Golin 2003; Hayward et al. 2012). Plant genetic resources are now, and will continue to be in the future, of inestimable value independently of whether scientists use them by means of conventional plant breeding or modern genetic engineering.

\subsection{Plant breeding}

Plant breeding is essentially an election made by man of the best plants as potential cultivars within a variable population. In other words, it is a selection made possible by the existence of variability (Hayward et al. 2012). Plant breeding involves methods for the creation, selection, and fixation of superior plants in the development of improved cultivars suited to needs of farmers and consumers (Moose and Mumm 2008).

Prehistoric selection for visible phenotypes that facilitated harvest and increased productivity led to the domestication of the first crop varieties (Harlan, 1992) and this can be considered the earliest examples of biotechnology. Darwin outlined the scientific principles of hybridization and selection, and Mendel defined the fundamental 
association between genotype and phenotype, discoveries that enabled a scientific approach to plant breeding at the beginning of the $20^{\text {th }}$ century. Subsequent advances in our understanding of plant biology, the analysis and induction of genetic variation, cytogenetic, quantitative genetics, molecular biology, biotechnology, and, most recently, genomics have been successively applied to further increase the scientific base and its application to the plant breeding process (Baenziger et al. 2006; Jauhar 2006; Varshney et al. 2006).

In the past, the main objective of plant breeding has been to increase yield by improvement of the potential productivity, followed by the successful expression of that potential. With changing demands on agriculture, objectives are now being altered to take account of these and new requirements. Quality and nutritive values are nowadays of increasing importance, particularly in association with improved efficiency of production (Byrne 2012).

Plant breeding has a long history of integrating the latest innovations in biology and genetics to enhance crop improvement. Modern breeding integrates techniques from cytology, physiology, pathology, entomology and chemistry (Jauhar 2006). In the last century, there have been many advanced in these areas which have made a substantial contribution to plant breeding (Lusser et al. 2012). These include the demonstration of the auto and allo-polyploid nature of many crop plants, opening the way to the production of artificial polyploid forms and their direct or indirect exploitation (Sattler et al. 2016). The discovery of the possibility of increasing the frequency of mutations by means of radiation or chemicals was hailed as a means of increasing the variability available to the breeders (Hayward et al. 2012). Genetics has given to breeding a better knowledge of the processes involved in the mechanism of variability and the necessary information for regulating and increasing such variability.

The success of a breeding program is dependent upon two main factors: first having available the necessary variation and second, being able to manipulate it to produce a stable new cultivar. Recent genetical advances have allowed breeders to design new methods, such as RFLP mapping, marker-assisted selection (MAS), gene cloning, genetic transformation, reverse breeding and haploids (Hs) or doubled haploids (DHs) production, which hold out great promise for the future, allowing the production of more efficient cultivars (Sharma et al. 2002; Varshney et al. 2005; Collard and Mackill 
2008; Moose and Mumm 2008; Germanà 2011a, b; Lusser et al. 2012; Hartung and Schiemann 2014).

\subsection{Breeding objectives and approaches: the case of some Mediterranean fruit trees}

Genetic improvement is the key of the great advances that have been made in agriculture over the centuries. Fruit breeding is a long-term process which takes a minimum of about a decade from the original cross to a finished cultivar (Byrne 2012). Fruit improvement programs began to develop at the beginning of XX century, such as in citrus (Cooper et al. 1962), almond (Gradziel 2009) or loquat (Badenes et al. 2013). The main objectives of these programs are generally oriented to achieve a higher quality product, with beneficial aspects for consumer health along with product uniformity, longer post-harvest life, reduced production costs and to make available new scions and rootstocks selected for their resistance or tolerance to abiotic and biotic stresses (Byrne 2012).

\subsubsection{Almond (Prunus dulcis Mill.)}

Almond is the most important tree nut crop in terms of commercial production. Its production is limited to areas characterized by a Mediterranean climate, including regions in the Mediterranean countries, the Central Valley of California, the Middle East, Central Asia, the Himalayan slopes, and some equivalent areas in the Southern Hemisphere, including Chile, Argentina, South Africa, and Australia. (Kester and Asay 1975).

Cultivated almonds, often resulted from traditional seed propagation, show high levels of genetic variability due, in part, to their self-incompatibility, that makes them obligate out-crossers, and possibly because their interspecific origin (Kester et al. 1991). Commercial cultivars within individual production areas, however, often show a limited genetic base due to their origin from only a few founder genotypes selected for their desirable regional value (Socias i Company and Felipe 1992). For example, the most commercially important California cultivars originated from crosses between only two parents: 'Nonpareil' and 'Mission' (Bartolozzi et al. 1998; Kester and Gradziel 1996). 
In addition, only a limited number of almond accessions are currently maintained in the main germplasm collections worldwide (FAO 2012).

In the case of almond, within each region, the best wild seedlings were routinely selected for propagation by local farmers, while natural selection continued its unrelenting pressures toward greater adaptation to local environments, including regionally important disease and insect pests (Gradziel 2009). The self-sterile nature of almond insured a continuous exchange and mixing among cultivated and wild germplasm including, in many cases, related species (Socias i Company 2002). In fact, because of the probable interspecies origin of many almond cultivars (Kester et al. 1991; Ladizinsky 1999; Socias i Company 2002), improvement of specific genetic traits may also benefit from the introduction of genes directly from related species. The range of almond species is extensive with a wide diversity of traits (Gradziel et al. 2001a; Kester and Gradziel 1996). Controlled crosses of Prunus dulcis with other almond species in sections Euamygdalus and Spartiodes have been often carried out (Gradziel et al. 2001a; Gradziel 2003). P. webbii grows throughout the Mediterranean region and its range intersects with cultivated almond in Italy (Sicily), Spain and Greece, where hybridization occurred and introgression evidently resulted. In Puglia (Italy), P. webbii has been found to be the source of self-fertility (Godini 2002). Despite their physical and developmental differences, crosses with peach $(P$. persica, $P$. mira, and $P$. davidiana) can be readily achieved and have proven to be particularly valuable as rootstocks as well as sources of commercially useful traits (Gradziel et al. 2001b; Gradziel 2003). The probable interspecies origin of many modern almond cultivars suggests promising opportunities for the manipulation not only of the traditional genetic (i.e., Mendelian) determinants, but also of the epigenetic controls, which are only recently becoming characterized.

One of the oldest almond germplasm collections was established at the Nikistki Botanical Garden in Yalta (Crimea), at the end of the nineteenth century (Rikhter 1969). Greater genetic variability and so increased breeding options for desired traits are being pursued through the incorporation of breeding material from other regions (Kester and Gradziel 1996; Martínez-Gómez et al. 2003; Socias i Company 1998).

In the early 1900s, formal plant breeding programs were established in most major production areas, to accelerate this selective process through controlled crosses and 
related genetic manipulations. Epigenetic modification may have particular value for almonds breeding because epigenetic variability appears to be greatly enhanced with interspecies hybrids (Grant-Downton and Dickinson 2006) and also because commercially valuable epigenetic variants can be effectively captured in cultivars by the vegetative propagation, usual employed in tree crop dissemination (Kester et al. 2004). This breeding approach has recently shown to be successfully for peach cultivar improvement, where advanced processing peach selections derived from almond-peach interspecific hybridization, expressed fruit ripening patterns not evident in either species parent (Gradziel 2003).

Basic objectives of most almond breeding programs target increased yields, improved quality, and decreased production costs (Socias i Company 1998). These traits have been found to be largely inherited in a quantitative manner, with a few exceptions such as self-compatibility and kernel bitterness (Kester et al. 1977; Spiegel-Roy and Kochba 1981). Inheritance of important breeding traits have been reviewed by Kester et al. (1996) and recently by Socias i Company et al. (2007).

While many goals such as total yield and production efficiency were similar among programs, regional breeding goals often varied due to different environments, disease, and pest problems. Regional almond breeding programs and their primary objectives have been reviewed by Kester and Gradziel (1996). At the same time, the globalization of the almond market imposes more stringent limits on acceptable kernel and shell characteristics. Despite the difficulties in defining a kernel quality ideotype, due to the differences in consumer preferences, almond quality is currently another important breeding goal (Alonso et al. 2012). Nowadays, self-compatibility has become the main objective along with late blooming, frost tolerance, resistance to diseases, and tree architecture.

Currently, there are active almond breeding programs in France, USA, Israel and Spain. In Spain, collections made by Antonio J. Felipe from the 1960s led to the independent discovery of self-compatibility, and incorporation of elite germplasm into his breeding program. Despite the negative characteristics of woody plant as almond for fast genetic improvement, including large plant size and the long juvenile period of 4 years or more, many commercially successful cultivars of almond have resulted from controlled crosses and selction in the last decades. Examples include the cultivars Guara from 
Spain (Felipe and Socias i Company 1987); Butte, Ruby, Sonora, Padre, and Winters from California; and Ferragnes, Ferraduel, and Ferrastar from France (Gradziel 2009). Summaries of the different almond breeding programs are available in Martínez-Gómez et al. (2006) and Gradziel (2008).

\subsubsection{Mandarin (Citrus reticulata Blanco)}

Citrus is the most extensively produced fruit crop in the world. The centre of origin is considered to be Southeastern Asia and China, northeastern India and surrounding areas. There are three basic taxa on the basis of morphological descriptors and molecular data: C. maxima (pummelos), C. medica (citrons) and C. reticulata (mandarins). The other cultivated species appeared by recombination among these three basic taxa (Ollitrault and Navarro 2012).

The agro-morphologic variability of citrus is considerable. It relates to the pomological and organoleptic characters as well as to susceptibility, tolerance or resistance to biotic and abiotic stresses. For example, tolerance to salinity of the Cleopatra mandarin; tolerance to cold of the Satsuma mandarins and P. trifoliata, tolerance to Citrus Tristeza Virus (CTV) of some mandarins, lemons, and several rootstocks such as citranges and resistance to Phytophthora of certain pummelos and mandarins, have been identified (Krueger and Navarro 2007). This variability opens very broad prospects for the exploitation of citrus genetic resources for breeding. The three basic taxa ( $C$. reticulata, C. maxima, and C. medica) constitute an essential reservoir as they contain the majority of the allelic diversity of cultivated citrus. Mandarins and pummelos from the original diversification areas (Southeast Asia) are clearly the highest priority, showing significant intraspecific polymorphism at the molecular and phenotypic levels (Ollitrault and Navarro 2012). A global citrus germoplasm network was developed in 1997. Significant genetic resource collections exist in many countries. These collections are preserving the germplasm variability within each species, which includes alleles of adaptativity, morphology and pomology. They also can be used as "mutant collection" for functional genomics studies (Ollitrault and Navarro 2012).

The main objectives in citrus breeding programs for fresh market are: fruit quality (size, color, easy-peeling), seedlessness, and the extension of the harvest season. The first formal citrus breeding program was started in 1893 by the United States Department of 
Agriculture (USDA) in Florida (Cooper et al. 1962). The University of Florida initiated a citrus breeding program in 1924, which is now one of the largest breeding programs worldwilde, and it is located at the Citrus Research and Education Center (CREC), Lake Alfred. Today, there are numerous citrus breeding programs spread in all major citrusproducing countries. These programs played a major role in shaping the current citrus industry by providing information on the use of numerous scion and rootstock. After rigorous evaluation of horticultural performance, economic analysis and test marketing for fresh market and processing use, the final selected genotypes may result in the introduction of a new variety. The current cultivars grown resulted from the selection, propagation and advanced testing of thousands of possible superior seedlings. Citrus breeders face many challenges in their quest to develop scion and rootstock that provide growers with productive, disease-resistant trees, and consumers with tasty and high quality fruits. A large proportion of the problems faced by the citrus industry could be overcome by the use of improved rootstocks (Wutscher and Hill 1995; Bowman 2000). Grafting allows combining a genotype that provides the best fruit characteristics with rootstocks that provide adaptability to soil characteristics and resistance or tolerance to biotic and abiotic stress. In addition, the development of biotechnologies such as somatic hybridization and genetic transformation considerably enlarge the gene pool that could be used for scion and rootstock breeding (Grosser et al. 1996, 2000; Ollitrault et al. 2001; Peña et al. 2007).

For sweet oranges, lemons, satsumas and grapefruits, new cultivars have only been selected from spontaneous or induced mutations, while both mutant selection and hybridizations resulted in varietal progress in mandarins (Ollitrault and Navarro 2012). Three major approaches are used to develop new cultivars: mutation, hybridization and gene introduction (Roose 2007). In citrus and other fruit crops with long generation times and in which the elite genotype used as commercial cultivars are very heterozygous, hybridization is so difficult that it has rarely been attempted. Mutation breeding has been used mainly to develop low seeded cultivars (Roose and Williams 2007; Kupper et al. 2010). Breeders identify rare mutants that express useful traits and then transfer the mutant gene into other cultivars by hybridization methods. Transgenic varieties with reduced juvenility have been developed and could facilitate the transfer of novel mutations. Molecular marker studies have given a clear understanding of the 
origin and diversification process of the cultivated species and serve as a good base for the establishment of citrus germplasm management strategies. SSR markers will probably be the reference markers for accessions of the three basic taxa and sexual hybrids, while alternative markers have to be developed for varietal characterization within species such as sweet orange, lemon, and some mandarin groups like clementines and satsumas (Luro et al. 2001; Barkley et al. 2006).

Reference genome sequences have been developed for citrus by the International Citrus Genomics Consortium (haploid from Clementine) and the University of Florida (diploid sweet orange). With these high quality reference sequences available (Xu et al. 2013; $\mathrm{Wu}$ et al. 2014), advances in genome sequencing make simpler to determine interesting mutants and cultivars. Comparative genome sequence information will allow the identification of candidate genes that may cause phenotypic differences among cultivars derived by mutation. Once genes are known, they can be more easily transferred to other cultivars by hybridization-selection, transgenic or targeted mutation approaches (Roose and Close 2008; Krueger and Roose, 2003; Ramadugu et al. 2010). Development of these methods will greatly facilitate the identification of genes that confer disease resistance, fruit quality and other important traits. Interesting cultivars from citrus breeding programs have been selected among mandarin $\times$ grapefruit hybrids, the tangelos (Nova, Orlando, Minneola, Page) and mandarin hybrids (Fairchild, Fremont, Fortune, Kara, Kinnow, Wilking, Honey) from the old sexual mandarin breeding project conducted in the USA (Frost 1935). Natural hybrids have been an important source of new cultivars, such as 'Clementine', the main mandarin-like in the Mediterranean area. Recently, triploid seedless cultivars have been released in Italy (Russo et al. 2004). 'Tacle' is a tangor obtained in Sicily by crossing the diploid 'Clementine' with the autotetraploid 'Tarocco' sweet orange (Starrantino 1999). In Spain, triploid hybrids obtained from $2 \mathrm{x} X \mathrm{X}$ crosses with 'Fortune' mandarin as female parent have been registered, and some of them have already been released for commercial propagation (Navarro et al. 2006; Aleza et al. 2010; Cuenca et al. 2010). The majority of the rootstocks used for propagation are original species or ancient natural hybrids. Nevertheless, some of these Citrus $\times$ Poncirus hybrids are now very important rootstocks used in many countries. Swingle citrumelo (grapefruit x trifoliate orange hybrid) and 'Carrizo' and 'Troyer' citranges (sweet orange x trifoliate orange 
hybrids) are examples of citrus rootstocks originating from breeding efforts. Crosses between mandarins and Poncirus appear very promising to combine tolerances to abiotic and biotic constraints both by sexual breeding (Forner et al. 2003) or somatic hybridization (Grosser et al. 2000; Ollitrault et al. 2000).

\subsubsection{Loquat (Eriobotrya japonica (Thunb.) Lindl.)}

Loquat has been cultivated in China for over 2000 years and many species occur there in the wild state (Lin et al. 1999). The process of loquat domestication has led to numerous ecotypes during its cultivation and acclimatization. From these initial ecotypes, a large number of varieties emerged in different countries where loquat was cultivated (Lin 2004; Lin et al. 2004; Yang et al. 2005).

Loquat specifically shares with the rest of the Rosaceae species, a gametophytic selfincompatibility (GSI) system based on S-RNases (Igic and Kohn 2001). Several alleles have been identified in loquat and inter-compatibility groups have been established (Carrera et al. 2009). The high number of alleles found at the S-locus makes it particularly interesting for genetic diversity studies and it is essential for correct orchard planning and suitable design of breeding programs (Badenes et al. 2013).

Although loquat is a minor crop in most of the world, it has a high potential for increase of cultivation areas and industry. For long time, breeding has been identified as a priority for expansion of the loquat industry (Badenes et al. 2013). Most loquat cultivars are often derived from clonal selection from open-pollination, or natural mutations. However, recently new varieties obtained by hybridization of elite varieties that carried the traits of interest, followed by selection, characterization, and testing of seedlings are available (Badenes et al. 2013). For instance, the prominent cultivar Tanaka came from hybridization (Lin 2007).

Breeding programs, based on hybridization, have been initiated in several countries. The greatest variability has certainly been recorded in China, its center of origin, followed by Japan and Europe. There are more than 1,000 cultivars in China belonging the genus Eriobotrya, most of which are seedling selections that are no longer in production, although, they are all conserved in the 'National Fruit Germplasm Repository' in Fuzhou. This is the reason why many research groups are currently focusing their attention on the study of such genetic resources (Cai et al. 2007 ; He et al. 2007a; Xie et 
al. 2007; $\mathrm{Xu}$ et al. 2007). These studies are generally focused towards the identification and classification of these accessions and their possible use in breeding programs to obtain new varieties.

There are loquat genebanks placed in China and Japan (Lin et al. 1999; Lin 2007). The only European collection is located at the 'Instituto Valenciano de Investigaciones Agrarias' (IVIA), Valencia, Spain (Blasco et al. 2014) and contains 120 accessions (Llácer et al. 1995), coming from eight different countries: China, Japan, Brazil, USA, Italy, Spain, Pakistan and Portugal. Spanish commercial production depends on only four cultivars: 'Magdal', 'Algerie', 'Golden Nugget' (from United States) and 'Tanaka' (Badenes et al. 2013).

The main breeding objectives in loquat are: improvement of yield, cold resistance, extended harvest season, seedless and bigger fruits, new colors of epicarp and mesocarp, etc. (Blasco et al. 2014). In the Mediterranean countries, breeding is focused on increasing the diversity of cultivars. More in details, cytological studies are aimed in obtaining and exploiting loquat ploidy (Guo et al. 2007; He et al. 2007b; Wu et al. 2007; Zheng 2007). In the case of Spain, 90\% of the production relies on 'Algerie' and its bud mutations. In other Mediterranean countries, the industry is based on clones that do not meet the international commercial standards of quality, and new cultivars with better fruit quality and yield are the main objectives.

Loquat breeding programs are currently carried out in China (Lin et al. 2007; Zheng 2007), Japan (Terai 2002) and Spain (Gisbert et al. 2007a, b), while Turkey is developing a selection program of local genetic resources (Polat 2007; Polat and Caliskan 2007; Karadeniz and Senyurt 2007). In Spain, the IVIA started an improvement program that has as its goals the achievement of new loquat varieties, competitive for their higher quality, increased productivity and resistance to biotic and abiotic factors (Gisbert et al. 2009). In the Mediterranean countries, loquat seedlings are usually used as rootstocks since they are well adapted to calcareous soils, which are abundant in this region. Nowadays, loquat cultural practices have been improved on issues of irrigation and physiology as well as of methods for increasing fruit quality and productivity (Cañete et al. 2007; Cuevas et al. 2007; Pinillos et al. 2007; Rodriguez et al. 2007). In China, seedlessness has also been achieved by selection of naturally occurring triploid clones which require applications of gibberellic acid for fruit set. A 
number of seedless triploids have been produced and are currently tested for commercial use (Badenes et al. 2013). However, more efforts are needed in breeding and genetic studies to meet growers and consumers demands.

\section{HAPLOIDS AND DOUBLED HAPLOIDS IN BREEDING}

Plant breeders use traditional and biotechnological techniques to create and use novel genetic variations, aimed at selecting new elite and suitable varieties, with improved traits to satisfy both farmers and consumers. Biotechnologies provide powerful tools for plant breeding, and among these ones, haploid $(\mathrm{H})$ and doubled haploid (DH) technology, can effectively help to select superior plants (Seguí-Simarro 2010; Hazarika et al. 2013). Hs are sporophytes with the gametophytic chromosome number ( $\mathrm{n}$ instead of $2 \mathrm{n}$ ) originated from a single, male or female, immature gamete (Germanà 2011a). They generally exhibit a lower plant vigor compared to donor plants and are sterile due to the inability of their chromosomes to pair during meiosis (Seguí-Simarro y Nuez 2008b). In order to propagate them through seed and to include them in breeding programs, their fertility has to be restored with spontaneous or induced chromosome doubling. To induce this process, different doubling agents such as colchicine, oryzalin or trifluralin, can be employed. When duplication of chromosomes of a $\mathrm{H}$ occurs, a $\mathrm{DH}$ is obtained (Kasha and Maluszynsky 2003). Therefore, DHs are homozygous at all loci and can represent a new variety (self-pollinated crops) or parental inbred line for the production of hybrid varieties (cross-pollinated crops). Haploid technology allows us to achieve completely homozygous lines from heterozygous parents in just one step, significantly reducing the time required to obtain the same result with conventional methods which requires several generations of self-pollination (Germanà 2011a, b). Indeed, this technique is the most rapid route to achieve homozygosity and, for self incompatible species, dioecious species and species that suffer from inbreeding depression due to self-pollination, haploidy may be the only way to develop inbred lines (Murovec and Bohanec 2011). 


\subsection{The importance of Hs and DHs in plant breeding}

Haploid plants arouse interest in the fields of genetic and developmental studies, as well as of plant breeding. Using DH technology, completely homozygous plants can be established in one generation thus saving several generations of selfing comparing to conventional methods, by which also only partial homozygosity is obtained. In fact, in annual self-pollinating crop it is possible to reach about $98 \%$ homozygosity after 6 years of selfing, while $100 \%$ can be achieved in one-step through haploidy technique (Germanà 2011b). The induction and regeneration of Hs followed by spontaneous or induced doubling of chromosomes are widely used techniques in advanced breeding programs of several agricultural species. They have been successfully used for commercial cultivar production and more than 300 varieties have already been released, with the majority of the protocols (http://www.scri.ac.uk/assoc/COST851/Default.htm) referred to as anthers culture. For example, $50 \%$ of the currently available barley cultivars produced in Europe come from DH systems (Dunwell 2010).

The role of $\mathrm{DH}$ in the breeding process largely depends on the plant type of reproduction. In self-pollinated species, they can represent final cultivars, while in cross-pollinated species they can be used as parental lines in hybrid production or testcrosses. Cross-pollinated species are known to possess numerous deleterious recessive alleles that are not expressed in heterozygous states. They are gradually fixed during self-pollination, causing inbreeding depression and difficulties in producing homozygous lines during conventional breeding. DH technology helps to overcome these problems through the rapid fixation of genes in one generation and early elimination of deleterious alleles from populations. In fact, as a result of the reduction of the frequency of harmful genes, $\mathrm{H}$ plants can be considered as a natural filter that discards harmful genes from a population, or any other breeding material, from which Hs were obtained (Eder and Chalyk 2002). Moreover, due to complete homozygosity, the efficiency of selection for both qualitative and quantitative characters is increased since recessive alleles are fixed in one generation and directly expressed (Murovec and Bohanec 2011). Humphreys et al. (2007) reported that, through gametic embryogenesis, an enhanced gene expression was produced for complex traits, such as freezingtolerance, greater of that found in the parent genotypes, allowing the use of the genetic potential that was underexpressed due to combinations of control by recessive alleles. 
In vegetable crops, in which it is difficult to produce fertile homozygous lines by self pollination often due to the inbreeding depression, one of the main uses of DHs is as parents for F1 hybrid seed production. The F1 plants often exhibit hybrid vigor (heterosis), consisting in a dramatic increase in yield compared with their parents (Maluszynski et al. 2001; Hochholdinger and Hoecker 2007). DHs provide a unique system to attempt the fixing of hybrid performance in homozygous lines and to avoid the step of hybrid seed production (Germanà 2011b). Kasha et al. (1977) carried out the first experiment that used $\mathrm{DH}$ procedures for fixation of heterosis in barley, identifying DH lines higher in yield than the heterotic F1.

DH technology can also be useful for inducing, selecting, and fixing mutations, which are generally recessive in nature or controlled by recessive alleles. In fact, haploid cells provide an ideal target for mutation induction and selection due to the potentiality to screen for both recessive and dominant mutants directly in the first generation, avoiding chimerism and shortening breeding times (Germanà 2011a, b). Indeed, as an alternative of the costly methods of repeated 'backcrossing' to the parental lines and/or 'single seed descent', doubled haploidy presents many attractive benefits in isolating and purifying desired mutations and in reducing the mutational load (Szarejko 2003; Szarejko and Forster 2006). The most interesting aspect of mutagenic treatments applied to haploid cells is the immediate expression of recessive mutations and the possibility to obtain, by doubling chromosomes, complete homozygous diploids, improving the effectiveness of the selection of desired recombinants (Forster and Thomas 2005). When uni-nucleate microspores are used as a target for mutagenic treatment, to avoid chimeric and heterozygous plant formation, it is important that the chemical or physical mutagens are applied before the first nuclear division (Kasha et al. 2001). Mutant DH lines have been successfully used in rice and wheat, and several of these lines exceeded the yield of the parental line (Szarejko and Forster 2006). The development of improved DH protocols now makes this a viable option for many species (Maluszynsky et al. 2003).

Another objective for using Hs in crop breeding is 'gametoclonal variation', which consited in morphological, genetic (chromosome number and structures) and biochemical differences present in plants regenerated from cultured gametic cells (Evans et al. 1984). Due to their homozygosity, the gametoclones directly display the expression of both dominant and recessive mutations. Gametoclonal variation can be 
induced by cell culture and chromosome doubling procedures by segregation and independent assortment, resulting from both meiotic and mitotic division (Huang 1996). Moreover, haploid technology can be particularly effective in accelerating breeding if combined with other biotechnologies, such as 'marker-assisted selection' (MAS), providing a shortcut in backcross conversion to select elite lines (Forster et al. 2007b; Tuvesson et al. 2007). In fact, in addition to being a powerful tool for genetic analysis as mentioned before, molecular markers are also useful for planning new crosses, predicting novel useful gene combinations (Tuvesson et al. 2007). DHs are also very useful for genome mapping, including the construction of genetic linkage maps and gene tagging, providing reliable information on the location of major genes for economically important traits (Khush and Virmani 1996). DH lines are a key feature in genomics, particularly in integrating genetic and physical maps. Indeed, the use of DHs have been very advantageous in establishing chromosomes maps in many species, such as barley, rice and wheat (Forster and Thomas 2005). Nowadays, several genome sequencing programs are using haploid genome because of its simplified assembly, such as many fruit crops like peach, pear, apple and citrus (Dunwell 2010).

Evidently, the availability of an efficient and cost-effective protocol for Hs and DHs production is necessary to take advantages of combining techniques with DH systems. There is not a universal suitable protocol and the development of new techniques is still required for many recalcitrant genotypes (Germanà 2011a, b).

\subsection{Status of art of Hs and DHs technology}

The first spontaneous haploid were repoted in thornapple (Datura stramonium L.) by Blakeslee et al. (1922) and, more than forty years later, Guha and Maheshwari (1964, 1966) obtained numerous embryos from in vitro anther culture and confirmed that regenerated plants had originated from immature pollen grains with a haploid number of chromosomes. As reported by Forster et al. (2007a), in a relatively short period, these discoveries had a tremendous impact in stimulating further development of in vitro procedures for the obtaining of $\mathrm{H}$ and $\mathrm{DH}$ plants in various important agriculture crops, such as tobacco (Nitsch and Nitsch 1969), brassica (Kameya and Hinata 1970), barley (Kasha and Kao 1970), tomato (Sharp et al. 1972) and pepper (Wang et al. 1973). Already in 1974, at the First International Symposium on 'Haploids in Higher Plants' 
(Guelph, Canada), the utilization of haploidy in plant breeding was discussed (Kasha 1974) and it was generally accepted that the application of DH technology to crop breeding had several advantages, compared to conventional methods, for producing homozygous lines (Forster and Thomas 2005). In the past few decades, even the Food and Agriculture Organization (FAO) and the International Atomic Energy Agency (IAEA) have supported and coordinated research focused on the development of more efficient DH production methods and their application in plant breeding (Dunwell 2010; Germanà 2011a, b). Nowadays, haploid technology has already had a huge impact on agricultural systems of many agronomically important crops, representing an integral part in their improvement programs and resulting in the development of more than 300 new varieties (Germanà 2011b). Nevertheless, DHs use is still limited to 'selected' species for many reasons. These might be categorized as biological, based on plant status (annual, biannual, perennial, authogamous, allogamous or vegetativelly propagated) or technical, which are the result of the feasibility and efficiency of DHs induction protocol (Murovec and Bohanec 2011). In fact, induction protocols vary not only among species but also among genotypes of the same species. Recently, species previously considered recalcitrant, such as woody plants (Germanà 2006, 2009; Chiancone and Germanà 2016; Cardoso et al. 2016), have been objects of successful studies, causing a resurgence of interest in Hs and DHs of higher plants (Forster et al. 2007a; Ferrie 2009; Wedzony et al. 2009; Dunwell 2010; Ferrie and Caswell 2011; Islam and Tuteja 2012). In addition, there is a strong commercial interest in methods for the production and exploitation of $\mathrm{H}$ and $\mathrm{DH}$ plants, verified by the extensive application of intellectual property protection and patenting system (Dunwell 2009, 2010).

\subsection{Methods to obtain Hs and DHs}

Haploids can be spontaneously produced trough parthenogenesis (the production of an embryo from an egg cell without the participation of the male gamete) or apogamy (the production of an embryo from a gametophytic cell other than the ovum). The recovery of spontaneous haploid has been reported in many angiosperm species (Kasha and Seguin-Swartz 1983). In fruit trees, spontaneous haploid plants have been recovered in 
apple, apricot, peach, pear, plum, etc., but with a too low frequency for practical application in their breeding programs (Zhang et al. 1990).

Various in vivo or in vitro approaches have been employed in order to obtain $\mathrm{H}$ and $\mathrm{DH}$ plants, such as reapeted pollination with pollen of the same species (e.g., maize), pollination with pollen of a wild relative (e.g., barley, potato) or unrelated species (e.g., wheat), pollination with irradiated pollen, genome elimination and gametic embryogenesis (andro and gyno-genesis) (Murovec and Bohanec 2011). For example, the induction of maternal $\mathrm{Hs}$ can be initiated when pollination is followed by fertilization of the egg cell and development of a hybrid embryo, in which paternal chromosome elimination occurs in early embryogenesis or when fertilization of the egg cell does not occur, and the development of the $\mathrm{H}$ embryo is triggered by pollination of polar nuclei and the development of endosperm. Moreover, if pollination occurs through irradiated pollen (usually by gamma rays from cobalt 60 ), embryo development is stimulated by pollen germination on the stigma and growth of the pollen tube within the style, although irradiated pollen is unable to fertilize the egg cell. This technique has been successfully used in several species, including some fruit crop, such as apple (Hofer and Lespinasse 1996), kiwifruit (Musial and Przywara 1998, 1999), mandarin (Froelicher et al. 2007; Aleza et al. 2009b) and pear (Bouvier et al. 1993). The dose of irradiation is the main factor controlling haploid induction, beside the developmental stage of the embryos at the time of culture, the culture conditions and the media composition (Germanà 2012). At lower irradiation doses, the generative nucleus could be just partly damaged and therefore maintains its capacity to fertilize the egg cell. It results in large numbers of obtained embryos but all of hybrid origin and abnormal (mutant) phenotype. Conversely, an increase in the irradiation dose may cause a decrease in the total number of developed embryos but the obtained regenerants are mostly of haploid origin. Gynogenic embryos have been also obtained in Citrus through parthenogenesis induced by pollination with pollen from a triploid plant, both in vivo by Oiyama and Kobayashi (1993) and in vitro by Germanà and Chiancone (2001).

Wide crossing between species has been shown to be a very effective method for haploid induction and has been used successfully in several cultivated species (Ocampo et al. 2000). It exploits haploidy from the female gametic line and involves both interspecific and inter-generic pollinations. The fertilization of polar nuclei and production 
of functional endosperm can trigger the parthenogenetic development of haploid embryos, which mature normally and are propagated through seeds (e.g., potato). In other cases, fertilization of ovules is followed by paternal chromosome elimination in hybrid embryos. The endosperms are absent or poorly developed, so embryo rescue and further in vitro culture of embryos are needed (Murovec and Bohanec 2011).

In addition, when embryogenesis is induced from a male (androgenesis) or female (ginogenesis) gamete-regenerated haploid embryos represent the progeny of the donor plant, denominating this process 'gametic embryogenesis' (Soriano et al. 2013). Gynogenesis, is another pathway of $\mathrm{H}$ embryo production exclusively from a female gametophyte. It can be achieved with the in vitro culture of various un-pollinated flower parts, such as ovules, ovaries or whole flower buds. The female gametophyte is usually immature at inoculation but its development continues during in vitro culture, leading to a mature embryo sac. Mature embryo sacs contain several haploid cells theoretically capable of forming haploid embryos, such as the egg cell, synergids, antipodal cells and non-fused polar nuclei (Musial et al. 2005). However, under optimal conditions, the egg cells in most gynogenetic responsive species undergo sporophytic development (haploid parthenogenesis) (Bohanec 2009). Gynogenic induction using un-pollinated flower parts has been successful in several species (Bohanec 2009; Chen et al. 2011); nevertheless, its application in breeding programs is very restricted. It is a very complex process since it is a very small, delicate, and highly hydrated structure that can be damaged very easily (Cardone et al. 2010). Consequently, gynogenesis is used mainly in dioecious plants, in plants showing male sterility or in which other induction techniques, such as androgenesis and the pollination methods above described, have failed (Bhat and Murthy 2007; Chen et al. 2011).

Indeed, the most effective and widely employed technology in obtaining DH plants is androgenesis, often more properly called pollen or microspore embryogenesis. Pollen embryogenesis is the process of induction and regeneration of $\mathrm{Hs}$ and DHs originating from immature male gametic cells. Seguí-Simarro (2010) described three main routes that can lead to the production of androgenic H or DH individuals (Fig. I.1). The first one involves the development of an haploid embryo within the embryo sac. After fertilization, the female zygote nucleus has been inactivated or removed, releasing a haploid cell zygote, with only male chromosomes, which continues its normal 
development. In the second rout, $\mathrm{H}$ or $\mathrm{DH}$ calluses are obtaining from meiocytes. The third rout relies on the ability of microspores and immature pollen grains (late uninucleate, vacuolate or early bi-cellular pollen stage) to convert their developmental pathway from gametophytic (leading to mature pollen grain) to sporophytic, resulting in cell division at a haploid level, followed by the formation of calluses or embryos (Seguí-Simarro and Nuez 2008a).

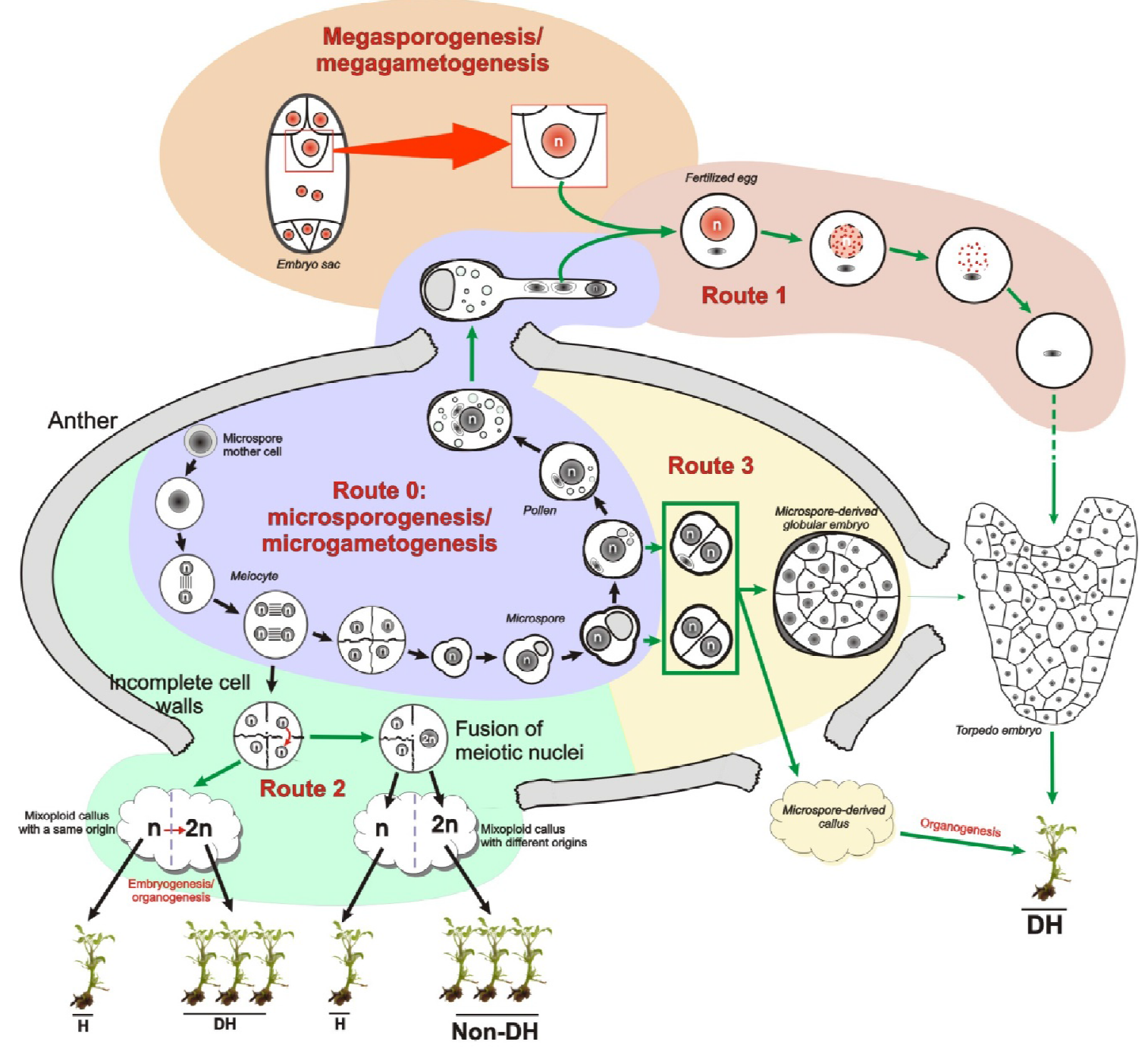

Fig. I.1 The different androgenic routes (Seguí-Simarro 2010 - modified)

Third rout is the most efficient and used, in fact pollen embryogenesis is generally achived thought in vitro anthers or isolated microspore culture. Anthers culture was the first discovered haploid inducing technique of which efficiency was sufficient for plant breeding purposes (Maluszynski et al. 2003). It is still widely used, although isolated 
microspore culture is an improved alternative. In fact, whit this technique a relatively high proportion of induced haploids spontaneously double their chromosome number, leading to regeneration of homozygous doubled haploids (Kasha et al. 2001). During isolation of microspores, the anther wall tissues are removed, thus preventing interference of maternal sporophytic tissue during pollen embryogenesis and regeneration of heterozygotes from somatic tissue. Moreover, basic research of haploid embryogenesis can be performed directly at the cellular, physiological, biochemical and molecular levels (Murovec and Bohanec 2011).

Usually, physical, thermal (heat, cold) and/or chemical (water stress, starvation) stresses are necessary to enable competent microspores to follow the sporophytic pathway instead of the gametophytic one. The development of a microspore to a whole plant can occur through the formation of callus (indirect embryogenesis or organogenesis) or through the development of a pollen-derived embryo (direct embryogenesis). Due to its high effectiveness and applicability in numerous plant species (Maluszynski et al. 2003), it has outstanding potential for plant breeding and commercial exploitation of DH varieties. Gamete embryogenesis is a particularly indispensable tool for obtaining homozygosity in woody plants, which are characterized by a high genome heterozygosity, a long generation cycle with a long juvenile period, a large size and, often, self-incompatibility (Germanà 2011a, b). Its major drawbacks are the high genotype-dependency within species and the recalcitrance of some important agricultural species, such as woody plants. In addition, many others endogenous and exogenous factors can affect the embryogenic response of immature gametes in culture. In fact, physiological state and conditions of growth of donor plants, stage of gamete development, pre-treatment of flower buds and in vitro culture media and conditions, together with their interactions, are all factors that greatly affect the gamete response to the in vitro culture (Smykal 2000; Wang et al. 2000; Datta 2005; Germanà 2011a).

Although gametic embryogenesis is first used to obtain Hs and DHs, the regenerating plants sometimes result from spontaneous polyploid chromosomal duplications. Polyploid embryos and plants were obtained in many species, such as in Pyrus pyrifolia (Kadota and Niimi 2004), Citrus clementina Hort. ex Tan. (Germanà et al. 2005) and Anthurium andreanum L. (Winarto et al. 2011). Sunderland et al. (1974) reported that triploids are formed by the fusion of two endoreduplicated generative nuclei and the 
vegetative nucleus, while the fusion of two endoreduplicated generative nuclei plus two children vegetative nuclei form tetraploid embryo. The dynamics and mechanisms of diploidization at early stages of microspore-derived embryos have been reviewed in Seguí-Simarro and Nuez (2008b). Anyway, the diploid or polyploidy plants originated in this way are completely homozygous.

\subsection{Characterization of Hs and DHs}

During the production of homozygous lines, various undesired heterozygous plantlets can be obtained. After a successful haploid induction and regeneration procedure, evaluation of regenerants is needed to distinguish between desired Hs (or spontaneously DHs) and redundant heterozygous diploids. Several direct and indirect approaches are available for determining the ploidy level of regenerated plants. Indirect approaches are based on comparisons of plant morphology (plant height, leaf dimensions), plant vigor and fertility, number of chloroplasts in stomatal guard cells and plastid dimensions, between regenerants and donor plants (Yuan et al. 2009). They are fairly unreliable and subject to environmental effects, but they do not require costly equipment. Direct methods are more reliable and include conventional cytological techniques, such as counting the chromosome number (Maluszynska 2003) or measurement of DNA content using flow cytometry (Bohanec 2003). Flow cytometry allows the analysis of a large number of target plants in a shorter period of time (Ochatt 2008), enabling detection of mixoploid regenerants (having cells with different ploidy) and the determination of their proportion, according to position of peaks representing the size of the nuclei. Because of the spontaneous chromosome doubling occurring in the haploid calli and embryos, ploidy level analysis cannot always identify pollen-derived plants. To determine regenerant origins, assessing homozygosity and distinguish between spontaneously DHs and heterozygous hybrid diploids, isozyme analyses, random amplified polymorphic DNA markers and microsatellites can be employed.

Isozyme analyses have been employed in Citrus to confirm the gametic origin of calluses, embryos and plantlets (Germanà and Chiancone 2001). These techniques allow the distinction between androgenetic and somatic tissue when the enzyme is heterozygotic in the diploid condition of the donor plant and the regenerant shows lack of an allele (Germanà 2007). Furthermore, several DNA molecular markers have been 
commonly adopted, such as AFLP (Amplified Fragment Length Polymorphism), RAPD (Random Amplified Polymorphic DNA), SCAR (Sequence Characterized Amplified Regions) or SSR (Simple Sequence Repeat), depending on their availability for a particular plant species (De Vienne 2003). Co-dominant molecular markers, as well as isozyme markers, have the advantage that a single locus, when heterozygous in donor plants, might be used for homozygosity determination. In contrast, a more complex profile is analyzed with dominant markers. In such a case, bands missing from the donor profile indirectly indicate homozygosity (Murovec and Bohanec 2011).

\section{POLYPLOIDS IN BREEDING}

\subsection{Definition and types of polyploids}

Polyploids are defined as those organisms which exceeds the diploid number of chromosomes per cell nucleus, which has been considered a ubiquitous phenomenon in plant evolution and diversification (Soltis et al. 2009). The elucidation of the causes and consequences of polyploidy has been the focus of several reviews in the last years (Otto and Whitton 2000; Wolfe 2001; Osborn et al. 2003; Soltis and Soltis 2009; Yang et al. 2011; Ramsey and Ramsey 2014). These studies have provided a wide range of information about different aspects of polyploidy, including classification, frequency, mechanisms of origin and ancient polyploidy events, as well as its ecological, genetic and evolutionary consequences (Sattler et al. 2016).

Polyploid plants, depending on their genomic origin, can be divided into autopolyploids (species that have genomes derived from a single ancestral species) and allopolyploids (species derived from the hybridization of two different genomes followed by genomic multiplication). The allopolyploidy has exerted greater influence that autopoliploidy on the development of the evolutionary process; in fact, most polyploid species observed in nature have hybrid origins.

Based on the number of groups of post duplication homologous chromosomes, polyploids can be also classified into: triploids, tetraploids, hexaploids, octoploids, etc. (Yang et al. 2011). Conversely, aneuploids are organisms characterized by the presence of an abnormal number of chromosomes, not being its chromosome number multiple of 
the basic (Acquaah 2007). Polyploids can also be divided into natural and synthetic, the first arising from the natural result of spontaneous genome duplication, the seconds from the result of a synthetic genome duplication induced with or without hybridization. Currently, major cultivated crops are polyploids, such as triploid banana, tetraploid potato, hexaploid wheat or octoploide strawberry and sugar cane.

\subsection{Modes of origin of polyploids}

Polyploidy is quite common in plants, providing a natural mechanism of adaptation. Thus, about $70 \%$ of angiosperms have had some process of polyploidy during their evolution (Chen et al. 2007). Different mechanisms have been proposed to explain how polyploids arise in nature. Two major pathways are known to lead to polyploidy in plants: the somatic doubling and the formation of unreduced reproductive cells.

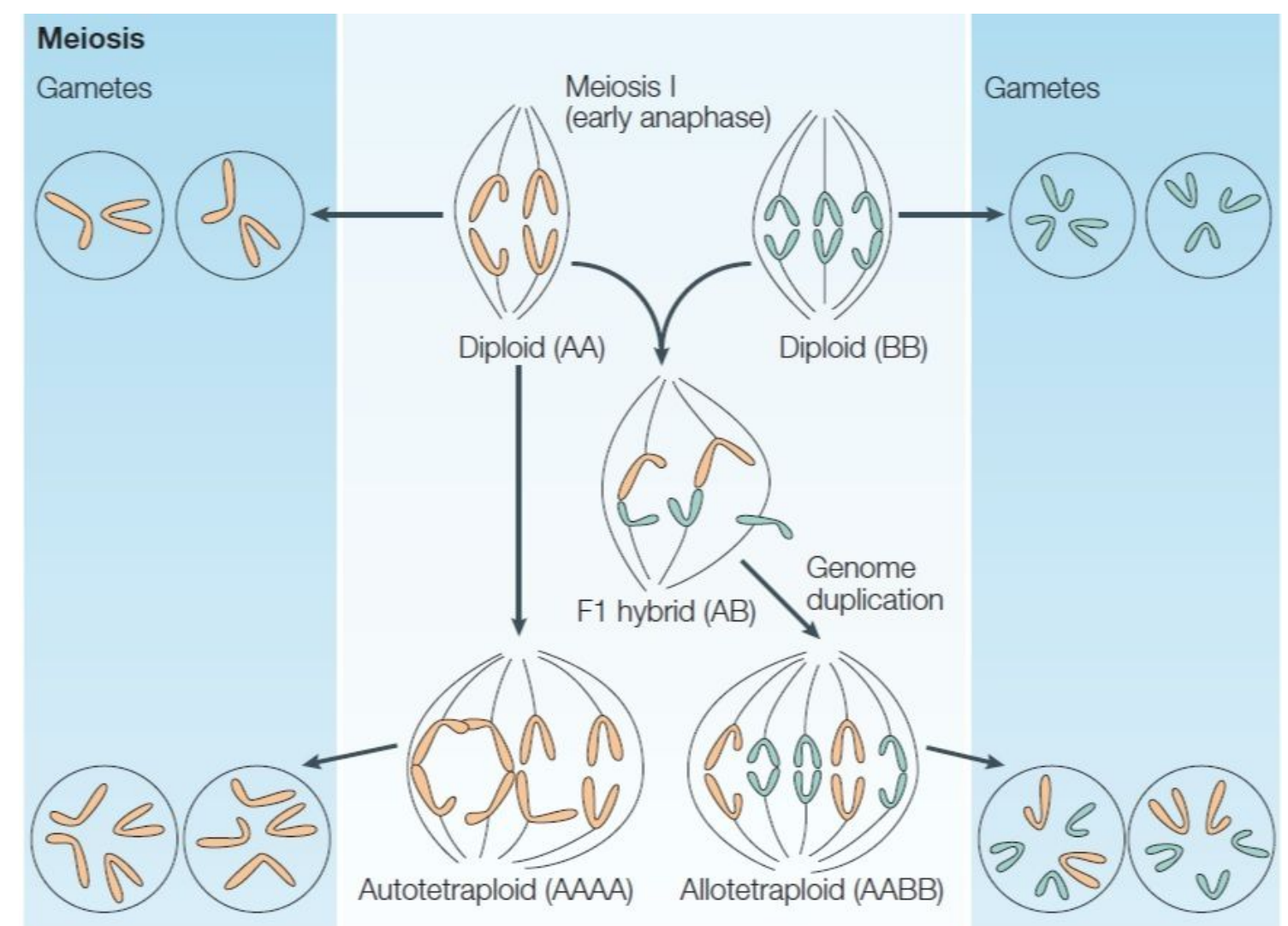

Fig. I.2 Polyploids formation (Comai 2005 - modified)

Somatic doubling is associated with mitotic events such as endomitosis or endoreduplication, which may occur either in a zygote cell or in apical meristematic 
tissues, giving rise to mixoploids or even completely polyploid organisms. Despite being constantly used to attain artificial polyploids, somatic doubling is supposed to have a minor role in the origin of natural polyploid organisms (Ramsey and Schemske 1998). As shown in Fig. I.2, the pairing of homologous chromosomes is defective in the F1 hybrid because of divergence in the structure and number of chromosomes. Pairing is restored by genome duplication, resulting in polyploids formation.

\subsubsection{Natural polyploids}

Although 'chromosome duplication' can be a method to obtain polyploids, the formation and fusion of unreduced gametes is considered the most common mechanism of polyploidization (De Wet 1980). The capacity of producing unreduced gametes is a heritable feature evidenced in many plant species. Besides genetic control, environmental factors such as temperature, herbivory, wounding, water deficit and nutrients shortage, can influence the production of unreduced gametes (Ramsey and Schemske 1998).

Production of male and female (pollen grain and ovule) gametes is a complex process, which occasionally causes failures in chromosome reduction during meiosis (Tate et al. 2005). Therefore, the binding of these unreduced gametes result in a direct polyploid, natural triploid if the bond is between a non-reduced and one normally reduced gamete and natural tetraploid if the bond is between two unreduced gametes. The latter mechanism was detected in F1 progenies of open pollination in apple, leading to natural tetraploid apple trees (Einset 1959). When unreduced gametes fuse in interspecific crosses they give rise to an allopolyploid.

An unusual way of polyploid formation occurs when an egg is fertilized by several male gametes, as in some ornamental plants such as orchids (Ramsey and Schemske 1998). Other processes of natural duplication of chromosomes have been registered by alterations in meristematic cells during mitosis, for instance in meristematic tissues of tomato (Ramsey and Schemske 1998).

During polyploids formation, 'diploidization' (a repeated loss of chromosomes) takes place. It is the process whereby necessary genomic changes occur to remove repeated genes and to avoid gene silencing (Clarkson et al. 2005; Comai 2005; Ozkan and Feldman 2009) so that, at the genetic level, the tetraploid behaves like a normal diploid. 
This phenomenon has been widely described in the genus Nicotiana and Cucumis (Chen et al. 2007; Comai 2005).

\subsubsection{Artificial polyploids}

Nowadays, the artificial induction of polyploidy through the inhibition of mitosis is widely practiced. Many inhibitors can be used to block cell cycle progression in cycling plant cells, such as the anti-mitotic drug colchicine or dinitroanilines. Colchicine $(\mathrm{N}-$ [(7S)-1,2,3,10-tetramethoxy-9-oxo-6,7-dihydro-5H-benzo[a]heptalen-7-yl]acetamide), an alkaloid extracted from meadow saffron (Colchicum autumnale L.), was the first anti-mitotic agent to be discovered (Blakeslee and Avery 1937) and has been used to induce polyploidy in a wide range of species such as blueberries, rye, watermelon, sugar beets, wheat and snuff (Hancock 1997). It showed to be effective also in many fruit species as Pyrus pyrifolia N. (Kadota and Niimi 2002), Punica granatum L. (Shao et al. 2003), Zizyphus jujuba (Gu et al. 2005), Vitis vinifera L. (Yang et al. 2006), Actinidia chinensis (Wu et al. 2011) and Eriobotrya japonica (Blasco et al. 2015). Colchicine has low affinity for plant tubulins and must be used at millimolar levels for effective polyploidy induction in plants (Dhooghe et al. 2011). Applications at relatively low concentrations can be tolerated by many species without being lethal.

Oryzalin (4- (Dipropylamino) -3,5-dinitrobenzenesulfonamida) has also been used successfully and it is considered less toxic than colchicine, but induces lower levels of tetraploidy (Aleza et al. 2009a; Contreras et al. 2010). Both agents have a similar mechanism of action, binding the tubulin dimmers preventing microtubules polymerization in metaphase and, consequently, avoiding the division of the replicated chromosomes into daughter cells (Petersen et al. 2003; Sajjad et al. 2013). Subsequently, when the concentration of the agent decreases, normal growth of the plant is resumed and mitosis of the generated polyploid cells occurs. Cytokinesis will also be compromised, resulting in the formation of cells with doubled chromosome number. The success of a polyploidization procedure depends on many factors, such as type and concentration of the antimitotic agent, the time of exposure, the method of antimitotic solution application and the type of explants (Sattler et al. 2016). 


\subsection{Polyploidy detection}

After induction of chromosome duplication, it is important to confirm the success of the experiment in yielding polyploidy plants. Chromosome counting has been considered the most accurate method to detect polyploid variants. Cytogenetic techniques are laborious and require specific protocols according to the species (Dolešel et al. 2007). Alternatively, flow cytometry is a reliable and simple method to measure the ploidy level, allowing the analysis of a large number of plants in a short period of time (Bohanec 2003; Ochatt 2008). Flow cytometry analysis infers the ploidy level by its correlation with the relative or absolute DNA content, assuming that an increment in DNA content corresponds to increments in chromosome number. The DNA content of a sample with known ploidy level is used as a reference standard to determinate the DNA ploidy level of the sample analysed (Dolešel et al. 2007).

\subsection{Application of polyploidy in plant breeding}

The revelation that a large number of plant species have a polyploid genome, including several important crops, has attracted the attention of plant breeders for the application of artificial polyploidy as a tool for crop improvement (Sattler et al. 2016). As highlighted by Dewey (1980), each crop species responds differently to polyploidization, depending on their original ploidy level, genome structure, reproduction mode, perenniality and the plant organ for which the crop is cultivated. Induced polyploids do not always reach the initial expectations and overcome their diploid progenitors. Nonetheless, such disturbances have the potential to produce novel genotypic and phenotypic variations, which may be useful for artificial selection in plant breeding programs.

In fact, the production of polyploids involves a series of changes at the genetic and physiological level that often include advantages that can be exploited in plant breeding. Polyploidization events often seem to be associated with increases in vigor and adaptation of the newly formed polyploid to novel conditions. The competitive advantage of polyploids over their diploid progenitors is mostly related to transgressive segregation, i.e., formation of extreme phenotypes and increased vigor (Van de Peer et al. 2009). The most widespread consequence of polyploidy in plants is the increase in cell size, caused by the larger number of gene copies and referred to as the 'gigas effect' 
(Sattler et al. 2016). Consequently, polyploids generally show larger leaves, flowers and fruit, stomatal density and greater number of chloroplasts (Stebbins 1950). Autopolyploidy induction in breeding programs is usually restricted to crops cultivated for their vegetative organs and those with vegetative propagation, due to the low rates of viable seed production (Paterson 2005). Therefore, this phenomenon has been widely exploited in improving ornamental plants (Dhawan and Lavania 1996, Blasco et al. 2015). Tetraploid plants producing fruits of higher quality, associated with changes in the hormonal balance (Wu et al. 2013), increased disease resistance (Predieri 2001), increased production and better adaptability (Liu et al. 2009) have also been described. Moreover, physiological changes in polyploids have been exploited in the production of plants with higher performance in the production of active principles, useful for pharmacological or insecticidal applications (Liu and Gao 2007).

The hybrid vigor present in the allopolyploids represents an advantage compared to diploids, preserving the double set of homologous chromosomes and then preventing the loss of the hybrid vigor by recombination (Comai 2005). An example of the exploitation of alloploidy is the obtainment of the interspecific hybrid 'triticale', where the wheat grain quality is combined with the hardiness of rye (Acquaah 2007; Chen 2010). The allohexaploid Triticum aestivum is the most widely cultivated species of wheat, exhibiting desirable features for bread making, followed by Triticum turgidum, which is the most suitable for pasta production (Pauly et al. 2013).

Moreover, in breeding programs seeking to maximize heterozygosity, the number of allelic combinations obtained from tetraploids self-pollination is greater than from diploids (Acquaah 2007). Likewise, in breeding programs where mutations are exploited as a method to generate diversity, polyploids represent an advantage because its duplicated genome can tolerate a higher mutation rate. For example, in orchids, autotetraploid obtained by treatment with colchicine, could withstand doses of product 20 times higher than the original diploid (Broertjes 1976).

A very important application of horticultural polyploids is the achievement of seedless fruits, through obtaining tetraploid plants and their subsequent hybridization with diploids, resulting in triploid seedless genotypes. Triploid watermelon (Wehner 2008) and table grapes (Ledbetter and Ramming 1989), with great acceptance by the consumer, have been obtained by this method. In addition to the mentioned advantages 
of polyploidy for crop improvement, polyploids may also be induced for other purposes, such as to restore the fertility of sterile hybrids and to serve as a "bridge" for genetic transfer when direct crossing between two species is not feasible (Dewey 1980; Hegarty et al. 2008). 'Bridge crossing' is a strategy employed for transferring genes between two species with different ploidy levels through transitional fertile allopolyploids. The same technique has been applied for gene introgression in other relevant crops, such as cowpea (Fatokun 2002), wheat (Chhuneja et al. 2007) and cotton (Ram 2014).

\subsection{Polyploidy in fruit trees}

Some crop species have been improved by a complex chain of interspecific hybridizations and/or crosses between different ploidy levels. Breeding strategies involving crosses between different ploidy levels is very common, for instance, in apples. Tetraploid varieties have no commercial value because of their low-quality fruits and low resistance to cold, being mostly used to develop triploid cultivars (Sedov 2014). The triploid forms of apples have more advantageous features than the diploids, including more regular fruit bearing, larger fruits with higher commercial appeal and scab resistance (Sedov et al. 2014).

In Citrus, a major breeding goal is the obtention of triploids hybrids that do not produce seeds and/or avoid their formation in other genotypes by cross-pollination. Natural citrus triploid have been selected from crosses $4 n \times 2 n$ (Luro et al. 2004; Ollitrault and Navarro 2012) and from crosses with meiotic restitution of one of the parental (Chen et al. 2008). However, the most common method used to obtain tetraploid citrus, useful as parents in triploids breeding programs, is the use of treatments with colchicine (Juárez et al. 2004; Navarro and Juarez 2007).

In loquat, natural triploids are described from hybridizations between unreduced gametes of the mother plant with normal male gametes. The frequency of unreduced gametes in loquat varies between $0.18 \%$ and $1.62 \%$ and it is highly genotype-dependent (Guo et al. 2007).

With this goal, the production of artificial triploids, obtained through hybridization of artificial tetraploid of elite varieties, is an interesting alternative for the production of seedless fruit that does not depend on the rate of gamete no-reduction. 
In grapes, triploid and tetraploid plants have been produced to obtain seedless and largeberried varieties, respectively. Autotetraploid grapes induced by colchicine have often shown poor fruitfulness, low vigor, and brittle shoots and decreased cold hardiness but increase in berry size (Notsuka et al. 2000). However, these artificial tetraploids have been used as bridges to overcome barriers in crossings between Vitis rotundifolia Michx., Vitis vinifera L. and Vitis labrusca L. (Dermen 1954; Park et al. 2002). In other crops, colchicine-induced plants have shown some improvements in characteristics of commercial relevance, such as in autotetraploids kiwifruit (Actinidia chinensis Planch.), in which a significant fruit size increase was achieved (Wu et al. 2012). Moreover, although several recently induced polyploid forms have not yet reached the required market qualities, they are valuable germplasm sources for improvement of fruit breeding programs. 



\section{OBJECTIVES}

\section{Objective I}

Study and induction of gametic embryogenesis (haploid technology), through in vitro culture of anthers or isolated microspores, for improvement of some selected Mediterranean fruits crops: almond (Prunus dulcis Mill.), mandarin (Citrus reticulata Blanco) and loquat (Eriobotrya japonica (Thunb.) Lindl.).

\section{Objective II}

Induce chromosome duplication, by treatments with colchicine on un-germinated seeds, in order to generate polyploid (e.g. tetraploid) loquat plants for further use in genetic breeding programs. 



\section{EXPERIMENTS}

Experiments have been conducted through years 2014, 2015 and 2016 at the 'Università degli Studi di Palermo' (UNIPA) as well as at the 'Instituto Valenciano de Investigaciones Agrarias' (IVIA). During the doctoral time, with the aim of regenerating homozygous lines, researches have been carried out on gametic embryogenesis by both in vitro anther and isolated microspore culture in different Mediterranean fruit crops, such as almond (Prunus dulcis Mill.), mandarin (Citrus reticulata Blanco) and loquat (Eriobotrya japonica (Thunb.) Lindl.), investigating different factors affecting these techniques. In addition, with the purpose of producing new plant variability, ploidy manipulation was also induced applying colchicine on ungerminated loquat seeds to generate polyploid (e.g. tetraploid) plants.

Particularly, with the objective of regenerating $\mathrm{Hs}$ or DHs, in the first experiment (Chapter 1), investigation on gametic embryogenesis was carried out through in vitro anther culture of seven almond genotypes ('Contino', 'Filippo Ceo', 'Genco', 'Tuono', 'Ferragnes', 'Lauranne' and 'Steliette'), studying and testing anthers and microspore responses to two solidified culture media ( $\mathrm{P}$ and N6) and two temperature treatments (direct cultured at $25 \pm 1{ }^{\circ} \mathrm{C}$ or subjected to hot thermal shock at $35 \pm 1{ }^{\circ} \mathrm{C}$ for 7 days).

In the second trial (Chapter 2), almond anthers of eight cultivars ('Desmayo largueta', 'Doble fina', 'Ferraduel', 'Ferragnes', 'Marcona', 'Planeta', 'Tarraco' and 'Vayro'), were submitted to a cold pre-treatment $\left(4^{\circ} \mathrm{C}\right.$ for 3 days) or directly cultured at $25 \pm 1{ }^{\circ} \mathrm{C}$ (as control) and four culture media with different 6-benzylaminopurine (BAP) concentrations $\left(0,1,1.5\right.$ and $\left.2 \mathrm{mg} \mathrm{L}^{-1}\right)$ were tested.

In the third experiment (Chapter 3), investigation has been conducted through isolated microspore technique in mandarin, cultivar 'Mandarino Tardivo di Ciaculli'. Isolated microspores were cultured at the concentration of 100,000 microspores per $\mathrm{mL}$ in four different liquid media (P, N6 and replacing $0.5 \mathrm{mg} \mathrm{L}^{-1}$ of BAP with $0.5 \mathrm{mg} \mathrm{L}^{-1}$ of metaTopolin in both of them). In addition, two thermal treatments $\left(26 \pm 1^{\circ} \mathrm{C}\right.$ or $35^{\circ} \mathrm{C}$ for 30 days) were tested. The experiments were repeated twice: in the first one, the flower buds were processed immediately after the collection, while in the second one, they were subjected to a cold pre-treatment $\left(4{ }^{\circ} \mathrm{C}\right.$ for 7 days). 
In the fourth investigation (Chapter 4), in order to determine optimum conditions for callus induction, anthers culture of seven different loquat genotypes ('Algerie', 'Cayetano', 'Magdal', 'Peluche', 'Redonet', 'Sanfilippara' and 'Zaozhong-6') was performed on four solid media supplemented with different concentrations $(0,2.68,5.36$ and $8 \mu \mathrm{M}$ ) of 1_naphtalene acetic acid (NAA).

Finally, the fifth experiment (Chapter 5) regarded the polyploid loquat production, very useful for the IVIA breeding program. With this aim, un-germinated loquat seeds (cultivars 'Cardona' and 'Magdal') were treated by immersion in a colchicine solution $(0.5 \% \mathrm{w} / \mathrm{v})$ for 24 or $48 \mathrm{~h}$ at room temperature in the dark, while seeds soaked only with distilled water were used as controls. 


\section{ALMOND ANTHER CULTURE}

\section{Introduction}

Almond (Prunus dulcis Mill.), a member of the Rosaceae family, is a tree native to the Mediterranean climate regions of the Middle East and South Asia, and produces nuts of great commercial value. Prunus dulcis is a worldwide known species, with over two million tons of almonds produced in 2012 (FAO 2014), with an increase of $30 \%$ compared to 2000. The volume of world exports of shelled almonds are around 533.000 t/year (average 2007-11, FAO 2014), with an average annual value of approximately $\$$ 2.5 billion, with a constantly growing trend.

Almond is a diploid species with a monoploid number of chromosomes $n=x=8$ (Martìnez-Gòmez et al. 2005) and it blooms early in the spring when temperatures are still low. Most of the almond cultivars express gametophytic self-incompatibility, which requires cross-pollination generating genetic variability within seedling populations. Genetic control of pollen-pistil self-incompatibility is through a single gene ( $S$-allele) (Tamura et al. 2000; Channuntapipat et al. 2003; López et al. 2004). In the early 1900s, formal plant breeding programs were established in most major production areas to accelerate the selection through controlled crosses and related genetic manipulations. The basic objectives of most almond breeding programs target increased yields, nut quality, resistance to biotic and abiotic stress and decreased production costs (Socias I Company 1998).

The technique of haploids (Hs) and doubled haploids (DHs) production is developing as a powerful biotechnological tool to obtain pure lines and to support the conventional fruit crop breeding programs. Hs are sporophytes with the gametophytic chromosome number ( $\mathrm{n}$ instead of $2 \mathrm{n}$ ), and they are originated from a single immature gamete (Germanà 2011a). When duplication of chromosomes of a H occurs, a DH is obtained (Kasha and Maluszynsky 2003). Haploid technology allows us to achieve completely homozygous lines from heterozygous parents in just one step, significantly reducing the time required to obtain the same result with the conventional method which requires several generations of self-pollination. 
The obtainment of homozygous plants had a significant impact on the breeding programs of many important crops (Germanà 2011b). Many laboratories and breeding companies, involved in the improvement of a wide range of crops, have now started to routinely use the DH technology (Tuvesson et al. 2007). Recently, species that were previously considered rather recalcitrant, such as forage, vegetable crops, legumes, aromatic, medicinal, and even woody plants, have become objects of successful studies on the induction of gametic embryogenesis (Germanà 2006, 2009; Dunwell 2010; Chiancone and Germanà 2016). Nowadays, the realization of the potential in these areas, alongside real and tangible results, is causing a resurgence of interest in Hs of higher plants (Forster et al. 2007). Moreover, the extensive application of intellectual property (IP) protection and patenting system to Hs, also attests to the commercial interest in methods for the production and exploitation of these plants, both in the USA and elsewhere (Dunwell 2010). Gametic embryogenesis is an indispensable tool to quickly obtain homozygosis in woody plants, since these are characterized by long juvenility, high levels of heterozygosis and, often, by self-incompatibility (Germanà 2009). Unfortunately, many woody species, as well as fruit crops, are still recalcitrant to this process, that can be carried out using various methods, mainly including in vitro culture of anthers or isolated microspores (Germanà 2011a, b; Chiancone et al. 2015; Karasawa et al. 2016). Anther culture is often the method of choice for the production of DHs in many crops because its simplicity, which allows a large scale approach and the application to a wide range of genotypes (Sopory and Munshi 1996; Germanà 2011a). To induce the formation of Hs and DHs through in vitro culture of anthers, especially in woody species, there are no standard conditions or well-defined protocols. In fact, there are numerous endogenous and exogenous factors, together with their interactions, which can affect the response of anther culture, such as the genotype, the pollen development stage, the pre-treatments, the culture medium and, the physiological state of the donor plants (Datta 2005).

With regard to Prunus species, somatic embryogenesis has been achieved after a callus phase and/or directly by an adventive pathway in P. subhirtella (Da Camara Machado et al. 1995), P. avium x P. pseudocerasus (Jones et al. 1984), P. incisa x serrula (Druart 1981, 1990), P. avium (De March et al. 1993; Garin et al. 1997), P. cerasus (Tang et al. 2000) and P. persica (Hammerschlag et al. 1985; Raj Bhansali et al. 1990). Moreover, 
somatic embryo-to-plant transformation system has already been exploited for cultivar improvement in some Prunus species (Da Camara Machado et al. 1995; GutieÁrrezPesce et al. 1998). Almond is considered to be recalcitrant to in vitro culture, particularly when this technology is required for Agrobacterium-mediated transformation (Martìnez-Gòmez et al. 2003). A few papers report sporadic shoot regeneration from callus cultures derived from $P$. dulcis cotyledons and leaves (Mehra and Mehra 1974), and somatic embryogenesis from a petiole-derived cell suspension (Durzan 1985).

To our knowledge, there are very few reports in the literature regarding anther culture in almond, in which only callus production was achieved (Michellon et al. 1974; Li et al. 2004). However, no microspore-derived embryo production has been reported to date. The aim of our studies was to apply in vitro anther culture to Prunus dulcis to induce gametic embryogenesis. 



\section{CHAPTER 1}

\section{Microspore embryogenesis induced through in vitro anther culture of almond (Prunus dulcis Mill.)}

\subsection{Abstract}

Anther culture is one of the most widely used methods to induce gametic embryogenesis. The aim of this investigation was to induce microspore embryogenesis in almond (Prunus dulcis Mill.), through this technique. Anthers were cultured at the vacuolated developmental stage, and seven cultivars, two culture media and two temperature treatments were assessed. Although evidence of the microspore induction was observed in all the genotypes and treatments tested (symmetrical nucleus division and multinucleated structures), calli were produced merely by anthers cultured in the medium $\mathrm{P}$ and the regeneration of embryos was detected only in anthers of 'Filippo Ceo', 'Lauranne' and 'Genco', placed on medium $\mathrm{P}$ and subjected to the Control treatment (direct culture at $25 \pm 1{ }^{\circ} \mathrm{C}$, without the hot thermal shock at $35 \pm 1{ }^{\circ} \mathrm{C}$ for 7 days).

Characterization by SSR marker analysis of the embryo genotypes revealed that the regenerants had a single allele for each locus whereas the parent cultivar was heterozygous, indicating their development from haploid microspores.

This study reports the evidence of gametic embryogenesis and, particularly, of microspore embryogenesis through in vitro anther culture, in almond, and, for the first time to our knowledge, the production of homozygous embryos.

\subsection{Materials and methods}

\subsubsection{Plant material}

Seven different almond cultivars were tested. In particular, four cultivars from Italy:

'Contino', 'Filippo Ceo', 'Genco', 'Tuono' and three from France: 'Ferragnes', 'Lauranne' and 'Steliette'. One year shoots bearing flower buds at different 
developmental stages were harvested on February in a field located in Canicattì (Agrigento, Italy).

\subsubsection{Bud size and microspore stage correlation}

Flowers buds of different sizes were selected to evaluate the pollen developmental stage (Fig. 1.1a). Ten anthers from each flower size were removed and squashed in a few drops of 4',6-diamidino-2-phenylindole (DAPI) staining solution and observed under a fluorescent microscope Zeiss Axiophot (Germany) to identify the pollen development stage and to determine the flower bud size containing anthers (Fig. 1.1b) with the highest percentage of uninucleated-vacuolated microspores (Fig. 1.1c). The assumption was that for almond, this stage is the most suitable to induce microspore embryogenesis, as it is in in many other fruit crops (Peixe et al. 2004; Germanà 2011a, b). Only flower buds with the correct size, containing anthers mostly with microspores at the uninucleated-vacuolated stage, were selected for the anther culture.

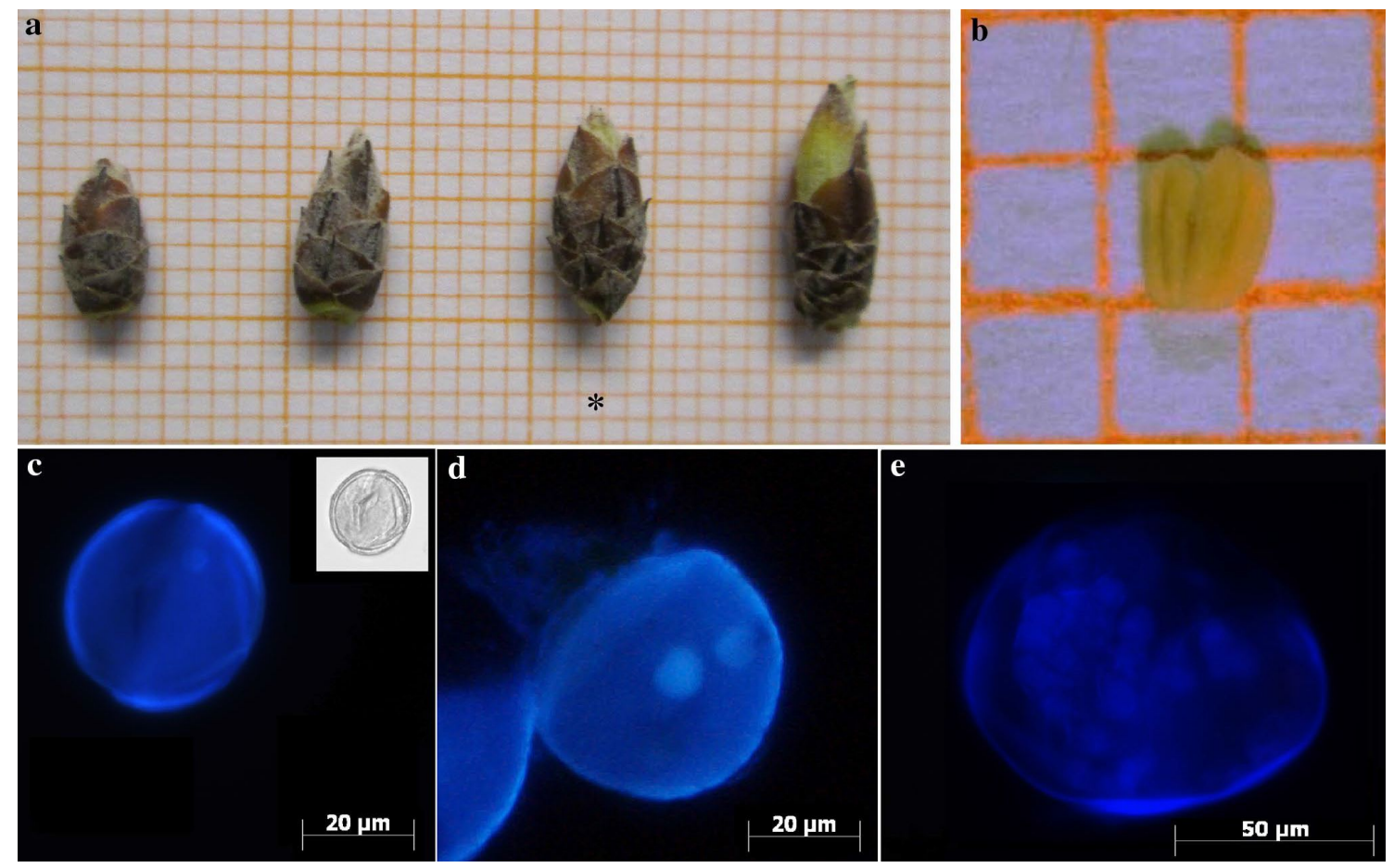

Fig. 1.1 a Phenological stages of flower buds selected in relation to the microspore developmental stage *(best stage $=$ vacuolated stage); b Anther of 'Ferragnes' containing vacuolated microspore; c Uninucleated-vacuolated microspore; d Microspore with two nuclei of equal size (symmetrical nucleus division) of 'Filippo Ceo'; e Multinucleated microspore of 'Filippo Ceo' 


\subsubsection{Flower bud sterilization and anther culture}

About seventy flower buds per each cultivar were removed from the shoots and surface sterilized. The sterilization was performed, under a laminar flow hood, by immersion in $70 \%(\mathrm{v} / \mathrm{v})$ ethyl alcohol for $5 \mathrm{~min}$, followed by immersion in sodium hypochlorite solution ( $0.5 \%$ active chlorine) with few drops of Tween-20 for 20 min and finally rinsed in sterile distilled water three times and processed. After sterilization, petals were aseptically removed using small forceps and anthers were carefully excised and immediately placed in Petri dishes $(60 \times 15 \mathrm{~mm})$ containing $10 \mathrm{~mL}$ of solidified medium (60 anthers/each Petri dish).

\subsubsection{Experimental design}

\section{Culture media}

Two different induction media, referred as $\mathrm{P}$ medium (Germanà et al. 1996) and N6 medium (Karasawa et al. 2016), were tested. The composition of the media is reported in Table 1.1. Growth regulators were added to the culture medium and $\mathrm{pH}$ was adjusted to 5.8 before autoclaving $\left(20 \mathrm{~min}, 120^{\circ} \mathrm{C}\right)$. When obtained, embryos were transferred onto a germination medium consisting in Murashige and Skoog (MS) (1962) basal salts, including MS vitamins, with the addition of $3 \%$ sucrose, $1 \mathrm{mg} \mathrm{L}^{-1}$ indolbutiric acid, and $0.75 \%$ agar, in order to induce their germination and conversion into plantlets.

\section{Temperature treatments}

The flower buds were subjected, as common cold inductive pretreatment, to a temperature of $4{ }^{\circ} \mathrm{C}$ for one week. The effect of two thermal treatments was observed applying the following conditions: five Petri dishes/cultivar were directly incubated in a growth chamber at $25 \pm 1{ }^{\circ} \mathrm{C}$ as control (C). Meanwhile, an additional hot thermal shock was applied just after placing the anthers in the two media, placing five Petri dishes/cultivar in a stove at a temperature of $35 \pm 1^{\circ} \mathrm{C}$ for 7 days $(\mathrm{H})$.

\section{Data collection and statistical analysis}

Sixty anthers were placed in each Petri dish and twenty Petri dishes were prepared per each genotype (10 per each medium, 5 per treatment, for a total of 1200 anthers per 
each genotype). Petri dishes were incubated in the dark for 30 days and, then, transferred under cool white fluorescent lamps Philips TLM 30W/84 conditions (Philips, France), with a photosynthetic photon flux density of $35 \mu \mathrm{mol} \mathrm{m} \mathrm{m}^{-2}$ and a photoperiod of $16 \mathrm{~h}$ light.

Table 1.1 Media composition (in $\mathrm{g} \mathrm{L}^{-1}$ or $\mathrm{mg} \mathrm{L}^{-1}$ )

\begin{tabular}{lcc}
\hline Components & P & N6 \\
\hline Chu Salts & $1 \mathrm{X}$ & $1 \mathrm{X}$ \\
N\&N Vitamins & $1 \mathrm{X}$ & $1 \mathrm{X}$ \\
Galactose & $18 \mathrm{~g}$ & $9 \mathrm{~g}$ \\
Lactose & $36 \mathrm{~g}$ & $18 \mathrm{~g}$ \\
Ascorbic Acid & $500 \mathrm{mg}$ & $500 \mathrm{mg}$ \\
Myoinositol & $5 \mathrm{~g}$ & - \\
Biotin & $500 \mathrm{mg}$ & $500 \mathrm{mg}$ \\
Thiamine & $5 \mathrm{mg}$ & - \\
Pyridoxine & $5 \mathrm{mg}$ & - \\
2,4-Dichlorophenoxyacetic & & \\
acid & $0.5 \mathrm{mg}$ & $0.02 \mathrm{mg}$ \\
1-Naphthaleneacetic acid & - & $0.02 \mathrm{mg}$ \\
Kinetin & $0.5 \mathrm{mg}$ & $1 \mathrm{mg}$ \\
Zeatin & $0.5 \mathrm{mg}$ & $0.5 \mathrm{mg}$ \\
Gibberellic acid & $0.5 \mathrm{mg}$ & $0.5 \mathrm{mg}$ \\
Thidiazuron & $0.5 \mathrm{mg}$ & $0.1 \mathrm{mg}$ \\
Benzyladenine & $0.5 \mathrm{mg}$ & $0.5 \mathrm{mg}$ \\
Coconut water & $100 \mathrm{~mL}$ & $50 \mathrm{~mL}$ \\
Casein & $500 \mathrm{mg}$ & $500 \mathrm{mg}$ \\
Serine & $100 \mathrm{mg}$ & - \\
Glycine & $2 \mathrm{mg}$ & - \\
Glutamine & $800 \mathrm{mg}$ & $200 \mathrm{mg}$ \\
Malt extract & $500 \mathrm{mg}$ & $800 \mathrm{mg}$
\end{tabular}

P (Germanà et al. 1996), N6 (Karasawa et al. 2016), Chu salts (Chu 1978), N\&N vitamins (Nitsch and Nitsch 1969)

The in vitro cultured anthers were observed weekly with a stereo-microscope (Leica MZ 125) to follow their development. Moreover, DAPI staining was carried out in anthers collected after one month of culture to observe the microspore developmental response. For each thesis ( 7 genotypes, 2 media and 2 thermal treatments), about 150 microspores were examined to evaluate the different structural features (uninucleated, binucleated, trinucleated microspore and multinucleated structures) using a fluorescence microscope (Zeiss, Axiophot, Germany). 
Four months after culturing, the number of undeveloped anthers, swollen anthers, anthers producing calli and anthers producing embryos were recorded for each Petri dish. These data were used to calculate means and to perform statistical analysis. The recorded data were tested by analysis of variance (ANOVA). Tukey's test $(p \leq 0.05)$ was used to compare the means for all parameters.

\subsubsection{Characterization of regenerants}

\section{Ploidy analysis}

The ploidy analysis of the regenerants was performed by flow cytometry. Tissues from embryos were chopped with a sharp razor blade in $2.0 \mathrm{~mL}$ of nuclear extraction buffer (Partec, Münster, Germany), and with a mother plant sample used as diploid control. Each nuclear suspension was filtered through a $50 \mu \mathrm{m}$ nylon filter (Nybolt, Zürich, Switzerland) and mixed with $4.0 \mathrm{~mL}$ of DAPI $\left(1 \mathrm{mg} \mathrm{L}^{-1}\right)$ staining solution. The fluorescence intensity of the nuclear mixture was measured by a CyFlow ${ }^{\circledR}$ Counter (Partec).

\section{DNA extraction}

DNA was extracted from $50 \mathrm{mg}$ of young leaves from the mother plants (used as control), previously lyophilized, and from the embryo tissues obtained from the in vitro anther culture, following the method of Doyle and Doyle (1987), with some minor modifications. Embryos were frozen in liquid nitrogen and then ground using a Tissuelyser (QIAGEN ${ }^{\circledR}$, Germany). DNA concentration of the samples was determined by NanoDrop ND- 1000 spectrophotometer (NanoDrop, Wilmington, DE, USA).

\section{Detection of homozygosity}

Simple Sequence Repeat (SSR) markers were adopted to assess the heterozygosity and to determine the origin (gametic or somatic) of the embryos. Fifteen SSR polymorphic microsatellites developed from apricot (Lopes et al. 2002; Messina et al. 2004) and peach (Dirlewanger et al. 2002; Yamamoto et al. 2002) were screened in a preliminary test and six of them (PaCITA-21, MA031a, BPPCT-007, UDAP-468, EPPCU-5990 and PaCITA-23) were selected for analysis because they amplified in almond and they are 
heterozygous in the donor plant. The polymerase chain reaction (PCR) was carried out with three primers: the specific forward primer of each microsatellite with M13(-21) tail at its 5 ' end, the sequence specific reverse primer and the universal fluorescent-labeled M13(-21) primer (Schuelke 2000). PCR reactions were performed in a GeneAmp ${ }^{\circledR}$ PCR System 9700 thermal cycler (Perkin-Elmer Corp, Freemont, CA) in a final volume of $25 \mu \mathrm{L}$, containing $2.5 \mu \mathrm{L}$ of 10X PCR buffer, $0.2 \mu \mathrm{L} \mathrm{MgCl}_{2}, 2 \mu \mathrm{L}$ dNTPs, $0.5 \mu \mathrm{L}$ of the forward primer $(5 \mu \mathrm{M}), 0.5 \mu \mathrm{L}$ of the $\mathrm{M} 13(-21)$ primer, $1 \mu \mathrm{L}$ of the reverse primer, $0.2 \mu \mathrm{L}$ Taq polymerase (Invitrogen) and $20 \mathrm{ng}$ of genomic DNA. PCR thermal profile was as follows: an initial denaturation step at $95{ }^{\circ} \mathrm{C}$ for $60 \mathrm{~s}$, followed by the annealing for 20 cycles at $60{ }^{\circ} \mathrm{C}\left(-0.5^{\circ} \mathrm{C} /\right.$ cycle $)$ for $60 \mathrm{~s}$, and extension at $72{ }^{\circ} \mathrm{C}$ for $90 \mathrm{~s}$; followed by a second thermal profile of one cycle at $95{ }^{\circ} \mathrm{C}$ for $60 \mathrm{~s} ; 40$ cycles at $50{ }^{\circ} \mathrm{C}$ for $60 \mathrm{~s}$, $72{ }^{\circ} \mathrm{C}$ for $90 \mathrm{~s}$, finishing with $72{ }^{\circ} \mathrm{C}$ for $30 \mathrm{~min}$. Three $\mu \mathrm{L}$ of desalted PCR product was mixed with $12 \mu \mathrm{L}$ of loading solution (70\% formamide and $1 \mathrm{mM}$ EDTA), $0.3 \mu \mathrm{L}$ of LIZ dye, denatured at $95{ }^{\circ} \mathrm{C}$ for $5 \mathrm{~min}$, and cooled on ice. Electrophoresis was performed on a ABI PRISM 3130 Genetic Analyzer capillary system (Applied Biosystems, Warrington, UK). Allele lengths were determined using an ABI Prism 3130 Genetic Analyzer with the GeneMapper software, version 4.0 (Applied Biosystems).

\subsection{Results and discussion}

The anther culture response can be strongly affected by the microspore development stage. Since in almond no previous information was available regarding the correlation between the flower bud size and the microspore developmental stage, this relationship was examined in this study in order to establish the most appropriate bud size to isolate the anthers aimed to induce microspore embryogenesis. The bud size and the corolla length are very often used as an external morphological indicator of the microspore stage for large-scale tests. Results of the preliminary investigation with DAPI staining showed a correlation between the floral bud size and the microspore developmental stages. Bud sizes of 7.0 to $9.0 \mathrm{~mm}$ (depending on the cultivar) in length (Fig. 1.1a*), corresponded to the highest percentage $(>70 \%)$ of the appropriate vacuolated stage (data not shown). 
Differences in microspore developmental responses were observed in anthers collected one month after culture by DAPI staining and fluorescence microscopy observations. Already after one month, microspore with two identical nuclei equal in size and chromatin condensation patterns (Fig. 1.1d) derived by a symmetrical nucleus division (SND), as well as multinucleated structures (Fig. 1.1e), were detected. The SND of the nucleus is considered one of the first signs of the beginning of the embryogenic program (Seguì-Simarro and Nuez 2008a). This is highlighted in Table 1.2, where the percentages of uninucleated, binucleated by asymmetrical nucleus division (AND) and SND, trinucleated microspores and multinucleated structures are reported. No statistically significant differences were recorded among cultivars in the percentage of uninucleated, binucleated (AND) and trinucleated microspores. Trinucleated microspores were separately counted, instead than added to the multinucleated, because in a previous research carried out on Citrus clementina anther culture, ploidy analysis by flow cytometry of 94 regenerants showed that as many as $82 \%$ of them were trihaploids, rather than haploids or doubled-haploids as expected (Germanà et al. 2005).

Table 1.2 Microspore developmental responses of the seven almond genotypes after one month of culture

\begin{tabular}{llllll}
\hline Cultivar & $\begin{array}{l}\text { Uninucleated } \\
\text { microspores } \\
(\%)\end{array}$ & $\begin{array}{l}\text { Binucleated } \\
\text { microspores } \\
\text { (AND) } \mathbf{( \% )}\end{array}$ & $\begin{array}{l}\text { Binucleated } \\
\text { microspores } \\
\text { (SND) } \mathbf{( \% )}\end{array}$ & $\begin{array}{l}\text { Trinucleated } \\
\text { microspores } \\
(\%)\end{array}$ & $\begin{array}{l}\text { Multinucleated } \\
\text { microspores } \\
(\%)\end{array}$ \\
\hline 'Contino' & $53.3 \mathrm{a}$ & $15.7 \mathrm{a}$ & $10.1 \mathrm{ab}$ & $3.8 \mathrm{a}$ & $17.1 \mathrm{a}$ \\
'Ferragnes' & $39.1 \mathrm{a}$ & $13.7 \mathrm{a}$ & $5.7 \mathrm{a}$ & $2.5 \mathrm{a}$ & $38.8 \mathrm{bc}$ \\
'Filippo Ceo' & $37.9 \mathrm{a}$ & $12.7 \mathrm{a}$ & $10.2 \mathrm{ab}$ & $3.8 \mathrm{a}$ & $35.4 \mathrm{abc}$ \\
'Genco' & $41.8 \mathrm{a}$ & $22.1 \mathrm{a}$ & $16.8 \mathrm{~b}$ & $2.4 \mathrm{a}$ & $16.8 \mathrm{a}$ \\
'Lauranne' & $24.9 \mathrm{a}$ & $14.5 \mathrm{a}$ & $8.9 \mathrm{ab}$ & $3.0 \mathrm{a}$ & $48.6 \mathrm{c}$ \\
'Steliette' & $48.5 \mathrm{a}$ & $17.2 \mathrm{a}$ & $7.8 \mathrm{a}$ & $4.6 \mathrm{a}$ & $21.9 \mathrm{ab}$ \\
'Tuono' & $44.9 \mathrm{a}$ & $19.5 \mathrm{a}$ & $12.5 \mathrm{ab}$ & $2.4 \mathrm{a}$ & $20.7 \mathrm{ab}$ \\
\hline
\end{tabular}

Within each column, values followed by different letters are significantly different at $p \leq 0.05$ (ANOVA, Tukey's test). AND: asymmetrical nucleus division, SND: symmetrical nucleus division

However, significant differences were detected regarding the percentages of binucleated microspores (SND) and multinucleated structures. In particular, 'Genco' exhibits the statistically significant highest rate (16.8) of microspores with two identical nuclei (SND) but the lowest percentages (16.8) of multinucleated structures, while 'Ferragnes' showed the lowest percentage (5.7) of binucleated microspores (SND) and 'Lauranne' presented the highest percentage (48.6) of multinucleated structures $(p \leq 0.05)$. Those features indicate that these microspores switched their developmental program toward 
the sporophytic pathway. Also bicellular pollen grains containing nuclei with different chromatin condensation patterns, a larger vegetative nucleus and a smaller generative one, were rarely observed, denoting an AND, which is typical of classic pollen maturation (Pacini, 2012).

Distinct features have been described in anther culture as signs of initiation of a morphogenic response and of a change in the developmental pathway. After one week of culture, a large number of anthers had already started to swell (Fig. 1.2a). The swelling is the first anatomical change accompanying the morphogenic response (Germanà 2006). In addition, after one month of culture, when transferred under cool white light, some anthers showed production of calli. Two different types of calli were observed: a soft and friable white callus (Fig. 1.2b) and a hard green callus (Fig. 1.2c) apparently morphogenic. Moreover, after three months in culture, few anthers exhibited embryo production (Fig. 1.2d). The embryos were obtained only through the route of the direct embryogenesis. This differs from what has been observed in Citrus, where most of embryos were obtained via embryogenic calli production (Germanà 2006).
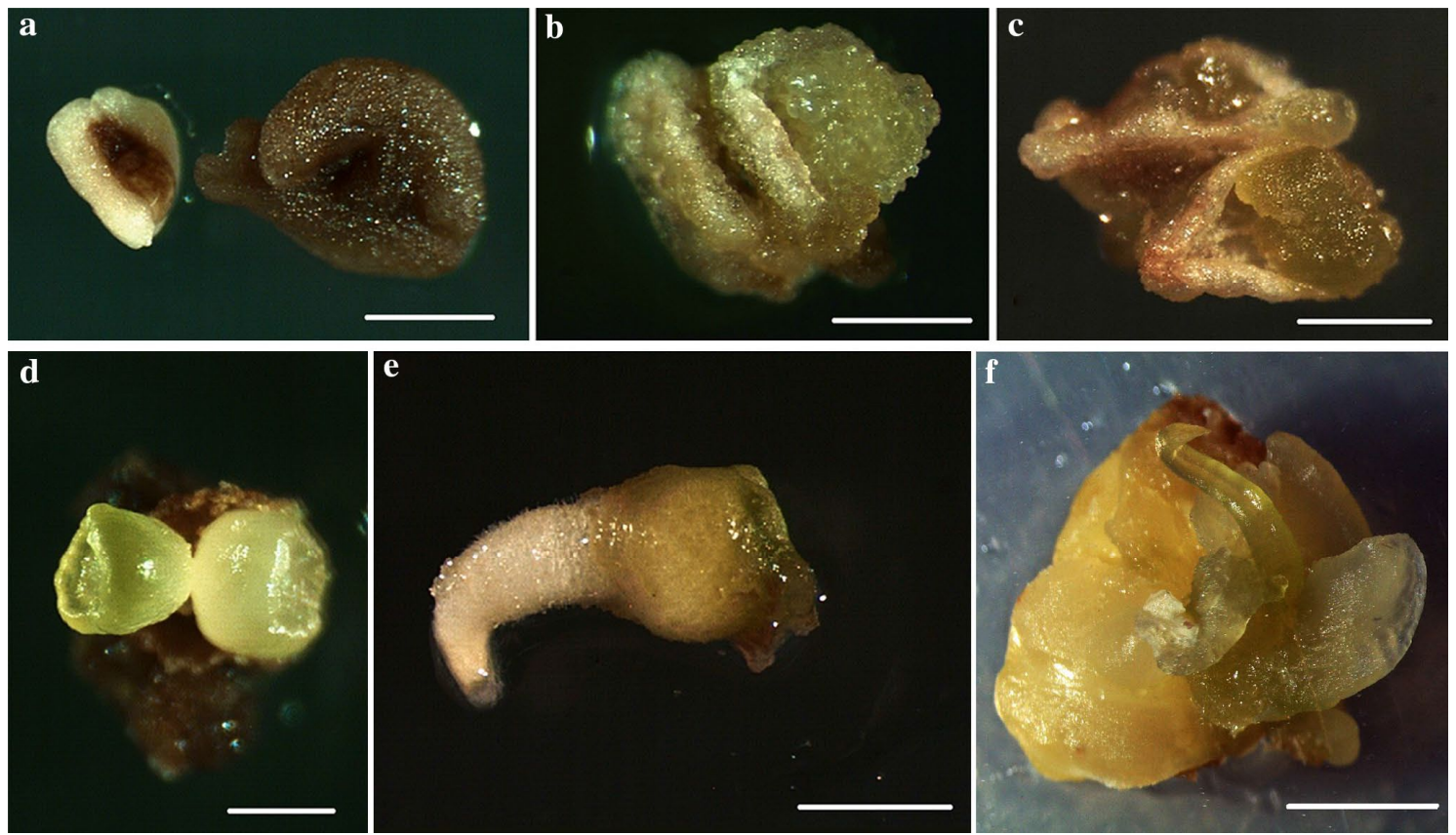

Fig. 1.2 a Not developed (left) and swollen (right) anthers of 'Filippo Ceo' after three months in culture; b Anther with friable white callus; c Anther with hard green callus; d Early embryos of 'Filippo Ceo' coming out from the anther; e Embryo of 'Filippo Ceo' developing the root axis; $\mathbf{f}$ Abnormal embryos of 'Lauranne' (Bars represent in a, b, c: $1 \mathrm{~mm}$, in d: $0.75 \mathrm{~mm}$, in e: $1.5 \mathrm{~mm}$, in $\mathrm{f:} 1 \mathrm{~cm}$ ) 
When embryos were isolated and transferred onto the germination medium, some of them started to turn color from white to green and germination occurred, showing the presence of the root meristem (Fig. 1.2e). In some cases, an absence of polarity was noticed as a result of a poor shoot meristem formation and cotyledons failed to develop. In other cases embryo development appeared abnormal (Fig. 1.2f). In Prunus, other authors already described a great variability in the morphology of the embryos obtained from in vitro culture (De March et al. 1993).

In woody plants, the effect of genotype on anther culture has been deeply studied (Tsay and $\mathrm{Su}$ 1985; Chen 1986; Germanà 2005) and the genotype of the donor plants have been reported to strongly affect the microspore embryogenic response.

The response to the anther culture of the seven tested cultivars with regard to the percentages of undeveloped anthers, swollen anthers, anthers producing calli and embryos, recorded after three months, is reported in Table 1.3. Statistical analysis of variance (ANOVA, Tukey's test) showed, as expected, a marked and significant ( $p \leq$ 0.05) genotype effect for all parameters. Concerning the culture media, P and N6 media were previously tested in many woody plant species, such as apricot, citrus, loquat and hazelnut, to induce gametic embryogenesis (Germanà et al. 1996; Germanà and Chiancone 2003; Karasawa et al. 2016; Cardoso et al. 2016). In our case, a significant $(p \leq 0.05)$ culture medium effect was observed (especially in the percentage of production of calli and embryos), with the exception of undeveloped anthers. In fact, only anthers cultured on $\mathrm{P}$ medium, in both $\mathrm{C}$ and $\mathrm{H}$ thermal treatments, produced calli and/or embryos. Conversely, anthers cultured on N6 medium started to swell but finally resulted in browning, their tissues became necrotic and no callogenic or embryogenic response was observed, although multinucleated structures were also present in anthers cultured in this medium (data not shown), indicating an interruption of the process. Regarding the undeveloped anthers, the lowest percentage (9.8) was observed in 'Steliette' when cultured onto $\mathrm{P}$ medium with the $\mathrm{H}$ treatment, while the highest percentage (52.3) was detected in 'Contino' in N6 medium with H treatment. Cultivar Ferragnes produced the lowest percentage (42.4) of swollen anthers (P medium and C treatment) and cv. 'Steliette' the highest (87.1) (N6 medium and H treatment). The only medium in which almond anthers produced callus was the $\mathrm{P}$ one. The highest rate (30.4) was achieved in 'Filippo Ceo' in $\mathrm{H}$ thermal treatments, while the lowest was found in 
'Tuono' (1.8) in C. In general, the hot thermal shock $(\mathrm{H})$ induced a higher production of calli in most of the genotypes tested (except 'Ferragnes').

Table 1.3 In vitro anther culture response of the seven almond genotypes after three months of culture

\begin{tabular}{|c|c|c|c|c|c|c|}
\hline Cultivar & Medium & Treatment & $\begin{array}{l}\text { Undeveloped } \\
\text { anthers (\%) }\end{array}$ & $\begin{array}{c}\text { Swollen } \\
\text { anthers (\%) }\end{array}$ & $\begin{array}{c}\text { Anthers with } \\
\text { callus (\%) }\end{array}$ & $\begin{array}{l}\text { Anthers with } \\
\text { embryos (\%) }\end{array}$ \\
\hline \multirow{4}{*}{ 'Contino' } & \multirow{2}{*}{$\mathrm{P}$} & $\mathrm{C}$ & 24.6 & 60.0 & 15.4 & 0 \\
\hline & & $\mathrm{H}$ & 32.0 & 50.1 & 17.8 & 0 \\
\hline & \multirow{2}{*}{ N6 } & $\mathrm{C}$ & 30.5 & 69.5 & 0 & 0 \\
\hline & & $\mathrm{H}$ & 52.3 & 47.7 & 0 & 0 \\
\hline \multirow{4}{*}{ 'Ferragnes' } & \multirow{2}{*}{$\mathrm{P}$} & $\mathrm{C}$ & 33.2 & 42.4 & 24.3 & 0 \\
\hline & & $\mathrm{H}$ & 23.9 & 56.4 & 19.6 & 0 \\
\hline & \multirow{2}{*}{ N6 } & $\mathrm{C}$ & 27.1 & 72.9 & 0 & 0 \\
\hline & & $\mathrm{H}$ & 24.3 & 75.7 & 0 & 0 \\
\hline \multirow{4}{*}{ 'Filippo Ceo' } & \multirow{2}{*}{$\mathrm{P}$} & $\mathrm{C}$ & 29.5 & 43.1 & 25.8 & 1.5 \\
\hline & & $\mathrm{H}$ & 21.7 & 47.8 & 30.4 & 0 \\
\hline & \multirow{2}{*}{ N6 } & $\mathrm{C}$ & 32.0 & 68.0 & 0 & 0 \\
\hline & & $\mathrm{H}$ & 37.3 & 62.7 & 0 & 0 \\
\hline \multirow{4}{*}{ ‘Genco' } & \multirow{2}{*}{$P$} & $\mathrm{C}$ & 16.9 & 64.7 & 18.0 & 0.3 \\
\hline & & $\mathrm{H}$ & 15.7 & 66.3 & 18.0 & 0 \\
\hline & \multirow{2}{*}{ N6 } & $\mathrm{C}$ & 29.7 & 70.3 & 0 & 0 \\
\hline & & $\mathrm{H}$ & 13.0 & 87.0 & 0 & 0 \\
\hline \multirow{4}{*}{ 'Lauranne' } & \multirow[b]{2}{*}{$\mathrm{P}$} & $\mathrm{C}$ & 24.0 & 58.5 & 16.9 & 0.6 \\
\hline & & $\mathrm{H}$ & 25.2 & 50.8 & 23.9 & 0 \\
\hline & \multirow{2}{*}{ N6 } & $\mathrm{C}$ & 21.5 & 78.5 & 0 & 0 \\
\hline & & $\mathrm{H}$ & 16.3 & 83.7 & 0 & 0 \\
\hline \multirow{4}{*}{ 'Steliette' } & \multirow{2}{*}{$\mathrm{P}$} & $\mathrm{C}$ & 33.8 & 57.8 & 8.3 & 0 \\
\hline & & $\mathrm{H}$ & 9.8 & 77.2 & 12.9 & 0 \\
\hline & \multirow{2}{*}{ N6 } & $\mathrm{C}$ & 22.2 & 77.8 & 0 & 0 \\
\hline & & $\mathrm{H}$ & 12.9 & 87.1 & 0 & 0 \\
\hline \multirow{4}{*}{ 'Tuono' } & \multirow{2}{*}{$\mathrm{P}$} & $\mathrm{C}$ & 35.0 & 63.1 & 1.8 & 0 \\
\hline & & $\mathrm{H}$ & 25.5 & 69.5 & 4.9 & 0 \\
\hline & \multirow{2}{*}{ N6 } & $\mathrm{C}$ & 22.5 & 77.5 & 0 & 0 \\
\hline & & $\mathrm{H}$ & 21.5 & 78.5 & 0 & 0 \\
\hline \multirow{2}{*}{\multicolumn{3}{|c|}{$\begin{array}{l}\text { Cultivar } \\
\text { Medium }\end{array}$}} & $p \leq 0.001$ & $p \leq 0.001$ & $p \leq 0.001$ & $p \leq 0.017$ \\
\hline & & & $p \leq 0.423$ & $p \leq 0.001$ & $p \leq 0.001$ & $p \leq 0.008$ \\
\hline \multicolumn{3}{|l|}{ Treatment } & $p \leq 0.001$ & $p \leq 0.041$ & $p \leq 0.036$ & $p \leq 0.008$ \\
\hline \multicolumn{3}{|c|}{ Cultivar x Medium } & $p \leq 0.001$ & $p \leq 0.001$ & $p \leq 0.001$ & $p \leq 0.016$ \\
\hline \multicolumn{3}{|c|}{ Cultivar $\mathrm{x}$ Treatment } & $p \leq 0.001$ & $p \leq 0.001$ & $p \leq 0.169$ & $p \leq 0.016$ \\
\hline \multicolumn{3}{|c|}{ Medium $x$ Treatment } & $p \leq 0.018$ & $p \leq 0.236$ & $p \leq 0.036$ & $p \leq 0.008$ \\
\hline
\end{tabular}

Statistically significant differences at $p \leq 0.05$ (multifactor ANOVA, Tukey's test). $\mathbf{P}$ (Germanà et al. 1996), $\mathbf{N 6}$ (Karasawa et al. 2016), C: $25 \pm 1{ }^{\circ} \mathrm{C} ; \mathbf{H}: 35 \pm 1{ }^{\circ} \mathrm{C}$ for $7 \mathrm{~d}$

The application of different cold or hot treatments to the anthers, before or during the culture, is commonly employed, together with starvation, for improving microspore embryogenesis in many major crops, such as brassica, tobacco, barley, apple, wheat, maize, citrus, rice (George and Rao 1982; Heberle-Bors 1982, 1985, ; Huang and Sunderland 1982; Custers et al. 1994; Binarova et al. 1997; Höfer 1999; Islam et al. 2001; Germanà 2003; Zatapa-Arias 2003; Ferrie and Caswell 2011). Nevertheless, the 
optimum temperature and duration of pretreatment vary with the genotype (Powell 1988; Osolnik et al. 1993; Germanà 2011a, b). In the present study embryo production was achieved only in 'Filippo Ceo', 'Lauranne' and 'Genco', when anthers were cultured at $25 \pm 1{ }^{\circ} \mathrm{C}$, without additional thermal shock treatment, except the common cold pretreatment at $4{ }^{\circ} \mathrm{C}$ for one week.

Flow cytometer is commonly used to detect the ploidy levels of in vitro regenerated plants. Due to the scarcity of the regenerants and to their small size, it was not been possible to carry out ploidy analyses by flow cytometry in all the regenerated embryos. Ploidy analysis by flow cytometry revealed that all the regenerants (embryos) obtained through in vitro anther culture of 'Lauranne' showed histograms of fluorescence intensity in nuclei equal to those of the parent plant. For this reason, the embryos were considered diploids.

To discriminate between the gametic and somatic origin of embryos, microsatellite analyses were performed in all the three cultivars that produced embryos. In a preliminary screening, microsatellite DNA loci that were heterozygous in the parental genotypes, were first selected in order to use them as control. Figures 1.3 and 1.4 show the results regarding the pherograms of the microsatellite markers respectively EPPCU5990 and UDAP-468 profiles of the mother plant (top) and of two different 'Filippo Ceo' embryos obtained by anthers culture.

The mother plant is heterozygous and carries two alleles, while the regenerants show only one of the mother plant alleles. The presence of alternative alleles from the mother plant has been considered as support for the gametic origin of regenerants.

SSR analysis confirmed previous isozymes studies which identified the almond as the most polymorphic species within the major Prunus tree crop species (Martìnez-Gòmez et al. 2006), making it an ideal candidate for map construction. Among the recent advances in the application of the new biotechnologies, haploid technology, could be usefully applied to almond, that, as well as other tree crops, to keep pace with the research progress that has already been made in annual crops. The difficulties in breeding such as large-sized and long generation-time plants are notable (MartìnezGòmez et al. 2003). However, the opportunities that the new technologies present for tree crops could be ground-breaking and overcome some of the obstacles to traditional breeding (Gradziel 2009). 

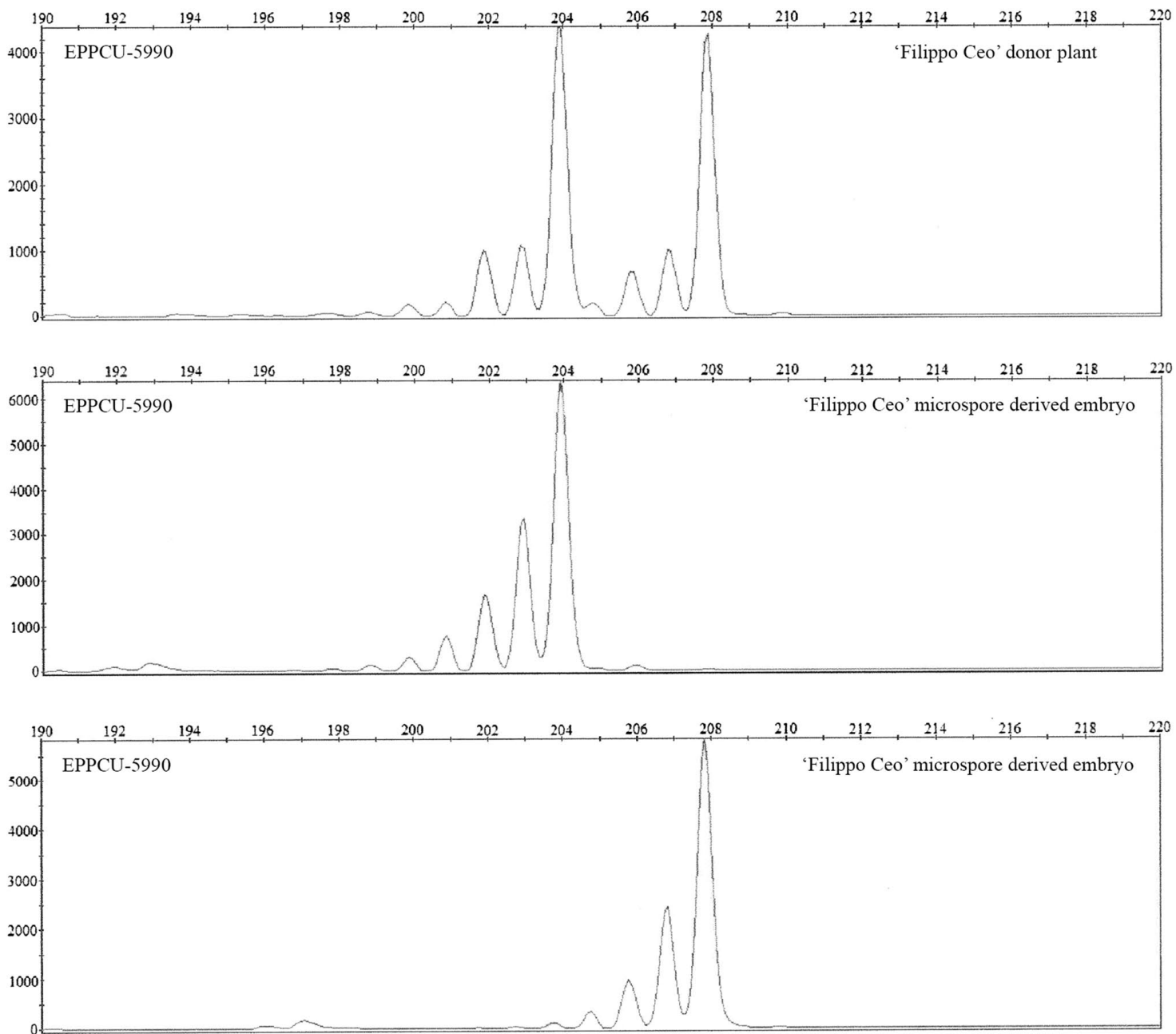

Fig. 1.3 Characterization of anther culture regenerants. Microsatellite analysis: Pherograms of the microsatellite markers EPPCU-5990 profiles of the mother plant (top) and two 'Filippo Ceo' regenerants. The mother plant is heterozygous and carries two alleles, the regenerants show only one of the mother plant alleles. The presence of alternative alleles from the mother plant has been considered as support for the gametic origin of regenerants 

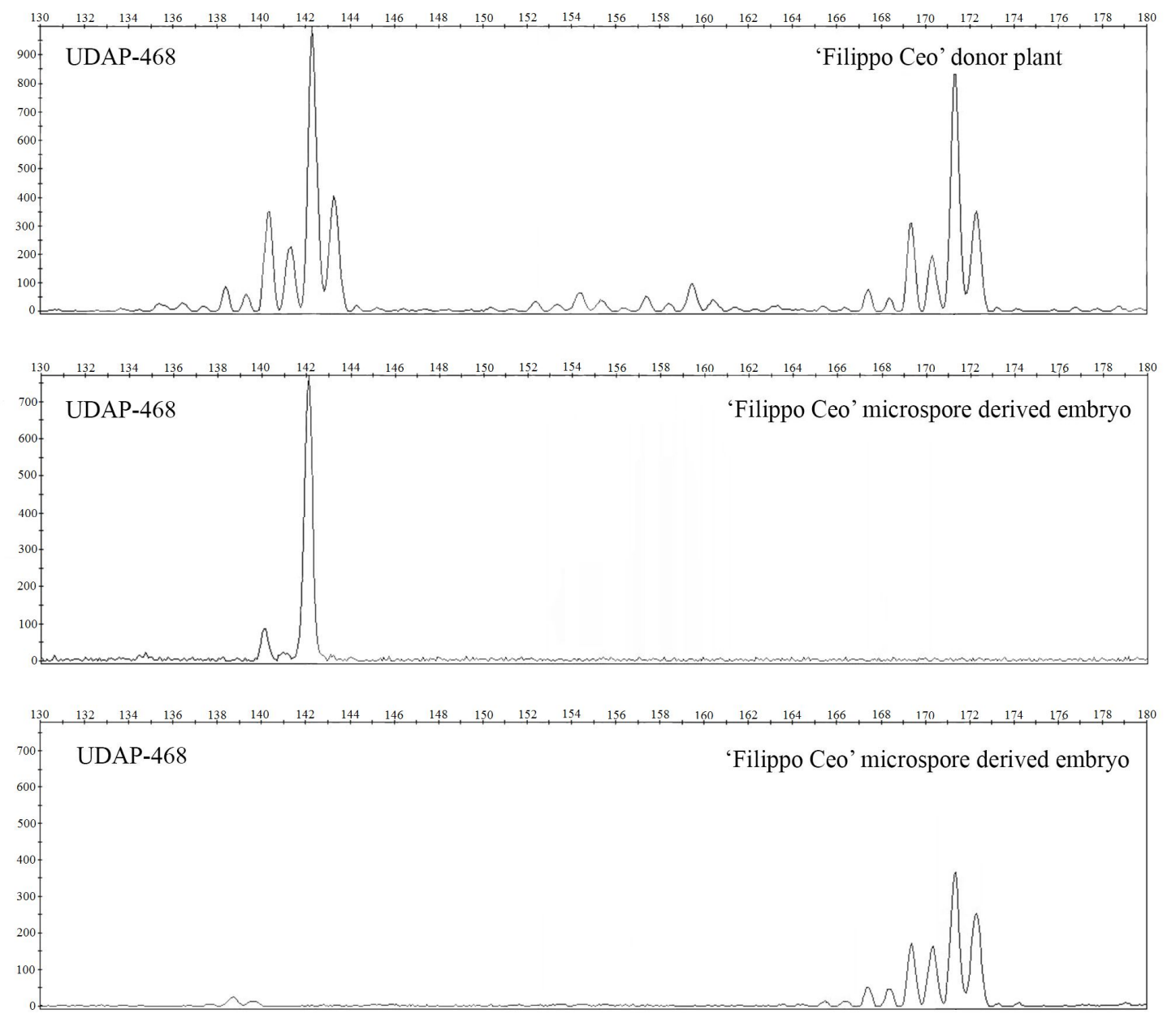

Fig. 1.4 Characterization of anther culture regenerants. Microsatellite analysis: Pherograms of the microsatellite markers UDAP-468 profiles of the mother plant (top) and two 'Filippo Ceo' regenerants. The mother plant is heterozygous and carries two alleles, the regenerants show only one of the mother plant alleles. The presence of alternative alleles from the mother plant has been considered as support for the gametic origin of regenerants 


\subsection{Conclusions}

To our knowledge, there are no reports on microspore-derived embryo production through anther culture in almond. The presence of multinucleated structures in all the tested cultivars, observed in this in vitro system, indicates that the induction of gametic embryogenesis, involving symmetrical microspore nucleus division and the switch from the gametophytic developmental program to the sporophytic embryogenic pathway, occurred. Anther culture responses to the culture media and the temperature treatments employed was, as expected and previously reported in other fruit crops, highly genotype-dependent, even if a better response to the $\mathrm{P}$ medium was common to all the genotypes. In any case, the results obtained represent a major advance in the research on gametic embryogenesis in almond and, in general, in woody species. This finding constitutes a crucial step in designing new protocols for regenerating microsporederived embryos and plants in almond, providing new opportunities for genetic improvement and for innovation in breeding methods in this species. Breeding of perennial plants is usually cumbersome and time-consuming due to their long reproductive cycle, high degree of heterozygosity and complex reproductive biology. The potential of gamete biotechnology, particularly for these plants, is enormous when compared to the conventional methods. Further studies are, however, necessary to increase the rate of regenerant obtainment and to achieve their conversion into plantlets. 


\section{CHAPTER 2}

\section{Application of different BAP concentrations for in vitro callus induction in almond (Prunus dulcis Mill.) anther culture}

\subsection{Abstract}

The aim of this investigation was to induce callus and embryo production in almond (Prunus dulcis Mill.) through anther culture technique. With this objective, anthers bearing microspore at the polarized uninucleate developmental stage were directly in vitro cultured, and eight genotypes, four culture media and two temperature treatments were tested. Production of calli was achieved, in all cultivars, only when the media were supplemented with 6-benzylaminopurine (BAP), being the response genotype dependent. Moreover, despite signs of the beginning of the embryogenic program (microspore with two identical nuclei equal in size and chromatin condensation patterns derived by a symmetrical nucleus division) were observed, no organogenic or embryogenic response was achieved. Flow cytometry analysis of the calli revealed that, some of these unorganized parenchyma cells showed only half of the fluorescence intensity displayed by the mother plant (used as diploid control), confirming their haploid status.

\subsection{Materials and methods}

\subsubsection{Plant material}

One year almond shoots, bearing flower buds at different developmental stages, were harvested on Jenuary in fields located in Llíria (Valencia, Spain). Eight almond cultivars from different origins ('Desmayo Largueta', 'Doble Fina', 'Ferraduel', 'Ferragnes', 'Marcona', 'Planeta', 'Tarraco' and 'Vayrò'), were tested in this experiment. 


\subsubsection{Bud size and microspore stage correlation}

Evaluation of microspore development stage within anthers was performed to ensure that the selected flower buds contained mostly polarized uninucleate microspores. Flowers buds were divided in different size groups and ten anthers, from each group and genotype, were used for microscopic analysis. DAPI (4',6-diamidino-2-phenylindole) staining solution was used to identify the pollen development stage and to determine the correct bud size, containing anthers with the highest percentage of uninucleatedvacuolated microspores. Only flower buds with the correct size were finally selected for the in vitro culture.

\subsubsection{Flower bud sterilization and anther culture}

Sterilization of the flower buds was performed by immersion in $70 \%(\mathrm{v} / \mathrm{v})$ ethyl alcohol for $5 \mathrm{~min}$, followed by immersion in sodium hypochlorite solution $(0.5 \%$ active chlorine) with few drops of Tween-20 for $20 \mathrm{~min}$ and finally rinsed in sterile distilled water three times. After sterilization, petals were aseptically removed, under a laminar flow hood, and anthers were excised and carefully processed. Twenty anthers were placed in each Petri dish and 80 Petri dishes were prepared per each genotype (10 per each medium, 40 per each temperature treatment, for a total of 1600 anthers per each genotype).

\subsubsection{Experimental design}

\section{Culture media}

Anthers were cultured on a basal callus induction medium, consisting of MS inorganic basal salts $(1 \mathrm{X})$, mixture vitamins $(26.6 \mathrm{mM}$ glycine, $2.9 \mathrm{mM}$ thiamine hydrochloride, $8.1 \mathrm{mM}$ nicotinic acid, $2.4 \mathrm{mM}$ pyridoxine hydrochloride and $2.8 \mathrm{mM}$ ascorbic acid), myo-inositol $(0.55 \mathrm{mM})$, casein $\left(0.5 \mathrm{~g} \mathrm{~L}^{-1}\right)$ and sucrose $(3 \% \mathrm{w} / \mathrm{v})$. In addition, the solid medium was supplemented with growth regulators, $0.1 \mathrm{mg} \mathrm{L}^{-1}$ indole-3-butyric acid (IBA) versus four doses of 6-benzylaminopurine (BAP, 0, 1, 1.5 and $2 \mathrm{mg} \mathrm{L}^{-1}$ ) in order to determine optimum conditions for callus induction. Growth regulators were added to the culture medium and $\mathrm{pH}$ was adjusted to 5.8 before autoclaving $\left(20 \mathrm{~min}, 120{ }^{\circ} \mathrm{C}\right)$. 
Anthers and calli were sub-cultured monthly onto new fresh medium. The composition of the four culture media is resumed in Table 2.1.

Table 2.1 Media composition (in $\mathrm{g} \mathrm{L}^{-1}$ or $\mathrm{mg} \mathrm{L}^{-1}$ )

\begin{tabular}{lrrrr}
\hline Components & BAP 0 & BAP 1 & BAP 1.5 & BAP 2 \\
\hline MS basal salt mixture & $4.3 \mathrm{~g}$ & $4.3 \mathrm{~g}$ & $4.3 \mathrm{~g}$ & $4.3 \mathrm{~g}$ \\
Glycine & $2 \mathrm{~g}$ & $2 \mathrm{~g}$ & $2 \mathrm{~g}$ & $2 \mathrm{~g}$ \\
Thiamine & $1 \mathrm{~g}$ & $1 \mathrm{~g}$ & $1 \mathrm{~g}$ & $1 \mathrm{~g}$ \\
Nicotinic acid & $1 \mathrm{~g}$ & $1 \mathrm{~g}$ & $1 \mathrm{~g}$ & $1 \mathrm{~g}$ \\
Pyridoxine & $0.5 \mathrm{~g}$ & $0.5 \mathrm{~g}$ & $0.5 \mathrm{~g}$ & $0.5 \mathrm{~g}$ \\
Ascorbic Acid & $0.5 \mathrm{~g}$ & $0.5 \mathrm{~g}$ & $0.5 \mathrm{~g}$ & $0.5 \mathrm{~g}$ \\
Myoinositol & $0.1 \mathrm{~g}$ & $0.1 \mathrm{~g}$ & $0.1 \mathrm{~g}$ & $0.1 \mathrm{~g}$ \\
Casein & $0.5 \mathrm{~g}$ & $0.5 \mathrm{~g}$ & $0.5 \mathrm{~g}$ & $0.5 \mathrm{~g}$ \\
Sucrose & $30 \mathrm{~g}$ & $30 \mathrm{~g}$ & $30 \mathrm{~g}$ & $30 \mathrm{~g}$ \\
Indole-3-butyric acid & $0.1 \mathrm{mg}$ & $0.1 \mathrm{mg}$ & $0.1 \mathrm{mg}$ & $0.1 \mathrm{mg}$ \\
6-Benzylaminopurine & $0 \mathrm{mg}$ & $1 \mathrm{mg}$ & $1.5 \mathrm{mg}$ & $2 \mathrm{mg}$ \\
\hline MS (Murashige and Skoog 1962) & & & &
\end{tabular}

\section{Temperature treatments}

The effect of two thermal treatments was observed applying the following conditions: half of the flower buds were directly incubated in a growth chamber at $25 \pm 1{ }^{\circ} \mathrm{C}$ as control (C). Meanwhile, the other half was subjected to a cold $\left(4{ }^{\circ} \mathrm{C}\right)$ inductive pretreatment for three days.

Cultures were finally incubated at $25 \pm 1{ }^{\circ} \mathrm{C}$ for four weeks in the dark and, then, transferred under cool white fluorescent lamps Philips TLM 30W/84 conditions (Philips, France), with a photosynthetic photon flux density of $35 \mu \mathrm{mol} \mathrm{m} \mathrm{m}^{-2} \mathrm{~s}^{-1}$ and a photoperiod of $16 \mathrm{~h}$ light.

\section{Data collection and statistical analysis}

One month after culturing, anthers were treated with a DAPI staining solution $\left(1 \mathrm{mg} \mathrm{L}^{-}\right.$ ${ }^{1}$ ), and microspores structural features were investigated using a fluorescence microscope (Zeiss, Axiophot, Germany). Furthermore, to follow their development, anthers were periodically observed with a stereo-microscope (Leica MZ 125). After three months of culture, per each Petri dish, the number of anthers producing calli were recorded. These data were used to calculate means and to perform statistical analysis. 
Differences among genotypes were tested by one-way analysis of variance (ANOVA), while, to avoid the genotype dependent effect, the influence of culture media and temperature treatments were analyzed separately for each cultivar (Tukey's test).

\section{Ploidy Analysis}

The calli obtained though the in vitro anthers culture were finally subjected to ploidy analysis, using a CyFlow ${ }^{\circledR}$ Counter (Partec). Calli were chopped with a sharp razor blade in $2.0 \mathrm{~mL}$ of nuclear extraction buffer (Partec, Münster, Germany). Each nuclear suspension was filtered through a $50 \mu \mathrm{m}$ nylon filter (Nybolt, Zürich, Switzerland) and mixed with $4.0 \mathrm{~mL}$ of DAPI ( $\left.1 \mathrm{mg} \mathrm{L}^{-1}\right)$ staining solution. Nuclei obtained from a mother plant sample were used as diploid control. The fluorescence intensity of the nuclear mixture resulted in histograms with peaks from $2 \mathrm{C}$ to $100 \mathrm{C}$ distributed along the abscissa axe.

\subsection{Results and discussion}

The appropriate gametophyte development stage is critical to induce pollen embryogenesis and can strongly affect the anther culture response. In many different species, cytological analysis showed that the optimum moment for pollen response lies between the first pollen mitosis and early bicellular pollen stage (Touraev et al. 2001; Dunwell 2010; Seguí-Simarro 2010; Germanà 2011a,b). The exact determination of the microspore stage would require cytological analysis but, for large-scale tests, external morphological indicators such as the bud size and the corolla length are very often used. In this experiment, the relationship between flower bud size and microspore developmental stage was carried out through DAPI staining. Results confirmed this correlation; flower buds from 7 to $9 \mathrm{~mm}$ in length (when petals begin to grow among the sepals and anthers turn fully opaque bright yellow) contained microspores at the suitable polarized-uninucleate stage (Fig. 2.1a). Other authors previously reported that, in almond, from pollen at the single nucleus stage was easier to induce callus or embryo production (Li et al. 2004; Cimò et al. 2016).

After one month of culture, it was possible to observe, monitoring the microspores by DAPI staining, that many microspores showed nuclear division. Bicellular pollen grains 
(Fig. 2.1b), containing nuclei with different chromatin condensation pattern (a larger vegetative nucleus and a smaller generative one) were detected, denoting an asymmetrical division (AND), typical of pollen maturation (Seguí-Simarro and Nuez 2008a). On the contrary, induced binucleate microspores showed two nuclei similar in size and chromatin condensation (Fig. 2.1c), indicating their origin by a symmetric division (SND).
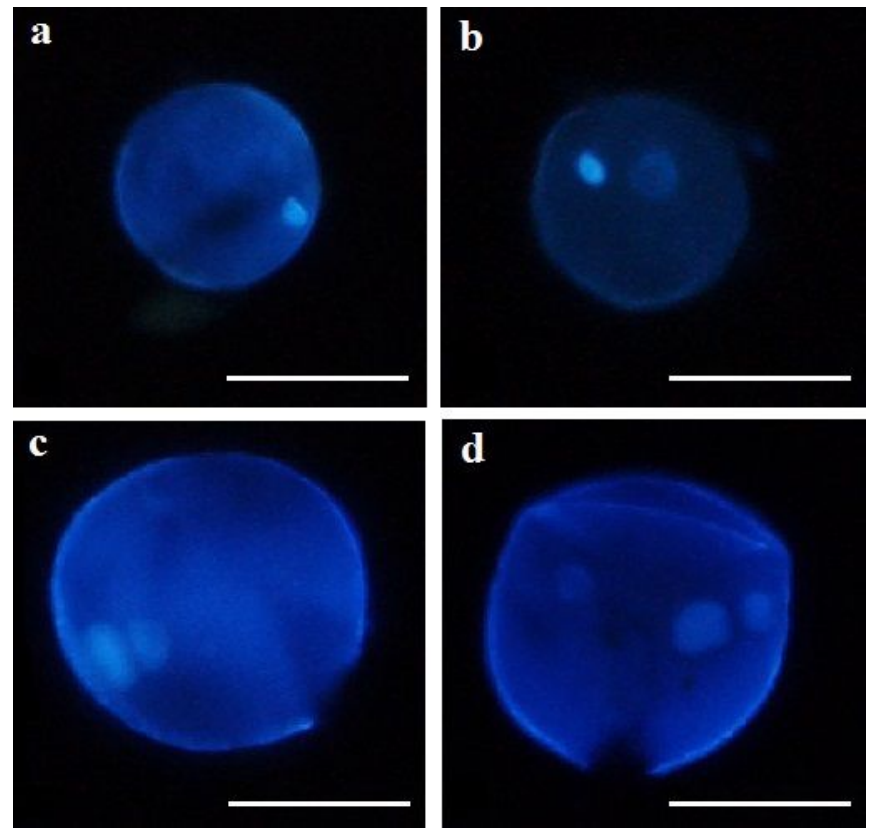

Fig. 2.1 a Polarized-uninucleate microspore; b Bicellular pollen grains containing two different nuclei (asymmetrical division); c Microspore with two nuclei similar in size and chromatin condensation (symmetrical division) of 'Vayrò'; d Trinucleated microspore of 'Vayrò' (Bars represent $20 \mu \mathrm{m}$ )

Symmetric division is considered the first step of the sporophytic pathway followed by the reprogramming to pollen embryogenesis (Seguì-Simarro and Nuez 2008a; Germanà 2011a, b; Soriano et al. 2013). The microspores that followed this pathway underwent subsequent divisions and, later, trinucleated microspores (Fig. 2.1d) were also found.

Furthermore, observations carried out after 3 months of culture showed that many anthers had increased their size (swollen anthers) and, some of them, had started to produce green/yellowish calli of different texture (Fig. 2.2a, b).

Regarding the calli production, differences among genotypes were tested by one-way analysis of variance (ANOVA). In general (pooled data), 'Ferraduel' showed the lowest percentage (2.5) of anthers producing callus, while 'Planeta' exhibited a much greater (58.6) callus production. Statistical analysis (Tukey's test) showed, as expected, a very 
significant $(p \leq 0.001)$ genotype effect (data not shown). For this reason, investigations of the influence of temperature treatments and culture media, on almond anther response, were carried out separately for each genotype (Multifactor ANOVA).

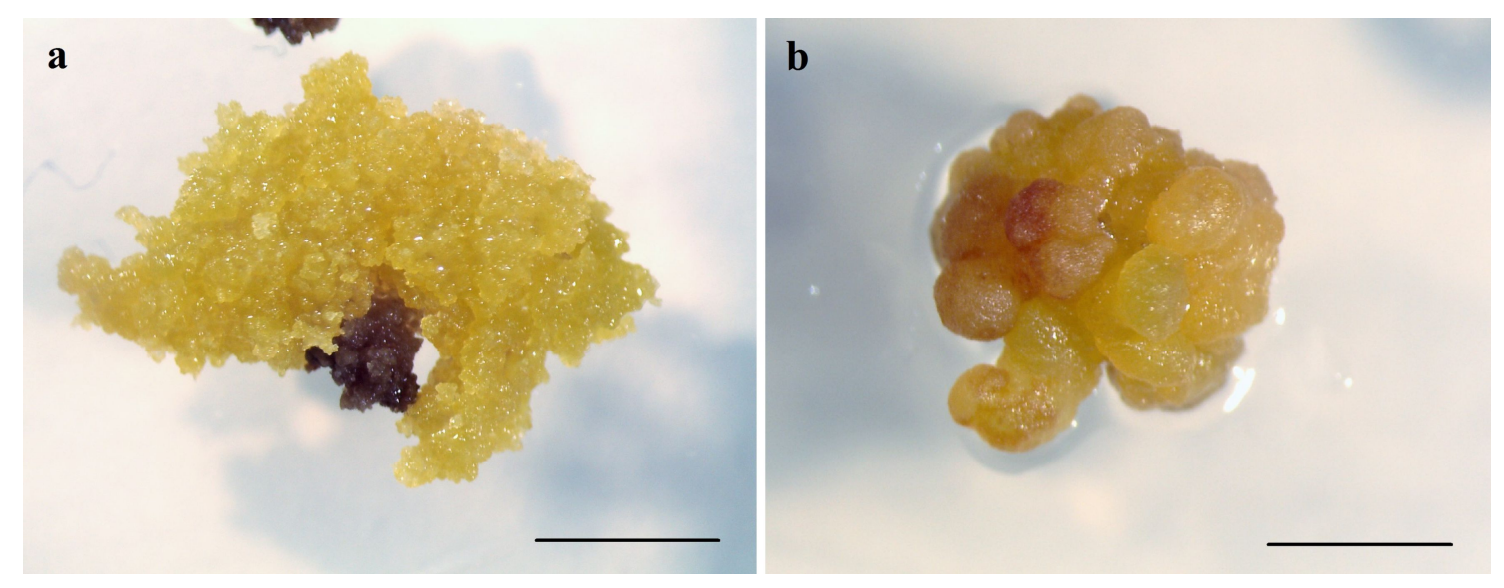

Fig. 2.2 a Anther with friable callus of 'Planeta'; b Hard callus of 'Tarraco' after three months of culture (Bars represent $0.5 \mathrm{~cm}$ )

The frequency of callus induction of the eight cultivars tested, recorded after three months of culture, is reported in Table 2.2.

The response to the pre-treatment at $4{ }^{\circ} \mathrm{C}$ for 3 days and a to the 'control' (no cold pretreatment) showed that in both cases, all genotypes tested produced calli, but the cold pretreatment did not have any statistical significant effect, except in 'Planeta', in which it had a significant negative effect when anthers were cultured onto the 'BAP 1' medium. Cold pretreatment of flower buds, before excising anthers for culture, is commonly employed for induce pollen embryogenesis in many crops (Ferrie and Caswell 2011; Zhang et al. 2013; Shahvali-Kohshour et al. 2013). Nevertheless, the optimum temperature and duration of pretreatment vary with the genotype (Germanà $2011 \mathrm{a}, \mathrm{b})$. Previous studies on anther culture, reported that pre-treatment with low temperatures ( $4{ }^{\circ} \mathrm{C}$ for 2 days) promoted callus induction ( $\mathrm{Li}$ et al. 2008). Conversely, Blasco et al. (2015) stated that cold pretreatment of the loquat flower buds resulted in total inhibition or a lower number of anthers producing calli, being the response genotype dependent. This divergences results of the effect of cold pretreatments on the microspore embryogenesis induction can be explained by the role of the physiological and growth conditions of donor plants (especially if the plants are cultivated in openair), which result in differences in the physiological state of the anthers (Germanà 
2011a). Type and concentration of plant growth regulators can strongly affect the anther culture response (Germanà 2011a, b; Cardoso et al. 2016). In fruit species, different cytokinin types and concentrations, such as BAP, have already been employed to induce callus production and organogenesis, also in Prunus species (Pérez-Jiménez et al. 2012). Concerning the four culture media tested, a significant $(p \leq 0.05)$ culture medium effect, related to the different BAP concentrations used, was observed. Indeed, calli production was achieved in all cultivars only when the media were supplemented with BAP, while no response (zero values) was observed when anthers were cultured on the basal ('BAP 0') medium. Moreover, the percentage of anthers producing calli varies according to the cultivar. In particular, 'Ferraduel' did not show any significant difference between the culture media tested, while in all other cultivars, the addition of BAP to the culture medium induced a significantly $(p \leq 0.05)$ higher production of calli. Nevertheless, no significant differences were detected between BAP doses $(1,1.5$ and 2 $m g \mathrm{~L}^{-1}$ ) applied, with the exception of 'Ferragnes' and 'Tarraco' in which, anthers cultured onto the medium supplied with $1.0 \mathrm{mg} \mathrm{L}^{-1}$ of BAP, without cold pretreatment, showed a significant greater percentage of calli production when compared with others doses applied (Table 2.2). In general, the highest percentages (87.5) of calli was observed in 'Planeta' in 'BAP 1' medium without cold pretreatment ( $4{ }^{\circ} \mathrm{C}$ for 3 days), while 'Ferraduel' anthers cultured on the same medium produced the lowest percentage (2.0) when cold pretreatment was applied. Furthermore, the increase in concentration of BAP apparently led to a reduction of callus production, being the response genotypedependent. 
Table 2.2 In vitro anther culture response of the eight almond cultivars tested after three months of culture

\begin{tabular}{|c|c|c|c|c|c|c|c|c|c|}
\hline $\begin{array}{l}\text { Cold } \\
\text { pre-treatment }\end{array}$ & $\begin{array}{l}\text { BAP } \\
\left(\mathrm{mg} \mathrm{L}^{-1}\right)\end{array}$ & $\begin{array}{c}\text { 'Desmayo' } \\
(\%)\end{array}$ & $\begin{array}{c}\text { 'Doble Fina' } \\
\text { (\%) }\end{array}$ & $\begin{array}{c}\text { 'Ferraduel' } \\
(\%)\end{array}$ & $\begin{array}{c}\text { 'Ferragnes' } \\
(\%)\end{array}$ & $\begin{array}{c}\text { 'Marcona' } \\
(\%)\end{array}$ & $\begin{array}{c}\text { 'Planeta' } \\
\text { (\%) }\end{array}$ & $\begin{array}{c}\text { 'Tarraco' } \\
(\%)\end{array}$ & $\begin{array}{c}\text { 'Vayrò' } \\
(\%)\end{array}$ \\
\hline \multirow{5}{*}{$\begin{array}{l}\text { No cold } \\
\text { treatment }\end{array}$} & $\mathbf{0}$ & $0 \quad \mathrm{a}$ & $0 \quad \mathrm{a}$ & $0 \quad \mathrm{a}$ & $0 \quad \mathrm{a}$ & & $0 \quad \mathrm{a}$ & & $0 \quad \mathrm{a}$ \\
\hline & 1.0 & $12.5 \mathrm{~b}$ & $13.0 \mathrm{~b}$ & $2.5 \mathrm{a}$ & $27.0 \mathrm{c}$ & $14.0 \mathrm{ab}$ & $87.5 \mathrm{c}$ & $21.5 \mathrm{~d}$ & $13.5 \mathrm{~b}$ \\
\hline & 1.5 & $20.5 \mathrm{bc}$ & $12.5 \mathrm{~b}$ & $4.5 \mathrm{a}$ & $18.0 \mathrm{bc}$ & $11.0 \mathrm{~b}$ & $80.0 \mathrm{bc}$ & $9.5 \mathrm{~b}$ & $12.0 \mathrm{~b}$ \\
\hline & 2.0 & $11.5 \mathrm{ab}$ & $11.0 \mathrm{~b}$ & $3.5 \mathrm{a}$ & $13.5 \mathrm{~b}$ & $12.0 \mathrm{~b}$ & $76.0 \mathrm{bc}$ & $13.0 \mathrm{bc}$ & $6.5 \mathrm{ab}$ \\
\hline & $\mathbf{0}$ & $0 \quad \mathrm{a}$ & $\mathrm{a}$ & $0 \quad \mathrm{a}$ & $\mathrm{a}$ & 0 & 0 & & $\mathrm{a}$ \\
\hline \multirow{3}{*}{$\begin{array}{l}4^{\circ} \mathrm{C} \text { for } \\
3 \text { days }\end{array}$} & 1.0 & $18.5 \mathrm{bc}$ & $13.5 \mathrm{~b}$ & $2.0 \mathrm{a}$ & $20.5 \mathrm{bc}$ & $5.5 \mathrm{ab}$ & $71.5 \mathrm{~b}$ & $13.5 \mathrm{bcd}$ & $11.5 \mathrm{~b}$ \\
\hline & 1.5 & $29.5 \mathrm{c}$ & $11.5 \mathrm{~b}$ & $4.0 \mathrm{a}$ & $11.5 \mathrm{~b}$ & $9.5 \mathrm{ab}$ & $81.5 \mathrm{bc}$ & $14.0 \mathrm{bcd}$ & $5.5 \mathrm{ab}$ \\
\hline & 2.0 & $25.0 \mathrm{c}$ & $7.5 \mathrm{ab}$ & $3.3 \mathrm{a}$ & $14.5 \mathrm{~b}$ & $8.5 \mathrm{ab}$ & $72.5 \mathrm{~b}$ & $20.5 \mathrm{~cd}$ & $9.5 \mathrm{ab}$ \\
\hline \multicolumn{2}{|l|}{ Medium } & $p \leq 0.001$ & $p \leq 0.001$ & $p \leq 0.055$ & $p \leq 0.001$ & $p \leq 0.001$ & $p \leq 0.001$ & $p \leq 0.001$ & $p \leq 0.001$ \\
\hline \multicolumn{2}{|l|}{ Treatment } & $p \leq 0.682$ & $p \leq 0.561$ & $p \leq 0.791$ & $p \leq 0.082$ & $p \leq 0.062$ & $p \leq 0.036$ & $p \leq 0.441$ & $p \leq 0.444$ \\
\hline \multicolumn{2}{|c|}{ Medium x Treatment } & $p \leq 0.601$ & $p \leq 0.847$ & $p \leq 0.998$ & $p \leq 0.242$ & $p \leq 0.364$ & $p \leq 0.018$ & $p \leq 0.001$ & $p \leq 0.301$ \\
\hline
\end{tabular}

Within each column, values followed by different letters are significantly different at $p \leq 0.05$ (Multifactor ANOVA, Tukey's test) 
Calli were monthly sub-cultured onto fresh medium and, after five month of culture, when transferred onto a new organogenic medium (OM) described by Pérez-Jiménez et al. (2012), finally resulted in browning without obtaining any organogenic response.

Flow cytometry is routinely used for measurement of the DNA content (Ochatt 2008). Ploidy analysis revealed that, calli obtained though the in vitro almond anthers culture showed histograms of fluorescence intensity equal to those of the mother plant (used as diploid control). For this reason, they were considered diploids. Actually, through this technique, it is possible to obtain heterozygous diploid embryoids from the somatic tissue of the anther (Cardoso et al. 2016). In fact, anther culture is often used to achieve somatic embryos, since they can be employed for clonal propagation, synthetic seed production, protoplast fusion or genetic transformation (Germanà 2005; Germanà et al. 2011a, b).

\subsection{Conclusions}

In woody species, generally characterized by large-sized and long generation-time, such as almond, the opportunities offered by new technologies applied to breeding are notable (Martìnez-Gòmez et al. 2003; Gradziel 2009). Among the recent advances in the application of the new biotechnologies, haploid technology, could be usefully applied to almond, providing new opportunities for genetic improvement and for innovation in breeding methods in this species. In this study, the presence of binucleated and trinucleated microspores, involving SND and their switch to the sporophytic pathway, indicates that first induction of pollen embryogenesis occurred. Regarding the culture medium, generally the 'BAP 1' gave the best results, inducing higher formation of calli, while increase in concentration apparently led to a reduction of callus production, being the response genotype dependent. Doubtless, the presence of an appropriate concentration of plant growth regulators in the medium plays a critical role in anther callus formation. These results represent an advancement in the knowledge of microspore embryogenesis in almond, however additional studies are necessary to better understand this process and to achieve organogenesis or embryogenesis. 



\section{MANDARIN ISOLATED MICROSPORE CULTURE}

\section{Introduction}

Citrus are native to the tropical regions of southeast Asia and China and represent the largest production of fruit worldwide, with over 136 million of tons produced during 2013 (FAOSTAT 2014). In particular, the FAO estimated the total mandarin production of 2.5 million of tons (FAOSTAT 2014), characterized by different species and hybrids throughout the world, including 'Clementines' in the Mediterreanean, 'Satsumas' in Japan, 'Ponkan' in China and hybrids in California. In the Mediterranean regions, Spain is the main producing country, followed by Italy and Turkey. In Italy, there has been a great decrease in the 'Avana' mandarin cultivation as well as in the 'Mandarino Tardivo di Ciaculli' (Vacante 2010).

The first formal Citrus breeding program was started in 1893 by the United States Department of Agriculture (USDA) in Florida in 1924, which now is one of the largest breeding programs, located at the Citrus Research and Education Center (CREC), Lake Alfred (Cooper et al. 1962). Fruit quality (size, color, easy-peeling), seedlessness and the extension of the harvest season are the main selection objectives for fresh market cultivars.

Biotechnology methods can be used to enhance the efficiency of traditional breeding programs. Haploid technology allows to achieve completely homozygous lines from heterozygous parents just in one step, reducing significantly the time required to obtain the same result with the conventional method, which involves several generations of selfing. It is particularly useful for woody species characterized by long juvenility, a high degree of heterozygosity and often self-incompatibility (Germanà 2009). Gametic embryogenesis leads to the production of Hs or DHs, homozygous at all loci. They can be used for important breeding applications such as mutation, selection, genetic analysis, transformation and gene sequencing (Germanà et al. 2013).

Anther culture is often the method of choice for gametic embryogenesis in many crops. However, isolated microspore culture is a better way to investigate the processes at the cellular, physiological, biochemical, and molecular levels as to avoid the influence of anther somatic tissue. 
With regard to Citrus species, haploid plantlets have been recovered from $C$. madurensis Lour. (Chen et al. 1980) and Poncirus trifoliata L. Raf. (Hidaka et al. 1979); homozygous plants and embryogenic calli with different ploidies have also been obtained via anther culture of C. clementina Hort. ex Tan. (Germanà et al. 1994, 2000, 2005), such as haploid embryos of Mapo tangelo (C. deliciosa $\times$ C. paradisi) (Germanà and Reforgiato 1997) and haploid and diploid calli, embryos and leafy structures of $C$. limon L. (Germanà et al. 1991). Moreover, one DH plantlet has been obtained from $C$. ichangensis $\times$ C. reticulata (Deng et al. 1992). More recently, homozygous plantlets have been recovered from the anthers of 'Rhode Red Valencia' sweet orange (Cao et al. 2011), such as homozygous callus from cv. 'Hamlin' (C. clementina $\times$ C. sinensis) (Cardoso et al. 2014), homozygous microspore-derived embryos from cvs. 'Monreal Rosso' and 'Nules' (Chiancone et al. 2015) and homozygous and triploid regenerants of 'Hernandina' and 'Corsica' clementines (Cardoso et al. 2016), were also obtained. However, mandarin (C. reticulata Blanco) can still be considered a very recalcitrant species to gametic embryogenesis. Futhermore, microspore embryogenesis response is affected by several factors, such as the thermal shock applied and the culture medium composition, particularly, the type and the concentration of plant growth regulators. Meta-Topolin (mT), a natural aromatic cytokinin, is considered an alternative to benzyladenine (BA), zeatin (ZEA), kinetin (KIN) in plant tissue culture (Aremu et al. 2012) and it has been previously used to early embryo achievement through isolated microspore culture in Citrus clementina (Chiancone et al. 2015).

In this study, the effect of $\mathrm{mT}$ instead of BA in the culture media, as well as of different thermal treatments, were investigated in isolated microspore culture of mandarin, 'Mandarino Tardivo di Ciaculli'. 


\section{CHAPTER 3}

\section{Gametic embryogenesis through isolated microspore culture in mandarin (Citrus reticulata Blanco), 'Mandarino Tardivo di Ciaculli'}

\subsection{Abstract}

Haploid technology, allowing the single-step development of complete homozygous genotypes from heterozygous plants through gametic embryogenesis, has already an enormous impact on breeding programs of many important crops. Microspore embryogenesis can be carried out through in vitro culture of anther or isolated microspore. Experiments have been carried out via isolated microspore culture in Citrus reticulata Blanco, 'Mandarino Tardivo di Ciaculli' (MTC), investigating the influence of two culture media, of two plant growth regulator types and of two temperature treatments applied before the culture or just after the culture. After ten months of culture, for all the media tested, different structural features have been observed and registered: uninucleated, binucleated, multinucleated microspores, and, for the first time in mandarin isolated culture, calli and microspore-derived embryos.

These results represent advancement in the knowledge of microspore embryogenesis in mandarin. Actually, this is the first time that embryo regeneration from isolated microspore cultures has been reported in mandarin, a genotype very recalcitrant to pollen embryogenesis.

\subsection{Material and methods}

\subsubsection{Plant material and pollen developmental stage}

Flower buds were harvested from trees of mandarin cultivar Mandarino Tardivo di Ciaculli (MTC), grown in the collection orchard (Campo d'Orlèans, Palermo $38^{\circ} \mathrm{N}$ ) of the Università degli Studi di Palermo, Italy. Anthers from buds of different sizes were squashed in a few drops of 4',6'-diamidino-2-phenylindole dihydrochloride (DAPI) solution $\left(1 \mathrm{mg} \mathrm{mL}^{-1}\right)$ and observed under a fluorescent microscope (Zeiss, Axiophot, 
Germany) to determine the microspore developmental stage. Only flower buds of the size, containing anthers with microspores at the uninucleated-vacuolated stage, were selected for the culture. In Citrus, this stage was previously identified as the most responsive for gametic embryogenesis (Cardoso et al. 2014; Chiancone et al. 2015; Chiancone and Germanà 2016).

\subsubsection{Microspore isolation and culture}

Firstly, flower buds were surface sterilized under a laminar flow hood by immersion in $70 \%(\mathrm{v} / \mathrm{v})$ ethyl alcohol for $5 \mathrm{~min}$, followed by immersion in sodium hypochlorite solution ( $0.5 \%$ active chlorine) with few drops of Tween-20 for $20 \mathrm{~min}$ and finally rinsed in sterile distilled water three times. After sterilization, petals were aseptically removed using small forceps and anthers were carefully excised. Microspores were isolated employing a Waring blender (Eberbach, Ann Arbor, MI, USA) as described by Karasawa et al. (2016) and cultured at the concentration of 100,000 microspores per $\mathrm{mL}$ in four liquid media: P (Germanà et al. 1996), N6 (Karasawa et al. 2016) and replacing $0.5 \mathrm{mg} / \mathrm{L}$ of BA with $0.5 \mathrm{mg} / \mathrm{L}$ of $\mathrm{mT}$, in both of them (PmT and N6mT). Media composition (in $\mathrm{g} \mathrm{L}^{-1}$ or $\mathrm{mg} \mathrm{L}^{-1}$ ) is reported in Table 3.1. Petri dishes (3001-type, 35 $\mathrm{mm} \times 10 \mathrm{~mm}, \mathrm{BD}$ Biosciences) were employed. All Petri dishes were put in the dark for the first 30 days, and then placed under cool white fluorescent lamp (Philips TLM $30 \mathrm{~W} / 84$, France), with a photosynthetic photon flux density of $35 \mu \mathrm{molm}^{-1} \mathrm{~s}^{-1}$ and a photoperiod of 16 light $\mathrm{h}$. In addition, two thermal treatments were tested: half of the Petri dishes were directly put at $26 \pm 1{ }^{\circ} \mathrm{C}$ (Control, C), the other half were placed at 35 ${ }^{\circ} \mathrm{C}$ for 30 days $(\mathrm{H})$. The experiments were repeated twice: in the first one, the flower buds were processed immediately after the collection (T0). In the second one they were subjected to a cold $\left(4{ }^{\circ} \mathrm{C}\right)$ pre-treatment for a week (T7). For each test, fifteen Petri dishes were prepared.

\subsubsection{Evaluation of the microspore response}

After several months in culture, per each thesis, 450 microspores (three replicates with around 150 microspores each) were observed under a fluorescence microscope (Zeiss, Axiophot, Germany) after DAPI staining to check their development. Moreover, the number of embryos produced per each Petri dish was registered using a binocular 
microscope (Leica MZ 125). These values were used to calculate means. Statistical analysis was carried out using Statgraphics software. Three factors were considered: 'Cold treatment', 'Hot treatment' and 'Culture medium'. Differences between them were tested by analysis of variance (ANOVA) at $p \leq 0.05$ level. Tukey's test was, then, used to separate means.

Table 3.1 Media composition (in $\mathrm{g} \mathrm{L}^{-1}$ or $\mathrm{mg} \mathrm{L}^{-1}$ )

\begin{tabular}{|c|c|c|c|c|}
\hline Components & $\mathbf{P}$ & N6 & PmT & N6mT \\
\hline Chu Salts & $1 \mathrm{X}$ & $1 \mathrm{X}$ & $1 \mathrm{X}$ & $1 \mathrm{X}$ \\
\hline N\&N Vitamins & $1 \mathrm{X}$ & $1 \mathrm{X}$ & $1 \mathrm{X}$ & $1 \mathrm{X}$ \\
\hline Galactose & $18 \mathrm{~g}$ & $9 \mathrm{~g}$ & $18 \mathrm{~g}$ & $9 \mathrm{~g}$ \\
\hline Lactose & $36 \mathrm{~g}$ & $18 \mathrm{~g}$ & $36 \mathrm{~g}$ & $18 \mathrm{~g}$ \\
\hline Ascorbic Acid & $500 \mathrm{mg}$ & $500 \mathrm{mg}$ & $500 \mathrm{mg}$ & $500 \mathrm{mg}$ \\
\hline Myoinositol & $5 \mathrm{~g}$ & - & $5 \mathrm{~g}$ & - \\
\hline Biotin & $500 \mathrm{mg}$ & $500 \mathrm{mg}$ & $500 \mathrm{mg}$ & $500 \mathrm{mg}$ \\
\hline Thiamine & $5 \mathrm{mg}$ & - & $5 \mathrm{mg}$ & - \\
\hline Pyridoxine & $5 \mathrm{mg}$ & - & $5 \mathrm{mg}$ & - \\
\hline 2,4-Dichlorophenoxyacetic acid & $0.5 \mathrm{mg}$ & $0.02 \mathrm{mg}$ & $0.5 \mathrm{mg}$ & $0.02 \mathrm{mg}$ \\
\hline 1-Naphthaleneacetic acid & - & $0.02 \mathrm{mg}$ & - & $0.02 \mathrm{mg}$ \\
\hline Kinetin & $0.5 \mathrm{mg}$ & $1 \mathrm{mg}$ & $0.5 \mathrm{mg}$ & $1 \mathrm{mg}$ \\
\hline Zeatin & $0.5 \mathrm{mg}$ & $0.5 \mathrm{mg}$ & $0.5 \mathrm{mg}$ & $0.5 \mathrm{mg}$ \\
\hline Gibberellic acid & $0.5 \mathrm{mg}$ & $0.5 \mathrm{mg}$ & $0.5 \mathrm{mg}$ & $0.5 \mathrm{mg}$ \\
\hline Thidiazuron & $0.5 \mathrm{mg}$ & $0.1 \mathrm{mg}$ & $0.5 \mathrm{mg}$ & $0.1 \mathrm{mg}$ \\
\hline Coconut water & - & $50 \mathrm{~mL}$ & - & $50 \mathrm{~mL}$ \\
\hline Casein & $500 \mathrm{mg}$ & $500 \mathrm{mg}$ & $500 \mathrm{mg}$ & $500 \mathrm{mg}$ \\
\hline Serine & $100 \mathrm{mg}$ & - & $100 \mathrm{mg}$ & - \\
\hline Glycine & $2 \mathrm{mg}$ & - & $2 \mathrm{mg}$ & - \\
\hline Glutamine & $800 \mathrm{mg}$ & $200 \mathrm{mg}$ & $800 \mathrm{mg}$ & $200 \mathrm{mg}$ \\
\hline Malt extract & $500 \mathrm{mg}$ & $800 \mathrm{mg}$ & $500 \mathrm{mg}$ & $800 \mathrm{mg}$ \\
\hline Benzyladenine & $0.5 \mathrm{mg}$ & $0.5 \mathrm{mg}$ & - & - \\
\hline Meta-Topolin & - & - & $0.5 \mathrm{mg}$ & $0.5 \mathrm{mg}$ \\
\hline
\end{tabular}

$\mathbf{P}$ (Germanà et al. 1996), N6 (Karasawa et al. 2016), N\&N vitamins (Nitsch and Nitsch 1969), Chu salts (Chu 1978)

\subsubsection{Allelic pattern detection by SSR analysis}

To check the homozygosity of the embryos, DNA was extracted from leaves of the mother plant and from the embryos obtained by in vitro culture. The leaves were frozen in liquid nitrogen and ground with mortar and pestle; the embryo was collected from the culture medium by an insulin syringe, placed in a $1.5 \mathrm{~mL}$ eppendorf with a small 
amount of quartz powder and ground with $600 \mu \mathrm{L}$ of extraction buffer directly in the eppendorf. DNA extraction was then performed as described in Doyle and Doyle (1987). The parent DNA was resuspended in $60 \mu \mathrm{L}$ TE buffer (Tris-EDTA, pH 8.0) and then diluted to $10 \mathrm{ng} / \mu \mathrm{L}$. Embryo DNA was resuspended in $25 \mu \mathrm{L}$ TE.

Ten SSR (Simple Sequence Repeats) loci isolated by Froelicher et al. (2008) from $C$. reticulata and Novelli et al. (2006) from C. sinensis were screened on the DNA from the leaves and 3 were selected for their heterozygosity in parental genotype: Ci08C05, mCrCIR01B10 (Froelicher et al. 2008) and CCSM147 (Novelli et al. 2006). These loci were used for assessing the allelic pattern of the embryo, as described in Chiancone et al. (2015).

Polymerase chain reactions (PCRs) were performed in two steps in a total volume of 10 $\mu \mathrm{L}$ containing $3 \mu \mathrm{L}$ DNA (corresponding to $30 \mathrm{ng}$ of DNA for the parent plant), $0.25 \mathrm{U}$ of KAPA Taq DNA polymerase (KAPABIOSYSTEMS, Wilmington MA, USA), $1 \mu \mathrm{L}$ of 10X PCR buffer, $200 \mu \mathrm{M}$ nucleotide mix and $0.5 \mu \mathrm{M}$ of each primer. PCR conditions were as follows: an initial denaturation step at $95{ }^{\circ} \mathrm{C}$ for $3 \mathrm{~min}$ followed by 34 cycles of denaturation $\left(30 \mathrm{~s}\right.$ at $\left.95^{\circ} \mathrm{C}\right)$, annealing $\left(45 \mathrm{~s}\right.$ at $\left.50{ }^{\circ} \mathrm{C}\right)$, and extension $\left(90 \mathrm{~s}\right.$ at $\left.72{ }^{\circ} \mathrm{C}\right)$. The final elongation step was at $72{ }^{\circ} \mathrm{C}$ for $30 \mathrm{~min}$. Four $\mu \mathrm{L}$ of the product obtained from the first amplification were then used as template for a second PCR, carried out for 28 cycles with the same conditions of the first one. PCR products were then analyzed by a 3130 Genetic Analyzer (Applied Biosystems, Foster City, CA,USA). Data were processed using GeneMapper Software (ver. 4.0; Applied Biosystems) and alleles were defined by their size in base pairs, by comparison with the standard size (GeneScan-500 LIZ, Applied Biosystems).

\subsection{Results and discussion}

The microspore culture response can be strongly affected by the microspore development stage. The bud size and the petal length are very often used as an external morphological indicator of the microspore stage for large-scale tests. Results of preliminary investigation with DAPI staining showed a correlation between the floral bud size and the microspore developmental stages. Bud sizes of 4.0 to $4.5 \mathrm{~mm}$ in length (Fig. 3.1a), corresponded to the highest percentage $(>80 \%)$ of the appropriate 
uninucleate-vacuolated stage (Fig. 3.1b). This stage was previously identified as the most responsive for gametic embryogenesis in Citrus (Cardoso et al. 2014; Chiancone et al. 2015; Chiancone and Germanà 2016).
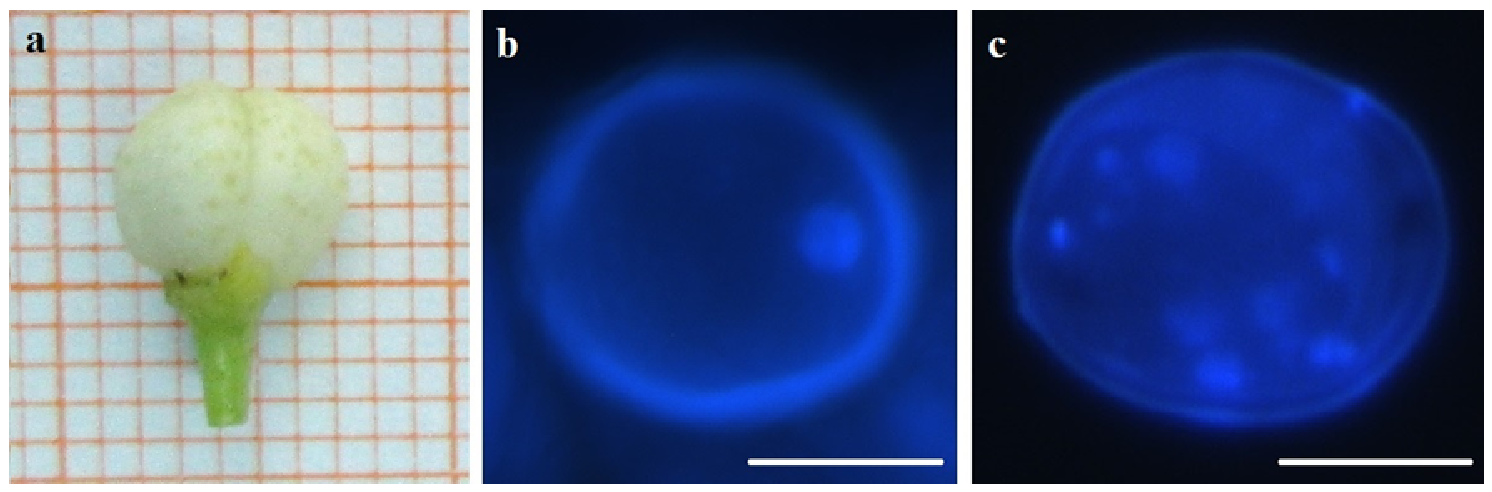

Fig. 3.1 a Phenological stages of flower bud of MTC selected in relation to the microspore developmental stage (best stage = vacuolate stage); b Uninucleate-vacuolate microspore of MTC; c Multinucleated structure of MTC (Bars represent $10 \mu \mathrm{m}$ )

After several months of culture, for all the media tested, different structural features have been observed. Among them, multinucleated structures (Fig. 3.1c), and, for the first time in mandarin isolated microspore culture, calli and microspore-derived embryos (Fig. 3.2a, b). These features indicate that these microspores switched their developmental program from the normal gametophytic pathway toward the sporophytic pathway (Segui'-Simarro and Nuez 2008a).
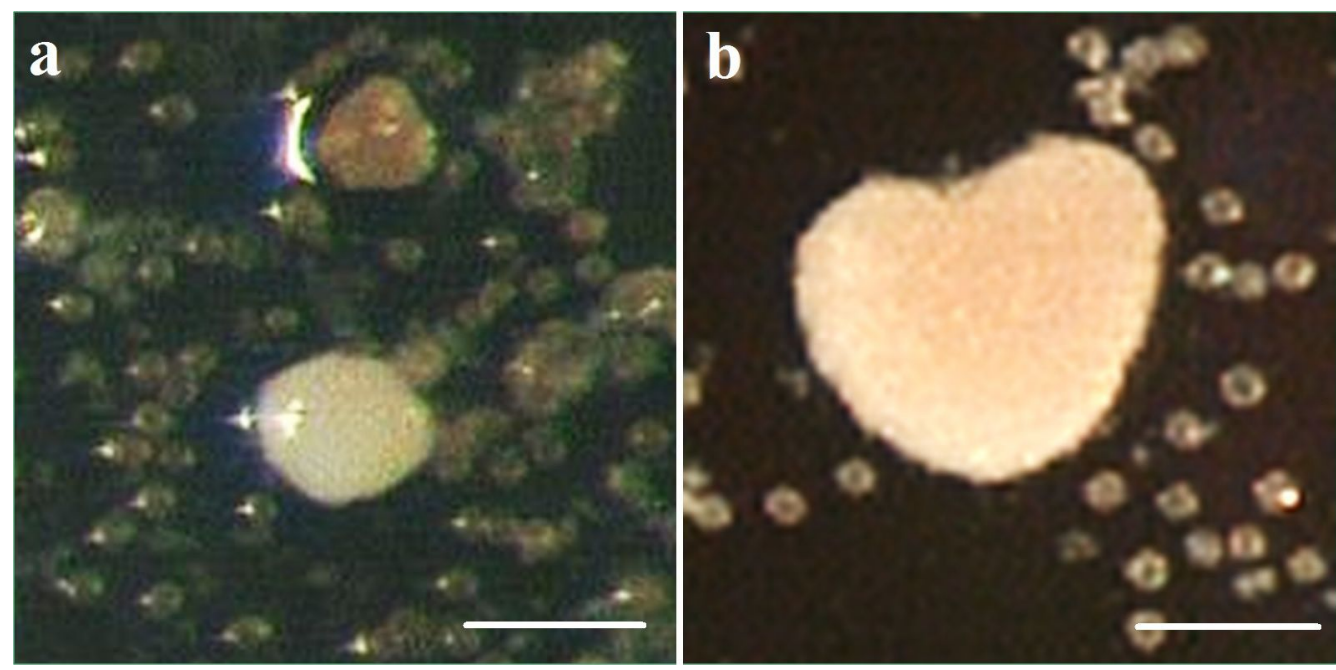

Fig. 3.2 a Miscrospore-derived calli and globular embryo of MTC; b Heart-shaped embryo of MTC (Bars represent $150 \mu \mathrm{m})$ 
Chiancone et al. (2015) previously reported the production of microspore-derived embryos obtained through isolated microspore culture in Citrus.

The in vitro isolated microspore culture response after several months of culture is showed in Table 3.2. The application of different cold or hot treatments, before or during the culture, is commonly employed to improve the microspore embryogenesis response (Germanà 2011a, b). In this experiment, a marked and significant $(\mathrm{p} \leq 0.05)$ 'Hot treatment' effect was observed in the embryo production. In fact, only isolated microspores cultured at $35{ }^{\circ} \mathrm{C}$ for 30 days $(\mathrm{H})$ finally produced embryos. On the contrary, no significant statistically differences were observed among microspores immediately processed (T0) or subjected to the cold (T7) pre-treatment.

Regarding the four culture media tested, 'P' and 'PmT' induced a higher average number of regenerated embryos per Petri dish, while the 'N6mT' medium the lowest. In addition, Tukey's test evidenced that 'PmT' medium produced a statistically significant $(p \leq 0.05)$ higher number of embryos per Petri dish when compared with 'N6' and 'N6mT' media (Table 3.2). The effect of $\mathrm{mT}$ on gametic embryogenesis induction could be due to its anti-senescence and plant growth stimulation activities. However, as reported in other studies, the response to $\mathrm{mT}$ in the culture media appears to be genotype-dependent. For example, Chiancone et al. (2015) reported that in Citrus clementina, microspore-derived embryo production seemed to be favored by $\mathrm{mT}$ addition in cv. 'Nules' but not in 'Monreal Rosso'.

Table 3.2 In vitro isolated microspore culture response after 10 months of culture

\begin{tabular}{llcl}
\hline Factors & & Embryo/Petri dish \\
\hline Cold treatment & T0 & 0.11 & $\mathrm{a}$ \\
& $\mathrm{T} 7$ & 0.25 & $\mathrm{a}$ \\
$p$ value & & 0.304 & \\
\hline Hot treatment & $\mathrm{C}$ & 0.0 & $\mathrm{a}$ \\
& $\mathrm{H}$ & 0.35 & $\mathrm{~b}$ \\
$p$ value & & 0.016 & \\
\hline Medium & $\mathrm{N} 6$ & 0.02 & $\mathrm{a}$ \\
& $\mathrm{N} 6 \mathrm{mT}$ & 0.0 & $\mathrm{a}$ \\
& $\mathrm{P}$ & 0.11 & $\mathrm{ab}$ \\
& $\mathrm{PmT}$ & 0.59 & $\mathrm{~b}$ \\
$p$ value & & 0.012 & \\
\hline
\end{tabular}

T0: No treatment; T7: $4{ }^{\circ} \mathrm{C}$ for $7 \mathrm{~d} ; \mathbf{C}: 26 \pm 1{ }^{\circ} \mathrm{C} ; \mathbf{H}: 35^{\circ} \mathrm{C}$ for $30 \mathrm{~d}$ 
Recently, Esteves et al. (2014) tested $\mathrm{mT}$ in the isolated microspore culture medium of recalcitrant barley genotypes, increasing embryo differentiation into green plants by 2.9fold. Although the microspore-derived embryos obtained were transferred to a solid medium to achieve conversion and plantlet production, no germination was achieved, probably due to immaturity and lack of accumulation of the storage compounds or a deficiency in the media compositions, as already observed in somatic embryogenesis process, that prevents maturation and germination (Ochatt and Revilla 2016). Since the embryos were of reduced dimensions, ploidy level could not be determined by flow cytometry. However, the analyses of the three SSR loci showed a clear amplification: while the parental genotype was heterozygous, the allelic pattern of the embryo showed a single allele, shared with the parental genotype (Fig. 3.3; Table 3.3). This result confirms the origin of the embryo from the MTC microspore. In Fig. 3.3 the amplicons of the SSR loci CCSM147 and Ci08C05 in the embryo and in the parental genotype are showed.

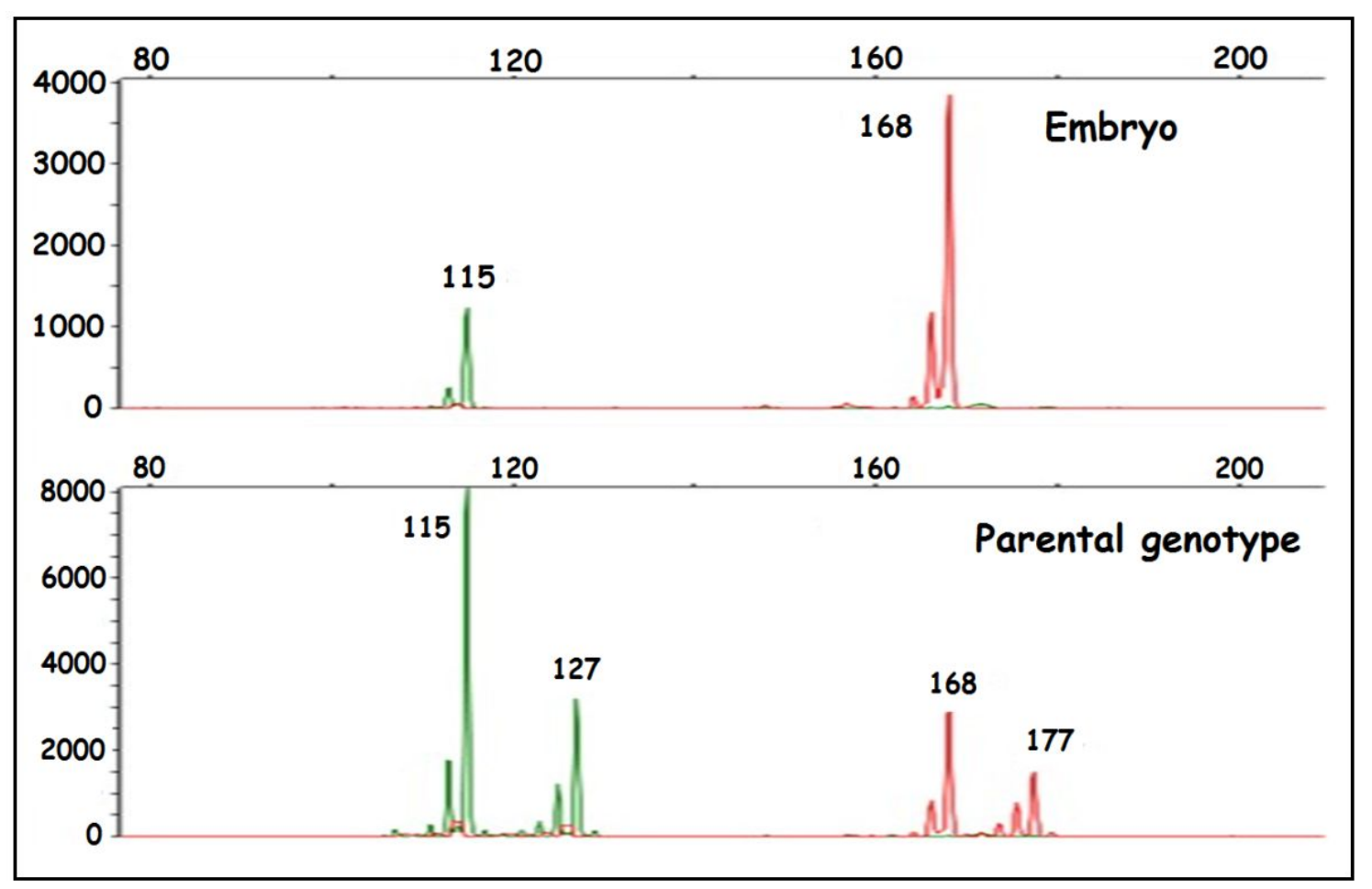

Fig. 3.3 Amplicons of the SSR loci CCSM147 (at left) and Ci08C05 (at right) in embryo (top) and in the parental genotype (bottom) of MTC. Values above each peak represent the allele size (bp). The allelic pattern of the embryo shows a single allele, shared with the parental genotype 
Table 3.3 Allelic pattern in parental genotype and embryo. Allele size in bp

\begin{tabular}{lll}
\hline Parental genotype & SSR locus & Allelic pattern \\
\hline \multirow{2}{*}{ MTC } & Ci08C05 & $168-177$ \\
& mCrCIR01B10 & $156-160$ \\
& CCSM147 & $115-127$ \\
\hline \multirow{2}{*}{ embryo } & Ci08C05 & 168 \\
& mCrCIR01B10 & 156 \\
& CCSM147 & 115 \\
\hline
\end{tabular}

MTC: 'Mandarino Tardivo di Ciaculli’

\subsection{Conclusions}

The production of homozygous plants in fruit trees is a efficient method for increasing breeding efficiency and for plant genome studies. In woody species, like Citrus, characterized by flower self-incompatibility, prolonged juvenility and high degree of heterozygosity, homozygous plant production is not possible through conventional methods. The only way to obtain homozygous lines is through gametic embryogenesis. Particularly, microspore embryogenesis is a promising tool for plant breeding as fully homozygous plants can be generated with a single step starting from heterozygous parents (Germanà 2011a, b; Chiancone and Germanà 2016). The potential value of this technique is evident. However, a well-defined and efficient procedure of regeneration through isolated microspore culture has to be set up.

These results represent an advancement in the knowledge of microspore embryogenesis in C. reticulata Blanco, 'Mandarino Tardivo di Ciaculli'. Actually, this is the first time that embryo regeneration from isolated microspore cultures has been reported in mandarin, a genotype extremely recalcitrant to pollen embryogenesis. However, further studies are necessary to better understand the gametic embryogenesis process, to optimize the rate of microspore-derived embryos and to achieve their germination into plantlets. 


\section{LOQUAT PLOIDY MANIPULATION}

\section{Introduction}

Loquat (Eriobotrya japonica (Thunb.) Lind1.), belonging to the Maloideae subfamily of the Rosaceae, is a subtropical evergreen fruit tree. It was introduced in the XII century from China to Japan and, only in the XVIII century in Europe. The process of loquat domestication has led to a large number of varieties emerged in the different countries where it was cultivated (Lin 2004; Lin et al. 2004; Yang et al. 2005). In fact, this crop showed a successful adaptation to the Mediterranean climate and now it is widely grown in regular orchards. The main producing country in the world is China, although there is production in Japan and in the Mediterranean countries. In Europe, Spain represents more than $50 \%$ of the total production, followed by Italy and Israel (Gisbert et al. 2009). Loquat produces a non-climacteric fruit, generally containing between 2 and 5 large seeds, consumed largely fresh (Tian et al. 2007), although small amounts are used in the preparation of jams, syrups and pies (Lin et al. 1999).

Loquat is a perennial fruit tree with a long juvenile period and high heterozygosity due to its self-incompatibility trait. Specifically, it shares with the rest of the Rosaceae species, a gametophytic self-incompatibility (GSI) system based on S-RNases (Igic and Kohn 2001). The high number of alleles found at the S-locus is particularly interesting for genetic diversity studies and it is essential for correct orchard planning and suitable design of breeding programs (Badenes et al. 2013).

Loquat breeding programs are focused on new cultivars that meet farmers and consumers demands. There are breeding programs in China, Japan and Spain. The objectives of the different breeding programs are related to the production of more competitive fruits and better adaptability to the environment. The breeding program from Spain is carried out at the 'Instituto Valenciano de Investigaciones Agrarias' (IVIA), the main objective is to obtain new varieties with the positive agronomic features of 'Algerie' but with more diversity in ripening date and fruit characteristics (Gisbert et al. 2006). Development of molecular markers for assisted selection, genetic diversity studies, haploidization and new breeding techniques are providing new tools for breeding progress. For instance, in vitro anther or isolated microspore culture 
(haploid technology) and poliploids production (chromosome duplication) have become successful techniques for the breeding industry (Maluszynski et al. 2003; Germanà 2011a, b; Sattler et al. 2016).

Regarding loquat, there have been reports on the establishment of plant regeneration system and haploid induction through anthers (Li et al. 2008; Blasco et al. 2015b) or isolated microspore culture (Padoan et al. 2010; Blasco et al. 2014). Haploids are of great interest, since they can allow the fixation of interesting traits in a homozygous state (Germanà 2011b). Moreover, they are important in genetic studies, since they offer higher efficiency in the selection of desired recombinants and recessive mutants (Srivastava and Chaturvedi 2008). A tremendous effort has been made also in the field of the conservation and evaluation of loquat biodiversity. One important tool for breeding are the genetic resources kept at the germplasm collections. The most important European collection is held at the IVIA, that includes more than 120 cultivars (Soriano et al. 2005; Gisbert et al. 2009; Blasco et al. 2014). In terms of increasing the diversity of fruit types, polyploidy has an important role in genetic and phenotype diversity and breeding (Dhooghe et al. 2011; Xing et al. 2011). In fact, natural polyploidy is considered to be one of the most frequent ways for generating new variability. Polyploid genotypes include many commercially successful features, such as large fruit size (Rugini et al. 1996), disease-resistance (Predieri 2001), good adaptability (Liu et al. 2009), fruit quality (Wu et al. 2013) and seedless fruits (Kagan-Zur et al. 1991). Seedlessness in loquat is especially relevant because the fruits are small (40 to 50 g) and the edible proportion is often lower than $70 \%$ (He et al. 2012). Loquat seedless fruits have been achieved by selection of naturally occurring triploid clones, followed by applications of gibberellic acid for fruit set (Mesejo et al. 2010) but the natural rate of polyploidy in loquat is about $0.35 \%$ (He et al. 2012). In the frame of developing new poliploid genotypes of loquat, the induction of polyploidy by means of antimitotic agents, such as colchicine, could be an efficient alternative.

The aim of this study was to induce gametic embryogenesis, through loquat anther culture technique, to achieve calli and embryo production. In addition, aimed at obtaining new genotypes, with different ploidy levels (polyploids), another biotechnological tool (chromosome duplication) was also assessed applying colchicine to loquat seeds before germination. 


\section{CHAPTER 4}

\section{Morphogenic callus induction through in vitro anther culture of loquat (Eriobotrya japonica (Thunb.) Lindl.)}

\subsection{Abstract}

Breeding of perennial plants is usually difficult and time-consuming due to their high degree of heterozygosity, long reproductive cycle and complex reproductive biology. The potential of gamete biotechnology can represent, particularly for them, a great advantage in comparison with the conventional methods. The aim of this investigation was to induce callus and embryo production in loquat (Eriobotrya japonica (Thunb.) Lindl.), through anther culture technique. With this objective, anthers bearing microspore at the polarized uninucleate developmental stage were directly in vitro cultured, and seven genotypes and four culture media were assessed. Production of calli was achieved, in all cultivars, only when the media were supplemented with 1_naphtalene acetic acid (NAA), being the response genotype dependent. Furthermore, despite evidences of the beginning of the embryogenic program (microspore symmetrical nucleus division) were observed, no embryo was achieved.

\subsection{Materials and methods}

\subsubsection{Plant material}

Seven different loquat cultivars were tested. In particular, five from Spain: 'Algerie', 'Cayetano', 'Magdal', 'Peluche', 'Redonet', one from Italy: 'Sanfilippara' and one from China: 'Zaozhong-6', were selected for this experiment. Terminal racemose inflorescences (panicles) of all the cultivars, bearing flower buds at different developmental stages, were harvested in November in fields belong to the European loquat germplasm collection located at IVIA, Valencia, Spain (latitude: $37^{\circ} 45^{\prime} 31.5 \mathrm{~N}$; longitude: $\left.1^{\mathrm{o}} 01^{\prime} 35.1 \mathrm{O}\right)$. 


\subsubsection{Bud size and microspore stage correlation}

Flowers buds of different sizes (Fig. 4.1a) were selected to evaluate the pollen developmental stage. Per each size group and per each genotype, ten anthers were removed from distinct buds and squashed in a few drops of 4',6-diamidino-2phenylindole (DAPI, Partec, Münster, Germany) staining solution. Microspores were observed under a fluorescent microscope to identify the pollen development stage and to determine the correct flower bud size (Fig. 4.1b), containing anthers with the highest percentage of uninucleated-vacuolated microspores. Only flower buds containing mostly anthers with microspores at the polarized uninucleate stage (Fig. 4.1c), were finally selected for the in vitro culture.

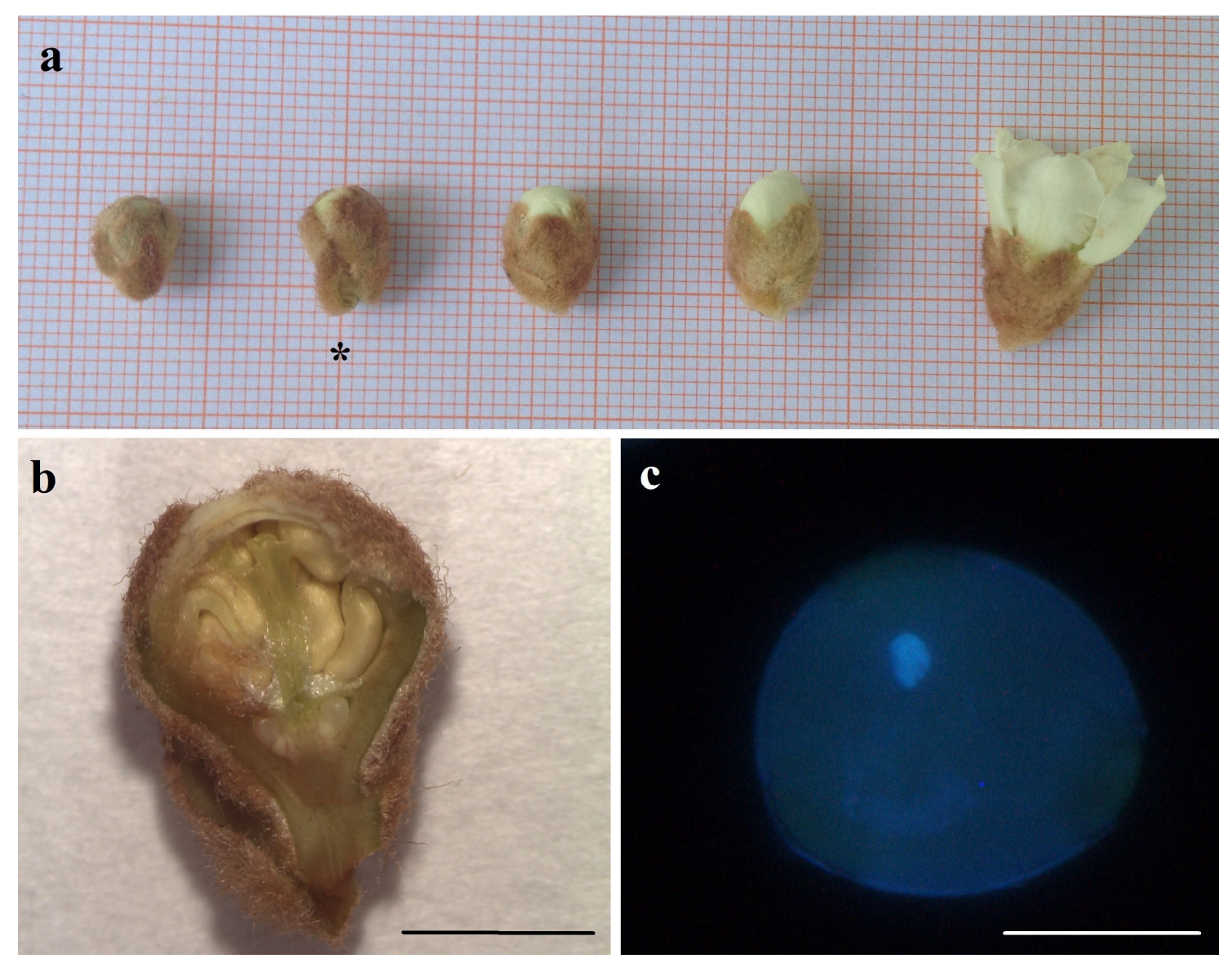

Fig. 4.1 a Phenological stages of flower buds selected in relation to the microspore developmental stage *(best stage $=$ polarized uninucleated stage); $\mathbf{b}$ Flower bud containing anthers with the correct microspore stage; c Uninucleated-vacuolated microspore (Bars represent in a: $3 \mathrm{~mm}$, in b: $10 \mu \mathrm{m}$ ) 


\subsubsection{Flower bud sterilization and anther culture}

Flower buds were removed from the panicles and surface sterilized. The sterilization was performed, under a laminar flow hood, by immersion in $70 \%(\mathrm{v} / \mathrm{v})$ ethanol for 5 min followed by immersion in $4 \%(\mathrm{w} / \mathrm{v})$ sodium hypochlorite with $0.1 \%(\mathrm{w} / \mathrm{v})$ of Tween-20® for $10 \mathrm{~min}$, rinsed three times in sterile distilled water and finally processed under aseptic conditions. Sepals and petals were aseptically removed using small forceps, anthers were carefully excised and immediately placed in Petri dishes (60x15 $\mathrm{mm}$ ) containing about $10 \mathrm{~mL}$ of solidified medium. Fifteen anthers were placed in each Petri dish and sixty Petri dishes were prepared per each genotype (15 per each medium, for a total of 900 anthers per each genotype). Cultures were incubated at $24 \pm 1{ }^{\circ} \mathrm{C}$ for four weeks in the dark and, then, transferred under cool white fluorescent lamps Philips TLM 30W/84 conditions (Philips, France), with a photosynthetic photon flux density of $35 \mu \mathrm{mol} \mathrm{m} \mathrm{s}^{-1}$ and a photoperiod of $16 \mathrm{~h}$ light.

\subsubsection{Culture media}

Anthers were cultured on a basal callus induction medium consisting of half-strength MS inorganic basal salts, L-cysteine $(16.5 \mu \mathrm{M})$, mixture of vitamins (26.6 mM glycine, $2.9 \mathrm{mM}$ thiamine hydrochloride, $8.1 \mathrm{mM}$ nicotinic acid, $2.4 \mathrm{mM}$ pyridoxine hydrochloride and $2.8 \mathrm{mM}$ ascorbic acid), myo-inositol $(1.1 \mathrm{mM})$ and sucrose $(2 \%$ $\mathrm{w} / \mathrm{v})$. Also, the solid medium was supplemented with growth regulators, $4.56 \mu \mathrm{M}$ zeatin (ZEA) versus four doses of 1_naphtalene acetic acid (NAA: 0, 0.5, 1 and $1.5 \mathrm{mg} \mathrm{L}^{-1}$ ) in order to determine optimum conditions for callus induction.

The morphogenic calli (MC) produced were cultivated on a embryo differentiation medium (EDM) (Li et al. 2008) containing MS basal salts, mixture vitamins, L-cysteine $(16.5 \mu \mathrm{M})$, myo-inositol $(1.1 \mathrm{mM})$ and sucrose $(2 \% \mathrm{w} / \mathrm{v})$, supplemented with $0.23 \mu \mathrm{M}$ Z, $0.1 \mu \mathrm{M}$ NAA and $0.1 \mu \mathrm{M}$ Indole-3-butyric acid (IBA). Anthers and calli were subcultured monthly onto new fresh medium. The composition of the different media is resumed in Table 4.1.

\subsubsection{Data collection and statistical analysis}

Anthers, collected after one month of culture, were treated with a DAPI staining solution to assess microspores structural features. For each thesis, about 300 
microspores were observed using a fluorescence microscope (Zeiss, Axiophot, Germany). Moreover, the cultured anthers were observed weekly with a stereomicroscope (Leica MZ 125) to follow their development. Three months after culturing, the number of anthers producing calli were recorded per each Petri dish. These data were used to calculate means and to perform statistical analysis. Differences among genotypes were tested by one-way analysis of variance (ANOVA) with Tukey's test ( $p$ $\leq 0.05$ ), while, to avoid the genotype dependent effect, the influence of the four culture media tested was analyzed separately for each cultivar (LSD test, $p \leq 0.05$ ).

Table 4.1 Media composition (in $\mathrm{g} \mathrm{L}^{-1}$ or $\mathrm{mg} \mathrm{L}^{-1}$ )

\begin{tabular}{lrrrrr}
\hline Components & NAA 0 & NAA 0.5 & NAA 1 & NAA 1.5 & EDM \\
\hline MS basal salt mixture & $2.2 \mathrm{~g}$ & $2.2 \mathrm{~g}$ & $2.2 \mathrm{~g}$ & $2.2 \mathrm{~g}$ & $4.3 \mathrm{~g}$ \\
Glycine & $2 \mathrm{~g}$ & $2 \mathrm{~g}$ & $2 \mathrm{~g}$ & $2 \mathrm{~g}$ & $2 \mathrm{~g}$ \\
Thiamine & $1 \mathrm{~g}$ & $1 \mathrm{~g}$ & $1 \mathrm{~g}$ & $1 \mathrm{~g}$ & $1 \mathrm{~g}$ \\
Nicotinic acid & $1 \mathrm{~g}$ & $1 \mathrm{~g}$ & $1 \mathrm{~g}$ & $1 \mathrm{~g}$ & $1 \mathrm{~g}$ \\
Pyridoxine & $0.5 \mathrm{~g}$ & $0.5 \mathrm{~g}$ & $0.5 \mathrm{~g}$ & $0.5 \mathrm{~g}$ & $0.5 \mathrm{~g}$ \\
Ascorbic Acid & $0.5 \mathrm{~g}$ & $0.5 \mathrm{~g}$ & $0.5 \mathrm{~g}$ & $0.5 \mathrm{~g}$ & $0.5 \mathrm{~g}$ \\
Myoinositol & $0.2 \mathrm{~g}$ & $0.2 \mathrm{~g}$ & $0.2 \mathrm{~g}$ & $0.2 \mathrm{~g}$ & $0.2 \mathrm{~g}$ \\
L-Cysteine & $2 \mathrm{mg}$ & $2 \mathrm{mg}$ & $2 \mathrm{mg}$ & $2 \mathrm{mg}$ & $2 \mathrm{mg}$ \\
Sucrose & $20 \mathrm{~g}$ & $20 \mathrm{~g}$ & $20 \mathrm{~g}$ & $20 \mathrm{~g}$ & $20 \mathrm{~g}$ \\
Zeatin & $1 \mathrm{mg}$ & $1 \mathrm{mg}$ & $1 \mathrm{mg}$ & $1 \mathrm{mg}$ & $0.05 \mathrm{mg}$ \\
1-Naphthaleneacetic acid & $0 \mathrm{mg}$ & $0.5 \mathrm{mg}$ & $1 \mathrm{mg}$ & $1.5 \mathrm{mg}$ & $0.018 \mathrm{mg}$ \\
Indole-3-butyric acid & - & - & - & - & $0.02 \mathrm{mg}$ \\
\hline
\end{tabular}

MS (Murashige and Skoog 1962), EDM (Li et al. 2008)

\subsubsection{Ploidy Analysis}

Ploidy analysis of the calli obtained though in vitro anthers culture was performed by flow cytometry. The unorganized parenchyma cells were chopped with a sharp razor blade in $2.0 \mathrm{~mL}$ of nuclear extraction buffer (Partec, Münster, Germany). Each nuclear suspension was filtered through a $50 \mu \mathrm{m}$ nylon filter (Nybolt, Zürich, Switzerland) and mixed with $4.0 \mathrm{~mL}$ of DAPI $\left(1 \mathrm{mg} \mathrm{L}^{-1}\right)$ staining solution. The fluorescence intensity of the nuclear mixture was measured by a CyFlow ${ }^{\circledR}$ Counter (Partec) and compared with a mother plant sample, used as diploid control. 


\subsection{Results and discussion}

The anthers culture response can be strongly affected by the microspore development stage. In fact, the appropriate stage is critical to induce in vitro pollen embryogenesis and, moreover, it varies among species (Dunwell 2010). Many studies report that, the optimum phase to switch the microspore developmental pathway from gametophytic to sporophytic, lies between the first pollen mitosis and the early bicellular pollen stage (Touraev et al. 2001; Seguí-Simarro and Nuez 2008a; Seguí-Simarro 2010; Soriano et al. 2013). With the assumption that, also for loquat (Li et al. 2008), this stage was the most suitable to induce microspore embryogenesis, the flower bud size was used as external morphological indicator of the microspore developmental stage, to select the explants. Previous studies conducted on loquat demonstrated that different microspore stages can be associated to the flower bud size. Recently, Padoan et al. (2010) and Blasco et al. (2015b) reported that loquat flower buds, reached a length of approximately $6.5-7.0 \mathrm{~mm}$ long, mostly contained microspores at the uninucleate-early binucleate pollen stage. In our case, results of this preliminary investigation, confirmed the correlation between the bud size and the microspore developmental stages. Indeed, bud sizes from 6.0 to $7.5 \mathrm{~mm}$ in length (depending on genotype) (Fig. 4.1 a*), corresponded to the highest percentage ( $>75 \%$ ) of the appropriate stage.

DAPI staining and fluorescence microscopy observations, carried out in anthers collected one month after culture, revealed the induction of microspore with two identical nuclei, equal in size and chromatin condensation patterns (Fig. 4.2a), derived by a symmetrical nucleus division (SND). The SND of the nucleus is considered one of the first signs of the switch from the gametophytic to the sporophytic pathway (SeguìSimarro and Nuez 2008a). This feature indicate that these microspores had undertaken their embryogenic program. On the contrary, also bicellular pollen grains, containing nuclei with different chromatin condensation patterns (Fig. 4.2b), a larger vegetative nucleus and a smaller generative one, were observed, denoting an asymmetrical nucleus division (AND), which is typical of classic pollen maturation (Pacini 2012). 


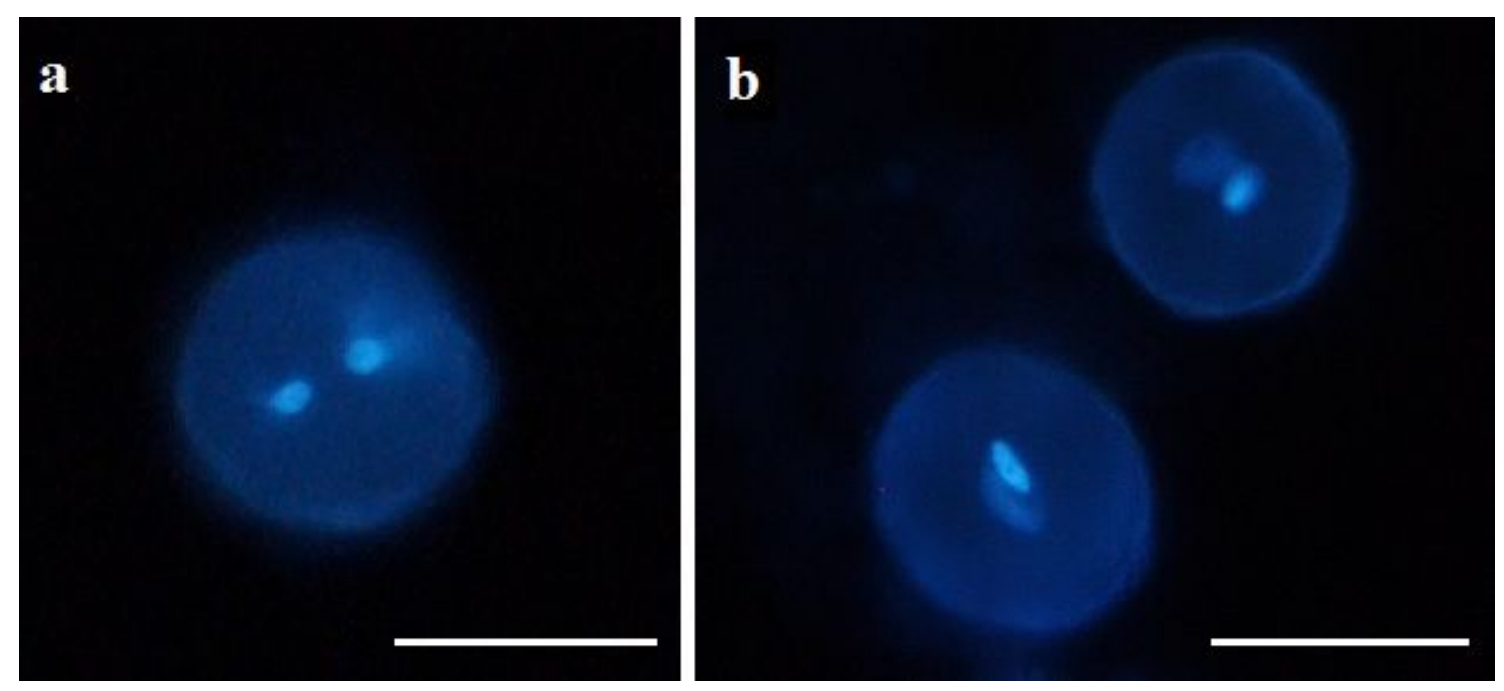

Fig. 4.2 a Microspore with two equal nuclei (symmetrical division) of 'Peluche'; b Bicellular pollen grains (asymmetrical division) of 'Algerie' (Bars represent $25 \mu \mathrm{m}$ )

In anthers culture, different features have been described as signs of initiation of the embryogenic pathway. After the first month in the dark, some of the anthers already showed androgenic response starting to produce a white and friable callus (Fig. 4.3a). Androgenic anthers (AA) showing callus production were monthly sub-cultured onto their corresponding (NAA $0,0.5,1$ or 1.5) fresh callus induction medium. When transferred under cool white light, some calli started to turn their color from white to green, generating a different type of callus (morphogenic), showing organized tissues (Fig. 4.3b).

a

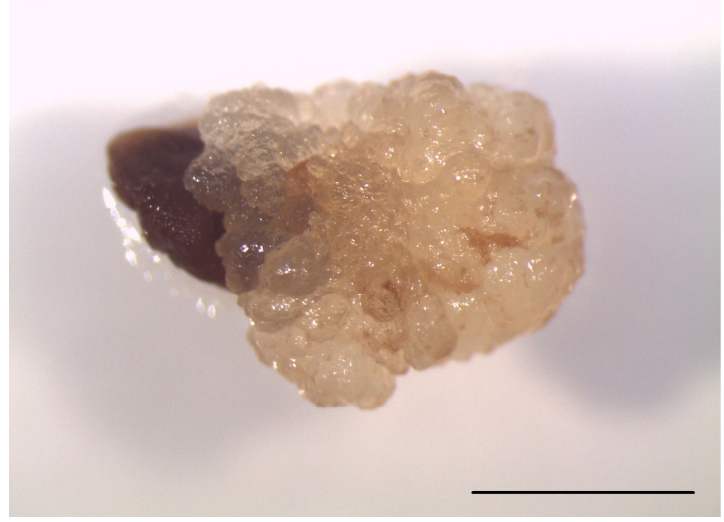

b

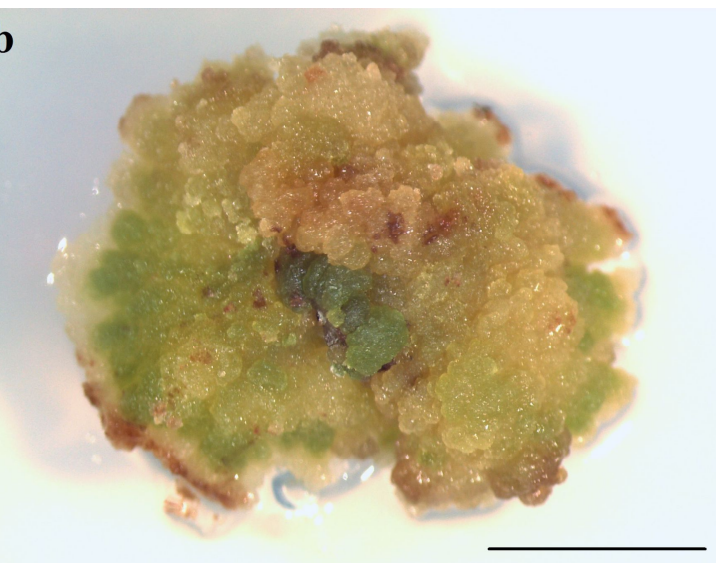

Fig. 4.3 a Anther producing white and friable callus after one month of culture; b Morphogenic callus showing organized tissues of 'Zaozhong-6' after three months of culture (Bars represent in a: 2 mm, in b: $5 \mathrm{~mm})$ 
The morphogenic calli (MC) were isolated from the anthers tissues and transferred onto the 'EDM' medium to induce cells organogenesis but, finally, most of them resulted in browning, their tissues became necrotic and no embryogenic response was observed.

Many previous studies on anthers culture reported that, in woody plants, the effect of the genotype of the donor plant can strongly affect the microspore embryogenic response (Germanà 2005; Germanà 2011a, b; Blasco et al. 2015b; Cimò et al. 2016). As shown in Table 4.2, also in our case, the response to callus induction was, as expected, highly genotype dependent. In fact, statistical analysis of variance (ANOVA, Tukey's test) highlighted significant $(p \leq 0.01)$ differences among the seven cultivars tested.

Table 4.2 Anthers culture responses to the seven genotypes tested

\begin{tabular}{lllll}
\hline CULTIVAR & AA $(\%)$ & MC $(\%)$ \\
\hline 'Redonet' & 1.9 & $\mathrm{a}$ & 0.9 & $\mathrm{a}$ \\
'Algerie' & 2.9 & $\mathrm{a}$ & 1.1 & $\mathrm{a}$ \\
'Zaozhong-6' & 4.3 & $\mathrm{ab}$ & 2.7 & $\mathrm{ab}$ \\
'Peluche' & 6.8 & $\mathrm{ab}$ & 5.1 & $\mathrm{ab}$ \\
'Magdal' & 7.4 & $\mathrm{ab}$ & 5.3 & $\mathrm{ab}$ \\
'Cayetano' & $10.0 \mathrm{~b}$ & 6.7 & $\mathrm{~b}$ \\
'Sanfilippara' & $19.3 \mathrm{c}$ & 12.7 & $\mathrm{c}$ \\
\hline Within each column, values followed by different letters are \\
significantly different (Tukey's test, $p \leq 0.05)$. AA: androgenic \\
anthers, MC: morphogenic calli
\end{tabular}

In particular, for both registered parameters (AA: androgenic anthers and $\mathrm{MC}$ : morphogenic calli), the highest percentages (19.3 and 12.7 respectively) were detected in 'Sanfilippara', while the lowest percentages (1.94 and 0.97) were observed in 'Redonet'. In anthers culture, the effect of type and concentration of plant growth regulators has been widely studied (Oleszczuk et al. 2004; Perera et al. 2009; Smýkalová et al. 2009; Germanà 2011a; Cardoso et al. 2016). In woody species, different auxin types and concentrations, such as NAA, TDZ or 2.4-D, have been already employed to induce callus production in mandarin (Germanà and Chiancone 2003), papaya (Rimberia et al. 2007) and also in loquat (Li et al. 2008; Blasco et al. 2015b).

Concerning the culture media, a significant $(p \leq 0.05)$ culture medium effect, related to the different NAA concentrations used, was also observed. Indeed, calli production was 
achieved, in all cultivars tested, only when the media were supplemented with NAA, while no response (zero values) was observed when anthers were cultured on the basal ('NAA 0') medium (Table 4.3). In addition, the percentage of anthers producing calli varies according to the genotype. For this reason, the investigation of the influence of the four media used was carried out separately for each genotype (LSD test, $p \leq 0.05$ ). Particularly, 'Magdal' and 'Zaozhong-6' did not show any significant difference between the culture media tested, while in 'Cayetano' and in 'Peluche', the addition of NAA to the culture medium induced a significantly $(p \leq 0.05)$ higher percentage in the production of both types of calli, even if no significant differences were detected among the different NAA applied concentrations $(2.68,5.36$ and $8 \mu \mathrm{M})$. On the contrary, when anthers were cultured onto the 'NAA 1' and the 'NAA 1.5' (5.36 and $8 \mu \mathrm{M})$ media, 'Algerie' exhibited a statistically significantly higher percentages of anthers producing both types of calli, if compared with the 'NAA 0.5 ' $(2.68 \mu \mathrm{M})$ medium. The highest percentages of AA and MC (38.9 and 26.1 respectively) were obtained in 'Sanfilippara', where the culture medium supplied with $1.5 \mathrm{mg} \mathrm{L}^{-1}(8 \mu \mathrm{M})$ of NAA exhibited a very significant $(p \leq 0.001)$ effect when compared with all the others concentrations applied (Table 4.3).

Recently, Blasco et al. (2015b) also obtained MC from anthers of different loquat genotypes. In addition, sub-culturing these calli onto an embryogenesis inducing medium (previously described by Li et al. (2008), they have been able to achieve embryo production, but only from the Chinese cultivar Jiefanghong (the remaining other callus did not show any response). Finally, in their experiment, only one of the embryo progressed into a plantlet and was therefore analyzed. The ploidy analysis results revealed that the obtained plantlet was triploid. Measurement of DNA content using flow cytometry is commonly employed to detect ploidy levels, allowing the analysis of a large number of samples in a short time (Bohanec 2003; Ochatt 2008). In our case, ploidy analysis revealed that all the MC analyzed showed histograms of fluorescence intensity in nuclei equal to those of the mother plant (used as diploid control). For this reason, they were considered diploids. Actually, many investigations, carried out to obtain Hs through anther culture, resulted instead in producing heterozygous plantlets. Through this technique, it is possible to recover heterozygous diploid embryoids from the somatic tissue of the anther (Cardoso et al. 2016). 
Table 4.3 Anthers culture responses to the four culture media tested three months after culture

\begin{tabular}{|c|c|c|c|c|c|c|c|c|c|c|c|c|c|c|}
\hline \multirow{3}{*}{$\begin{array}{c}\text { NAA } \\
\mathrm{mg} \mathrm{L}^{-1}\end{array}$} & \multicolumn{2}{|c|}{ 'Algerie' } & \multicolumn{2}{|c|}{ 'Cayetano' } & \multicolumn{2}{|c|}{ 'Magdal' } & \multicolumn{2}{|c|}{ 'Peluche' } & \multicolumn{2}{|c|}{ 'Redonet' } & \multicolumn{2}{|c|}{ 'Sanfilippara' } & \multicolumn{2}{|c|}{ 'Zaozhong-6' } \\
\hline & AA & $\mathrm{MC}$ & $\mathrm{AA}$ & $\mathrm{MC}$ & AA & $\mathrm{MC}$ & AA & $\mathrm{MC}$ & AA & $\mathrm{MC}$ & $\mathrm{AA}$ & $\mathrm{MC}$ & AA & $\mathrm{MC}$ \\
\hline & $\%$ & $\%$ & $\%$ & $\%$ & $\%$ & $\%$ & $\%$ & $\%$ & $\%$ & $\%$ & $\%$ & $\%$ & $\%$ & $\%$ \\
\hline $\mathbf{0}$ & $0 \quad \mathrm{a}$ & $\begin{array}{ll}0 & \mathrm{a}\end{array}$ & 0 & 0 & 0 & $0 \quad \mathrm{a}$ & 0 & $0 \mathrm{a}$ & $0 \quad \mathrm{a}$ & $0 \quad \mathrm{a}$ & 0 & 0 & $0 \quad \mathrm{a}$ & $0 \quad \mathrm{a}$ \\
\hline 0.5 & $0.9 \mathrm{a}$ & $0 \quad \mathrm{a}$ & $11.1 \mathrm{~b}$ & $6.6 \mathrm{~b}$ & $11.1 \mathrm{a}$ & $8.4 \mathrm{a}$ & $4.9 \mathrm{ab}$ & $3.9 \mathrm{ab}$ & $0.5 \mathrm{a}$ & $0.6 \mathrm{ab}$ & $15.6 \mathrm{~b}$ & $10.5 \mathrm{~b}$ & $4.5 \mathrm{a}$ & $3.1 \mathrm{a}$ \\
\hline 1.0 & $5.3 \mathrm{~b}$ & $2.2 \mathrm{~b}$ & $12.2 \mathrm{~b}$ & $8.9 \mathrm{~b}$ & $7.1 \mathrm{a}$ & $5.3 \mathrm{a}$ & $12.2 \mathrm{~b}$ & $8.9 \mathrm{~b}$ & $0.5 \mathrm{a}$ & $0.6 \mathrm{ab}$ & $22.7 \mathrm{~b}$ & $14.5 \mathrm{~b}$ & $6.2 \mathrm{a}$ & $4.0 \mathrm{a}$ \\
\hline 1.5 & $5.3 \mathrm{~b}$ & $2.2 \mathrm{~b}$ & $16.7 \mathrm{~b}$ & $11.1 \mathrm{~b}$ & $11.6 \mathrm{a}$ & $7.6 \mathrm{a}$ & $9.9 \mathrm{~b}$ & $7.8 \mathrm{~b}$ & $6.6 \mathrm{~b}$ & $2.8 \mathrm{~b}$ & $38.9 \mathrm{c}$ & $26.1 \mathrm{c}$ & $6.6 \mathrm{a}$ & $4.0 \mathrm{a}$ \\
\hline$p$ valu & 0.012 & 0.041 & 0.001 & 0.004 & 0.196 & 0.221 & 0.015 & 0.017 & 0.001 & 0.191 & 0.001 & 0.001 & 0.256 & 0.304 \\
\hline
\end{tabular}

Within each column, values followed by different letters are significantly different among treatments (LSD test, $p \leq 0.05$ ). AA: androgenic anthers, MC: morphogenic calli 
In fact, anther culture is also employed to obtain somatic embryos or the regeneration of many woody plants. Those somatic calli and plants can also have high value in fruit trees breeding and propagation, since they can be used for protoplast fusion, genetic transformation, clonal propagation, synthetic seed production or germplasm storage (Germanà 2005; Germanà et al. 2011a, b).

\subsection{Conclusions}

In perennial woody species, like loquat, characterized by a long juvenile period, a high degree of heterozygosity, large size and self-incompatibility, homozygous plant production is not possible through conventional methods. Haploid technology is a highly promising method for increasing breeding efficiency, as completely homozygous plants can be generated in a single step (Germanà 2011a, b; Chiancone and Germanà 2016). However, a well-defined and efficient procedure of regeneration through in vitro anthers culture is still necessary.

In this experiment, the anther culture response was, as expected and previously reported in other fruit crops, highly genotype-dependent. Regarding the culture media tested, the 'NAA 1.5' gave the highest results in inducing the production of both AA and MC. Indeed, the increase in auxin concentration led, in general, to a greater callus formation. The appropriate concentration of plant growth regulators can strongly affect the anther culture response. Considering the influence of the genotype and of the medium composition, it will be necessary to enlarge the number of genotypes analyzed and to improve the experimental conditions. Further studies are, certainly, necessary to obtain organogenesis and embryo production. 


\title{
CHAPTER 5
}

\section{Induced mutagenesis using colchicine for polyploids production in loquat (Eriobotrya japonica (Thunb.) Lindl.), cultivars Cardona and Magdal}

\begin{abstract}
Plant breeding searchs for novel genetic combinations that allow to select varieties with improved traits that meet farmers and consumers demands. In loquat (Eriobotrya japonica (Thunb.) Lindl), induction of polyploidy have great interest for further production of larger and seedless fruits.

The success of a polyploidization procedure depends on many factors, such as type, concentration and time of exposure to the antimitotic agent plus type of explant used. Colchicine was the first anti-mitotic agent to be discovered and has been already used to induce polyploidy in a wide range of species. In this study we used colchicine aimed at obtaining tetraploid plants of loquat for further use in breeding.

The experiments consisted in applying colchicine $(0.5 \%)$ for 24 and $48 \mathrm{~h}$, on ungerminated seeds of loquat cultivars, 'Cardona' and 'Magdal'. Polyploidy levels were detected by flow cytometry. Soaking un-germinated seeds to a $0.5 \%(\mathrm{w} / \mathrm{v})$ colchicine solution for $48 \mathrm{~h}$ led to the production of one triploid and one tetraploid in 'Cardona', while applying the same concentration of this antimitotic agent for $24 \mathrm{~h}$ resulted in two triploids in 'Magdal' seeds. Results indicate that the induction of polyploidy by the antimitotic agent colchicine is a reliable method for obtaining poliploid genotypes in loquat species.
\end{abstract}

\section{Material and Methods}

\section{Plant Material}

Fruits from open-pollinated loquat trees, cvs 'Cardona' and 'Magdal', belong to the European loquat germplasm collection located at IVIA, Valencia, Spain (latitude: $37^{\circ}$ 
$45^{\prime} 31.5 \mathrm{~N}$; longitude: $1^{\circ} 01^{\prime} 35.1 \mathrm{O}$ ), were collected in early April. Seeds were carefully extracted and stored at $4{ }^{\circ} \mathrm{C}$.

\section{Seeds treatment}

Seeds were piled and surface-sterilized by immersion in a diluted commercial bleach solution $(4 \% \mathrm{w} / \mathrm{v}$ sodium hypochlorite) with $0.1 \%(\mathrm{v} / \mathrm{v})$ of Tween-20® for $5 \mathrm{~min}$, followed by rinses in distilled water. After sterilization, un-germinated seeds were directly treated by immersion in a $0.5 \%(\mathrm{w} / \mathrm{v})$ colchicine solution for $24 \mathrm{~h}$ and $48 \mathrm{~h}$ at room temperature (RT) in the dark. For each treatment and cultivar, a sample of 150 seeds was used. The experiments were repeated twice. Seeds soaked with distilled water were used as controls. Treated and control seeds were germinated in pots (250 cc) containing a mixture of peat and perlite (3:1). All plants were grown under natural photoperiod in greenhouse (Fig. 5.1).

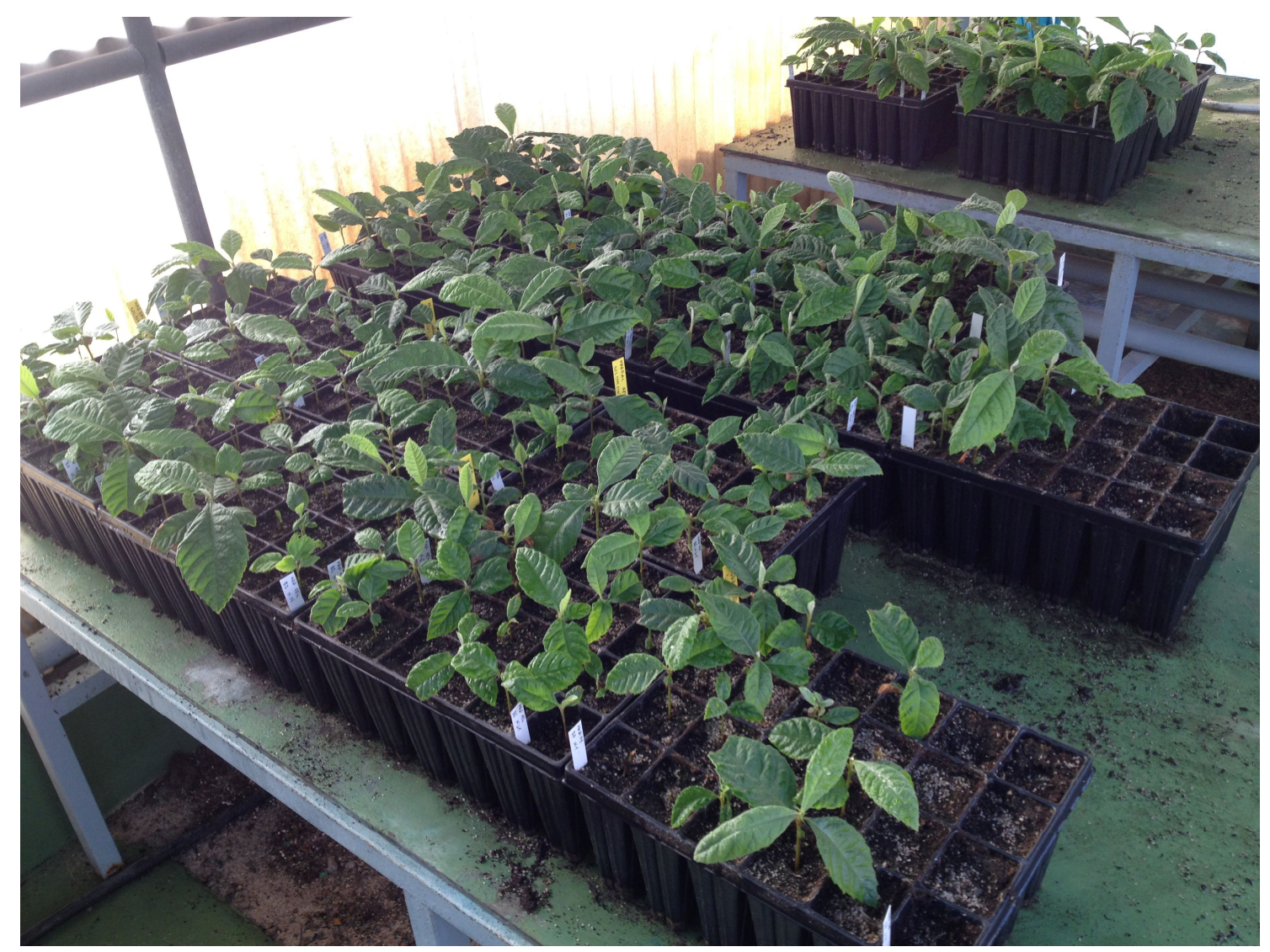

Fig. 5.1 Loquat seedlings growing in pots under natural photoperiod and greenhouse conditions 


\section{Determination of ploidy level}

DNA content was determined using a flow cytometer with fluorescence excitation provided by a mercury arc lamp (PA-II Ploidy Analyzer; Partec). Each sample was composed of a leaf-piece of the analyzed plant (approx $0.5 \mathrm{~mm}^{2}$ ) with a similar leafpiece from a diploid control plant. Samples were chopped on a $50 \mathrm{~mm}$ petri dish with a sharp razor blade in $1.0 \mathrm{~mL}$ of nuclei isolation buffer (Partec, Münster, Germany). Then samples were re-suspended, filtered through a $50 \mu \mathrm{m}$ nylon filter (Nybolt, Zürich, Switzerland) and $3.0 \mathrm{~mL}$ of fluorescent DNA staining (Partec, Münster, Germany) containing $1 \mathrm{mg} \mathrm{L}^{-1}$ of DAPI (4,6-diamino-2-phenyl-indole) were finally added. About 600 to 1200 nuclei per sample were measured. The plot of data on a semilogarithmic scale resulted in histograms with peaks from $2 \mathrm{C}$ to $50 \mathrm{C}$ evenly distributed along the abscise axe. Calibration was carried out using the $2 \mathrm{C}$-peak of nuclei of leaves from the diploids loquat (controls).

\section{Statical analysis}

Polyploid induction efficiency and survival rate of all colchicine treatments were evaluated for both genotypes, 'Cardona and 'Magdal'. Analysis of Variance (ANOVA, Tukey's test, $p<0.05$ ) was performed using the software Statgraphics Centurion XVI.I (Statistical Graphics Corporation, USA).

\section{Results and Discussion}

\section{Survival rate}

Two months after the colchicine treatment, seeds did not exhibit any significant difference in survival rate compared with control samples. Indeed, in the first experiment, the rate of treated germinated seeds ranged from $88 \%$ to $97.3 \%$ (Table 1 ), while in the second experiment ranged from $78.7 \%$ to $87.3 \%$ (Table 2 ), there were no significant differences compared with the control samples.

The highest 'lethality' was observed, in both experiments, in the cultivar Magdal, treated with $0.5 \%$ colchicine solution for $48 \mathrm{~h}$ (12\% and $20 \%$ respectively). Other authors described similar experiments on colchicine treated loquat seeds, they used 
different genotypes and colchicine dosis, being the survival rate significantly different depending on colchicine dose, genotype and time of exposure (Blasco et al. 2015a).

Table 5.1 Effect of colchicine treatment and time of exposure on loquat un-germinated seed (Exp. 1)

\begin{tabular}{|c|c|c|c|c|c|}
\hline $\begin{array}{l}\text { Colchicine } \\
\text { concentration }\end{array}$ & Genotype & $\begin{array}{l}\text { Time of } \\
\text { exposure }\end{array}$ & $\begin{array}{l}N^{\circ} \text { Treated } \\
\text { explant }\end{array}$ & $\begin{array}{l}N^{\circ} \text { Survival } \\
\text { explant (\%) }\end{array}$ & $\begin{array}{l}\mathrm{N}^{\circ} \text { Polyploids } \\
\text { identified }(\%)\end{array}$ \\
\hline \multirow{4}{*}{0 (Control) } & \multirow{2}{*}{ 'Cardona' } & $24 \mathrm{~h}$ & 24 & $21(87.5)$ & $0(0.0)$ \\
\hline & & $48 \mathrm{~h}$ & 24 & $22(91.7)$ & $0(0.0)$ \\
\hline & \multirow{2}{*}{ 'Magdal' } & $24 \mathrm{~h}$ & 24 & $21(87.5)$ & $0(0.0)$ \\
\hline & & $48 \mathrm{~h}$ & 24 & $20(83.3)$ & $0(0.0)$ \\
\hline \multirow{4}{*}{$0.5 \%$} & \multirow{2}{*}{ 'Cardona' } & $24 \mathrm{~h}$ & 150 & $138(92.0)$ & $0(0.0)$ \\
\hline & & $48 \mathrm{~h}$ & 150 & $146(97.3)$ & $0(0.0)$ \\
\hline & \multirow{2}{*}{ 'Magdal' } & $24 \mathrm{~h}$ & 150 & 139 (92.7) & $2(1.4) *$ \\
\hline & & $48 \mathrm{~h}$ & 150 & $132(88.0)$ & $0(0.0)$ \\
\hline
\end{tabular}

* Significantly different to the control (One way ANOVA, Tukey's test, $p<0.05$ )

The effect of colchicine in loquat observed in this study differs from the results obtained in other species. The concentration of colchicine $(0.5 \%)$ that we used, in both experiments, was higher than commonly doses used in other fruit crops, in which usually range between 0.02 and $0.1 \%$ (Dhooghe et al. 2011). In loquat, as already obtained in previous studies by Blasco et al. (2015a), the lethality resulted by $0.5 \%$ dose was lower than lethality observed in other species.

Table 5.2 Effect of colchicine treatment and time of exposure on loquat un-germinated seed (Exp. 2)

\begin{tabular}{|c|c|c|c|c|c|}
\hline $\begin{array}{l}\text { Colchicine } \\
\text { concentration }\end{array}$ & Genotype & $\begin{array}{l}\text { Time of } \\
\text { exposure }\end{array}$ & $\begin{array}{l}\mathrm{N}^{\circ} \text { Treated } \\
\text { explant }\end{array}$ & $\begin{array}{l}N^{\circ} \text { Survival } \\
\text { explant }(\%)\end{array}$ & $\begin{array}{l}\mathrm{N}^{\circ} \text { Polyploids } \\
\text { identified }(\%)\end{array}$ \\
\hline \multirow{4}{*}{0 (Control) } & \multirow{2}{*}{ 'Cardona' } & $24 \mathrm{~h}$ & 24 & $20(83.3)$ & $0(0.0)$ \\
\hline & & $48 \mathrm{~h}$ & 24 & $19(79.2)$ & $0(0.0)$ \\
\hline & \multirow{2}{*}{ 'Magdal' } & $24 \mathrm{~h}$ & 24 & $20(83.3)$ & $0(0.0)$ \\
\hline & & $48 \mathrm{~h}$ & 24 & $19(79.2)$ & $0(0.0)$ \\
\hline \multirow{4}{*}{$0.5 \%$} & \multirow{2}{*}{ 'Cardona' } & $24 \mathrm{~h}$ & 150 & $131(87.3)$ & $0(0.0)$ \\
\hline & & $48 \mathrm{~h}$ & 150 & $121(80.7)$ & $2(1.7) *$ \\
\hline & \multirow{2}{*}{ 'Magdal' } & $24 \mathrm{~h}$ & 150 & $122(81.3)$ & $0(0.0)$ \\
\hline & & $48 \mathrm{~h}$ & 150 & $120(80.0)$ & $0(0.0)$ \\
\hline
\end{tabular}

* Significantly different to the control (One way ANOVA, Tukey's test, $p<0.05$ ) 
It is well known that colchicine could have a highly toxic effect. High concentrations of this antimitotic agent are often associated with plant cell death, because of the block of the spindle fiber development and the alteration of the differentiation processes (Pintos et al. 2007). Nevertheless, a strong interaction between antimitotic agents and species is expected. Elyazid and El-Shereif (2014) stated that, in mandarin (Citrus reticulata Blanco) seeds, soaked in different concentrations of colchicine $(0.01,0.05,0.1$ and 0.2 $\%$ ) for different times of exposure $(12,24$ and $48 \mathrm{~h})$, the survival rate decreased by increasing colchicine concentration and time of exposure, showing the lowest percentage at $0.2 \%$ for $48 \mathrm{~h}$ and indicating that colchicine treatment at $0.1 \%$ for $48 \mathrm{~h}$ had the highest tetraploid induction efficiency. Rubuluza et al. (2007) observed a high polyploidy induction in un-germinated seeds of Colophospermum mopane exposed to equal concentration of colchicine $(0.1 \%$ for $48 \mathrm{~h})$, indicating that higher concentrations were toxic and lethal, while Udensi and Ontui (2013) reported that the germination rate of treated pigeon pea (Cajanus cajan L.) seeds decreased proportionately with the increase in soaking duration and colchicine concentration, but the percentage of survival seedling were not significantly affected.

\section{Flow cytometric analysis}

Three months after the colchicine treatments, when plants had unfolded 4 to 6 true leaves, one leaf per seedling and treatment was subjected to flow cytometry to quantify the DNA content and to detect the presence of polyploids plants. In the first experiment, from 555 seedlings analyzed, only two triploids were detected, both of them obtained in 'Magdal' with the $24 \mathrm{~h}$ treatment (Table 1). The relative fluorescence was 1.5 -fold higher $(\approx 52)$ in triploids when compared to diploid $(\approx 34)$ controls (Fig 5.2).

In the second experiment, on a total of 494 seedlings analyzed, one triploid and one tetraploid were detected, both of them obtained in 'Cardona' with the $48 \mathrm{~h}$ treatment (Table 2). The relative fluorescence was 1.5 -fold higher $(\approx 55)$ in the triploid and 2 -fold higher $(\approx 73)$ in the tetraploid seedling if compared to diploid $(\approx 35)$ controls (Fig. 5.3). Flow cytometry is the most efficient and precise method for determining the ploidy levels of large numbers of samples (Bohanec 2003). It is a quick and reproducible method and presents important advantages, e.g. samples are easily and rapidly prepared and only a few milligrams of tissue are needed (Ochatt 2008). 


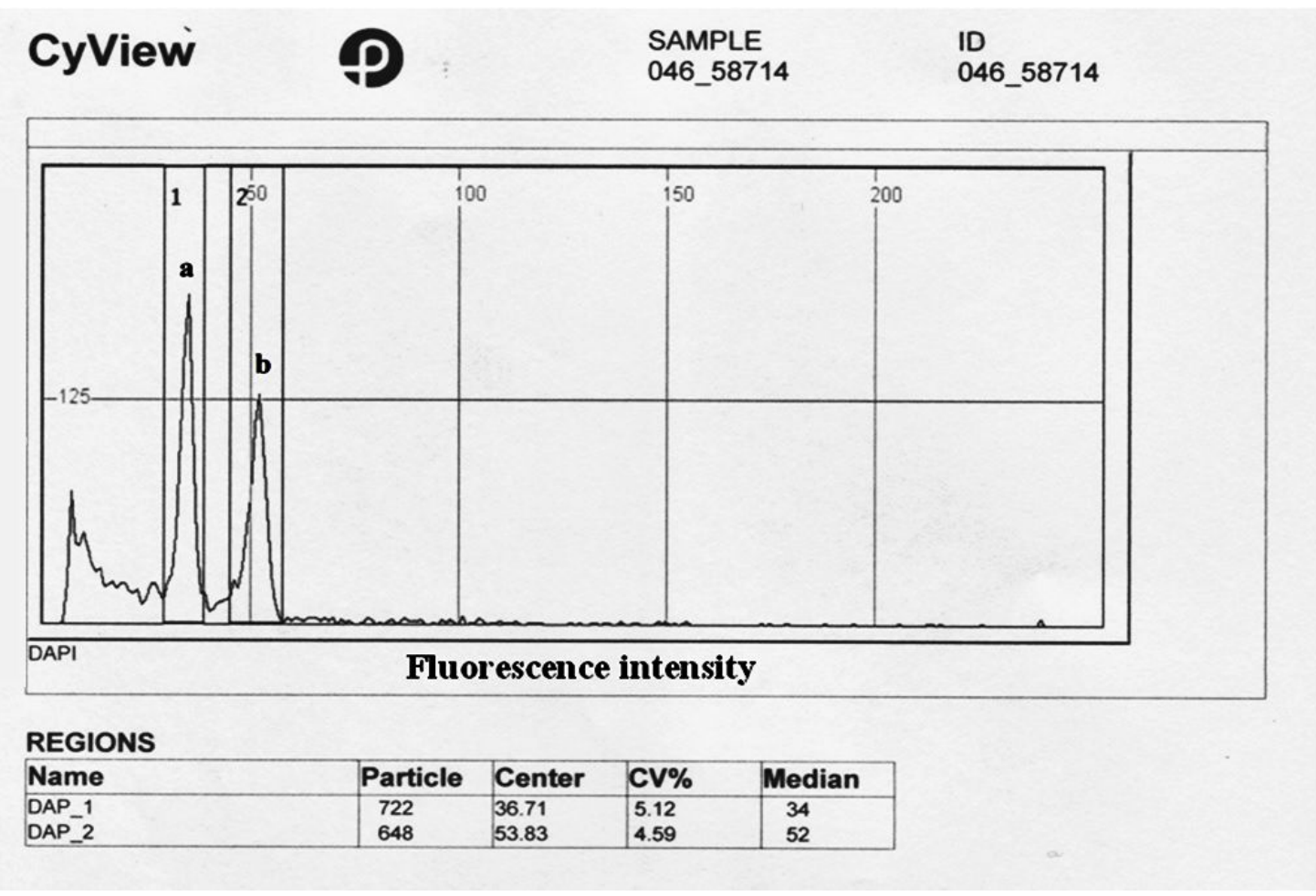

Fig. 5.2 Flow cytometry histogram of 'Magdal' plants obtained from un-germinated seeds treated with colchicine $(0.5 \%)$. a Diploid control plant $(2 x)$, b Triploid plant $(3 x)$

Regarding the artificial induction of polyploidy, previous experiments had been carried out in loquat. Yahata et al. (2004) obtained one tetraploid plant by either immersing germinated shoot tips from loquat seeds in a $0.2 \%$ colchicine solution for 14 days and with a $2 \%$ colchicine treatment for 4 days. Blasco et al. (2015a) conducted various in vitro studies, employing diverse concentration of colchicine (from 0.01 to $0.5 \%$ ), times of exposure (from $15 \mathrm{~min}$ to $48 \mathrm{~h}$ ), and different type of explants (shoot apex, whole plant or seeds). Early results (pre-screening) on whole plant and shoot apex treatments showed the achievement of a total of 59 'putative' polyploids but finally none of them results on a stable tetraploid plant, maybe due to the production of chimeras, a common effect of colchicine treatments (Tel-Zur et al. 2011). In addition, in meristem treatments only part of the cells or cell layers could result affected, and reversion to a diploid status would be expected (Väinölä 2000; Harbard et al. 2012). However, on un-germinated seed treated with colchicine $(0.5 \%)$, out of 8 putative polyploid obtained, two of them (25\%) have been confirmed to be triploid and another one $(12.5 \%)$ a tetraploid stable plant. Based on these results, in this study we decided to use un-germinated seeds as 
only type of explant and to perform the colchicine treatment at a concentration of $0.5 \%$ for $24 \mathrm{~h}$ and $48 \mathrm{~h}$.

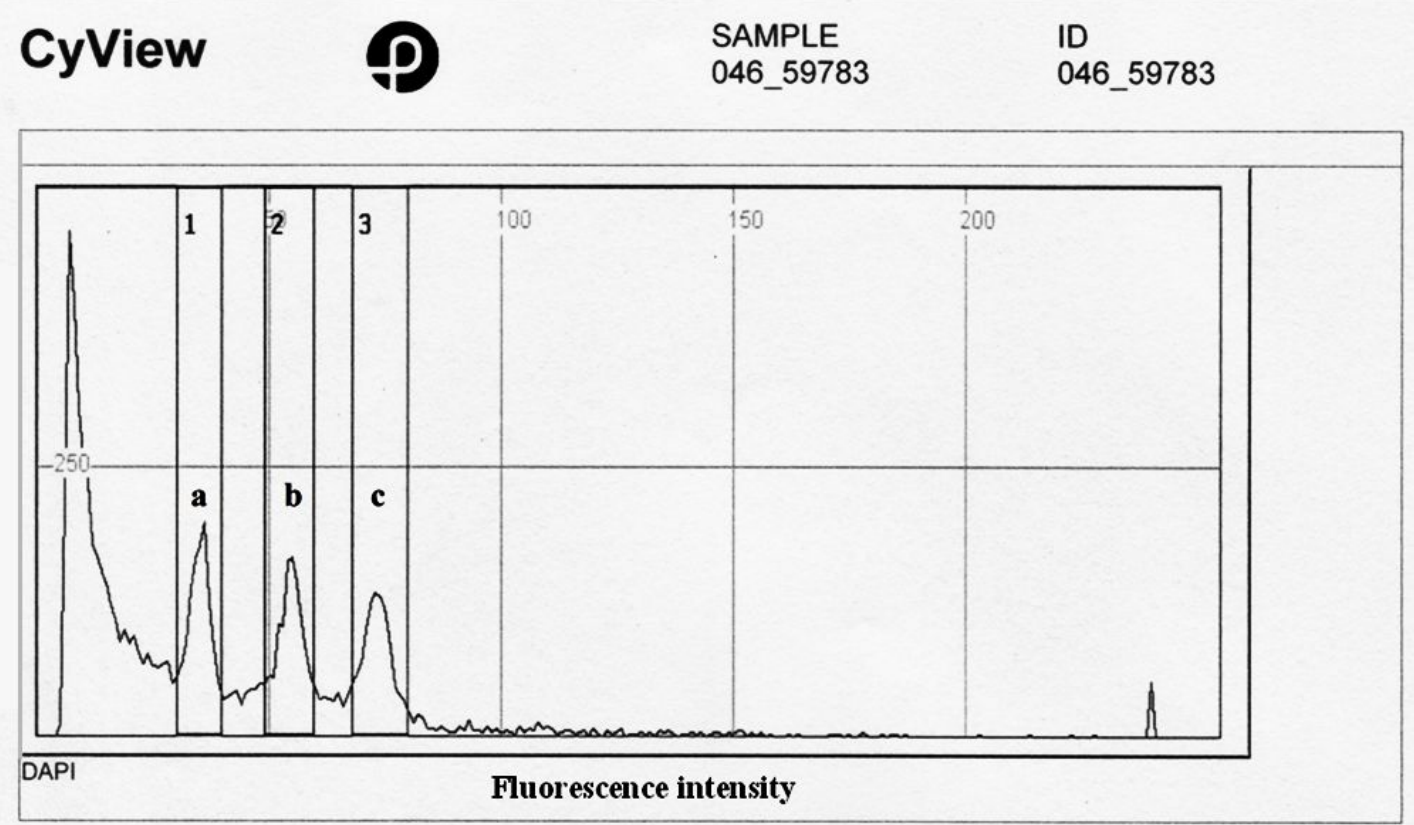

\section{REGIONS}

\begin{tabular}{|l|l|l|l|l|}
\hline Name & Particle & Center & CV\% & Median \\
\hline DAP_1 & 1103 & 37.19 & 6.51 & 35 \\
\hline DAP_2 & 1036 & 57.22 & 4.62 & 55 \\
\hline DAP_3 & 951 & 75.59 & 3.67 & 73 \\
\hline
\end{tabular}

Fig. 5.3 Flow cytometry histogram of 'Cardona' plants obtained from un-germinated seeds treated with colchicine (0.5\%). a Diploid control plant (2x), b Triploid plant (3x), $\mathbf{c}$ Tetraploid plant (4x)

A very important application of horticultural triploids is the achievement of seedless fruits, with great acceptance by the consumer. It is rather unusual to obtain triploids without the mediation of diplod $\times$ tetraploid crosses. Triploids have been recovered from interspecific crosses in different species (Hahn et al. 1990) or from selfing in the same species (Ollitrault et al. 2007). Moreover, natural spontaneous triploids may came from the union of a non-reduced (rarely caused by failures in chromosome reduction during meiosis) and one normally reduced gamete (Ramsey and Schemske 1998, Tate et al. 2005). In our case, triploids recovered from un-germinated seeds, treated with colchicine, were probably been originated during previous hybridization. Guo et al. (2007) proved a genotypic effect in diploid $\mathrm{x}$ diploid loquat crosses, in which the spontaneous triploid recovery rates was between $0.18 \%$ and $1.62 \%$. 
Polyploids generally show bigger leaves, flowers and fruit, larger stomatal density and higher number of chloroplasts (Stebbins 1950). Previous studies reported that, loquat tetraploid plant showed reduced plant height, higher number of internodes, shorter internodal distances and higher number of chloroplasts per stomata, when compared with diploid plants. Moreover, there were a significant reduction in stomatal frequency among diploid $\left(56.9 / \mathrm{mm}^{2}\right)$, triploid $\left(43.0 / \mathrm{mm}^{2}\right)$ and tetraploid $\left(35.7 / \mathrm{mm}^{2}\right)$ plants respectively (Blasco et al. 2015a).

\section{Conclusions}

Tetraploids can represent an advantage compared to diploids, increasing production and adaptability (Liu et al. 2009), disease resistance (Predieri 2001) or/and producing fruits of higher quality ( $\mathrm{Wu}$ et al. 2013). They can be also used to develop new triploid cultivars (Sedov 2014). Indeed, although recently induced polyploid forms have not yet reached the required market qualities, they certainly constitute valuable germplasm sources for their prospective application in fruit breeding programs. From the results obtained we can conclude that, the antimitotic agent colchicine can induce artificial tetraploids in loquat revealing a useful and reliable tool. Nevertheless, this method needs to increase the efficiency and further studies are necessary to increase the tetraploids achievement rate. The polyploid plants obtained in these experiments are currently growing at the IVIA loquat germplasm collection field. Their morphological, cytological and fertility characteristics will be investigated for their possible future use in loquat breeding programs. 


\section{DISCUSSION}

The present study was carried out through years 2014, 2015 and 2016 at the 'Università degli Studi di Palermo' (UNIPA) as well as at the 'Instituto Valenciano de Investigaciones Agrarias' (IVIA). The main objective of this thesis was to develop efficient protocols for ploidy manipulation in some Mediterranean fruit crops. Almond (Prunus dulcis Mill.), mandarin (Citrus reticulata Blanco) and loquat (Eriobotrya japonica (Thunb.) Lindl.) were the species selected for these experiments.

In woody species, genetic improvement through conventional methods is limited by many factors, such as long juvenile period, high heterozygosity, large size of the plants and sexual incompatibility (Germanà 2009). Development of molecular markers for assisted selection, genetic diversity studies, haploidization and new breeding techniques are providing new tools for breeding progress. For instance, in vitro anther or isolated microspore culture (gametic embryogenesis) and polypoid production (chromosome duplication) have become in many cases successful techniques for breeding (Maluszynski et al. 2003; Germanà 2011a, b; Sattler et al. 2016). Haploids (Hs) and double haploids (DHs), obtained through gametic embryogenesis, have a recognized useful potential use in fruit crop breeding. They can be used in mutation research, genetic analysis, plant transformation and production of homozygous genotypes. Nevertheless, the switch of microspores from their standard gametophytic pathway towards the sporophytic one is strongly affected by many factors, such as: genotype, gamete development stage, stress treatments, medium composition, donor plant growth situations and conditions of incubation (Germanà 2011a, b).

In this thesis, factors affecting haploid induction, in anther and microspore culture techniques, were studied. First, the identification of the most appropriate microspores development stage, for reprogramming their pathway towards gametic embryogenesis, was conducted in three selected species through 4',6-diamidino-2-phenylindole (DAPI) staining. The flower bud size and the petal length are very often used as external morphological indicators of the microspore stage. Results revealed that, the polarized uninucleated stage, considered the most responsive to induce gametic embryogenesis (Seguí-Simarro 2010; Soriano et al. 2013), corresponded to a flower bud length of 7 to 9 $\mathrm{mm}$ in almond, 4 to $4.5 \mathrm{~mm}$ in mandarin and 6 to $7.5 \mathrm{~mm}$ in loquat, being the range 
depended on the cultivar. These results allowed to establish a quick selection criteria of the pollen development stage, though, as mentioned before, there are many others factors affecting the embryogenic process.

In almond, with the aim of regenerating Hs or DHs through anther culture technique, two different experiments were carried out. In both experiments, DAPI staining and fluorescence microscopy observations, carried out one month after culture, revealed the presence of microspore with two identical nuclei, equal in size and chromatin condensation patterns, derived by a symmetrical nucleus division (SND). Symmetric division is considered one of the first signs of the beginning of the embryogenic program (Seguì-Simarro and Nuez 2008a). Later, these microspores underwent subsequent divisions and trinucleated microspores, as well as multinucleated structures, were detected, indicating that the induction of gametic embryogenesis occurred. Moreover, in the first experiment (Chapter 1), almond anthers showed calli formation and, for the first time to our knowledge, production of embryo was achieved through the direct embryogenesis route. The application of different cold or hot treatments to the anthers is commonly employed in many major crops for improving the embryogenic response. In this experiment, the hot thermal shock (H: $35 \pm 1{ }^{\circ} \mathrm{C}$ for 7 days) induced a higher production of calli in most of the genotypes tested (except 'Ferragnes') but not in a statistically significant way. However, results showed a significant effect of culture media (ANOVA, Tukey's test), indeed, only anthers cultured on ' $\mathrm{P}$ ' medium, in both thermal treatments applied, produced calli and embryos. The highest rate (30.4) of calli production was achieved in 'Filippo Ceo' with the H thermal treatments, while embryo production was achieved only in 'Filippo Ceo', 'Lauranne' and 'Genco', when anthers were directly cultured at $25 \pm 1{ }^{\circ} \mathrm{C}$, without additional thermal shock (except the common cold pre-treatment at $4{ }^{\circ} \mathrm{C}$ for one week). Nevertheless, anther culture responses to the culture media and the temperature treatments employed was, as expected and previously reported in other fruit crops, highly genotype-dependent. Microsatellite analyses were performed in the regenerants of the three cultivars producing embryos to discriminate between gametic and somatic origin of the embryos, confirming the gametic origin of the embryos.

In the second experiment (Chapter 2), we compared the responses to almond anther culture to four culture media supplemented with different 6-benzylaminopurine (BAP) 
concentrations $\left(0,1,1.5\right.$ and $\left.2.0 \mathrm{mg} \mathrm{L}^{-1}\right)$, using a cold pre-treatment $\left(4{ }^{\circ} \mathrm{C}\right.$ for 3 days) and a 'control' (no cold pre-treatment). The optimum temperature and duration of pretreatment vary among species (Germanà 2011b). In both cases, all genotypes tested showed anthers producing calli, but the cold pretreatment did not have any statistical significant effect (except in 'Planeta'). Different responses to cold pre-treatments can be explained by the role of the growth conditions of the mother plants, which resulted in differences in the physiological state of the anthers (Germanà 2011a), especially if the trees are cultivated under field conditions. Concerning the four culture media tested, a significant culture medium effect, related to the different BAP concentrations used, was observed. Indeed, calli production was achieved in all cultivars only when the media were supplemented with BAP, while no response (zero values) was observed when anthers were cultured on the basal medium. Nevertheless, no significant differences were detected between BAP doses (1, 1.5 and $\left.2.0 \mathrm{mg} \mathrm{L}^{-1}\right)$ applied, with the exception of 'Ferragnes' and 'Tarraco' in which, anthers cultured on the medium supplied with 1.0 $\mathrm{mg} \mathrm{L}^{-1}$ of BAP, without cold pretreatment, showed a significant higher percentage of calli production when compared with the other doses applied. The highest percentage (87.5) of calli corresponded to the cultivar Planeta cultured in 'BAP 1' medium without cold pre-treatment. Doubtless, the presence of an appropriate concentration of plant growth regulators in the medium plays a critical role in anther callus formation. Flow cytometry revealed that, the analyzed calli showed histograms of fluorescence intensity equal to those of the mother plant (used as diploid control), and, for this reason, they were considered diploids. Anther culture is often used to achieve embryos from the somatic tissue of the anther (Cardoso et al. 2016), since they can be employed for clonal propagation, synthetic seed production, protoplast fusion or genetic transformation (Germanà 2005; Germanà et al. 2011a, b).

Regarding the experiment carried out via isolated microspore culture in mandarin, 'Mandarino Tardivo di Ciaculli' (Chapter 3), the study was focused on the influence of culture media composition and incubation conditions. The experiment was repeated twice: in the first one, the flower buds were processed immediately after the collection, while in the second one, they were subjected to a cold pre-treatment ( $4{ }^{\circ} \mathrm{C}$ for 7 days) before microspore culturing. Four different liquid media (P, N6 and replacing $0.5 \mathrm{mg} \mathrm{L}-$ ${ }^{1}$ of BAP with $0.5 \mathrm{mg} \mathrm{L}^{-1}$ of meta-Topolin (mT) in both of them) and two thermal 
treatments $\left(26 \pm 1{ }^{\circ} \mathrm{C}\right.$ or $35^{\circ} \mathrm{C}$ for 30 days $)$ were tested. Different features indicated that, after ten months of culture, the isolated microspores changed their developmental program toward the sporophytic pathway. Indeed, for all the media tested, binucleated, multinucleated microspores and, for the first time in mandarin, calli and isolated microspore-derived embryos were detected. A significant effect of the thermal treatment was observed in the embryo production rate. Hot temperature treatment $\left(35^{\circ} \mathrm{C}\right.$ for 30 days) was essential for triggering pollen totipotency. On the other hand, no significant differences were observed among microspores immediately processed or subjected to the cold pre-treatment. The higher number of embryos per Petri dish was recorded in the ' $\mathrm{P}$ ' media, especially when supplemented with $\mathrm{mT}$, probably due to the anti-senescence and growth stimulation activities of this plant growth regulator. Results of the simple sequence repeat (SSR) loci analyses showed that, while the parental genotype was heterozygous, the allelic pattern of the embryo showed a single allele shared with the mother plant, confirming that the embryo originated from a haploid gametophyte.

In the fourth experiment (Chapter 4), anthers culture of seven loquat genotypes was carried out using four solid media, supplemented with different concentrations $(0,2.68$, 5.36 and $8 \mu \mathrm{M}$ ) of 1_naphtalene acetic acid (NAA). After one month of culture, some anthers already showed androgenic response starting to produce a white and friable callus. When transferred under cool white light, some callus started to turn its color from white to green, generating callus showing organized tissues. In this study, a significant effect of culture medium, related to the different NAA concentrations used, was observed. Indeed, calli production was achieved, in all cultivars tested, only when the media were supplemented with this auxin, being the response highly genotype dependent. Regarding the four media tested, no significant differences were detected in cultivars Magdal and Zaozhong-6, while the addition of NAA to the culture medium, induced a significant calli production in the rest of genotypes. The highest percentages (26.1) of MC was observed in 'Sanfilippara', using the medium supplied with $1.5 \mathrm{mg} \mathrm{L}^{\text {' }}$ ${ }^{1}(8 \mu \mathrm{M})$ of NAA, which had a very significant $(p \leq 0.001)$ effect compared with the rest of concentrations applied. Again, the addition of plant growth regulators in the culture medium affects strongly the microspore induction response. Ploidy analysis, carried out through flow cytometry, revealed that the showed histograms of fluorescence intensity equal to those of the parental plant, so they were considered diploids. 
The results obtained in this doctoral thesis represent a major advance in the research on gametic embryogenesis in woody species. This finding constitutes a crucial step in designing new protocols for regenerating microspore-derived embryos and plants, providing new opportunities for genetic improvement and for innovation in breeding methods. Further studies are, however, necessary to better understand the gametic embryogenesis process, to increase the rate of regenerant obtainment and to achieve their conversion into plantlets.

In addition, in the context of the breeding program carried out at the IVIA, another biotechnological tool, the chemical mutagenesis, was explored for implementing the program and increase the available diversity. Ploidy manipulation was investigated through the application of the antimitotic agent colchicine on un-germinated loquat seeds not obtaining any significant difference in survival rate, depending on the different colchicine exposure times.

Flow cytometry showed the presence of three triploids $(3 \mathrm{x})$ and one tetraploid $(4 \mathrm{x})$. As previously observed in banana (Rowe and Rosales 1993), watermelon (Ellul et al. 2007), citrus (Ollitrault et al. 2008) and also in loquat (Naval et al. 2014), triploidy generally lead to seedlessness. In loquat fruits, containing large seeds and with an edible proportion often lower than $70 \%$ (He et al. 2012), this achievement could result very promising. Nevertheless, since colchicine causes chromosomal duplication, in our case, the triploids recovered were probably been originated during the previous hybridization process by the non-reduction of one of the gametes of the parent plants. Guo et al. (2007) proved a genotypic effect in diploid x diploid loquat crosses, in which the spontaneous triploid recovery rates was between $0.18 \%$ and $1.62 \%$.

Tetraploids, as mentioned before, can represent an advantage compared to diploids, increasing production, resistance, fruit quality and, moreover, they can also be used to develop triploid cultivars. Breeding strategies involving crosses between different ploidy levels are very common. Some crop species, such as apple, have been improved by a complex chain of interspecific hybridizations and/or crosses between different ploidy levels (Sedov 2014). Furthermore, although recently induced polyploid forms have not yet reached the required market qualities, they certainly constitute valuable germplasm sources for their prospective application in fruit breeding programs. 
In conclusion, the artificial induction of polyploidy, applying colchicine, could become a reliable tool for breeding new loquat varieties. Nevertheless, this method is susceptible of improvement and further studies are necessary to increase the tetraploids achievement rate. 


\section{CONCLUSIONS}

I. Callogenesis and embryo production were achieved in different almond (Prunus dulcis Mill.) cultivars through in vitro anther culture technique. Simple sequence repeat (SSR) loci analysis revealed that the embryos had a single allele for each locus, indicating their homozygosity and gametic origins.

II. Homozygous embryo regeneration was obtained, for the first time, through isolated microspore culture technique, in mandarin (Citrus reticulata Blanco), 'Mandarino Tardivo di Ciaculli'.

III. Production of calli was achieved in different loquat (Eriobotrya japonica (Thunb.) Lind1.) cultivars through in vitro anther culture.

IV. Loquat polyploid plants, one tetraploid $(4 \mathrm{x})$ and three triploids $(3 \mathrm{x})$ were obtained from seeds of 'Cardona' and 'Magdal' using the mutagenic agent colchicine. The tetraploid has been incorporated to the IVIA plant material for further characterization and potential use in breeding. 



\section{REFERENCES}

Acanda Y, Martínez Ó, González MV, Prado MJ, Rey M (2015) Highly efficient in vitro tetraploid plant production via colchicine treatment using embryogenic suspension cultures in grapevine (Vitis vinifera cv. Mencía). Plant Cell Tiss Org 123(3):547-555

Acquaah G (2007) Principles of plant genetics and breeding Wiley-Blackwell, Malden

Ahuja MR and Jain SM (2015) Genetic Diversity and Erosion in Plants. ISO 690

Aleza P, Juárez J, Ollitrault P, Navarro L (2009a) Production of tetraploid plants of non apomictic citrus genotypes. Plant Cell Rep 28:1837-1846. Doi: 10.1007/s00299-009$0783-2$

Aleza P, Juarez J, Hernandez M, Pina JA, Ollitrault P, Navarro L (2009b) Recovery and characterization of a Citrus clementina Hort. ex Tan. 'Clemenules' haploid plant selected to establish the reference whole Citrus genome sequence. BMC Plant Biology, Vol. 9, pp 110

Aleza P, Cuenca C, Juarez J, Pina JA, Navarro L (2010) 'Garbi' mandarin: a new late maturing triploid hybrid. Hort Sci 45(1):139-141

Alonso JM, Ossama K, Gradziel TM (2012) Almond. In Badenes ML and Byrne DH (eds) Fruit breeding. Handbook of Plant Breeding. Springer, New York. pp 697-728

Andrus CF, Seshadri VS, Grimball PC (1971) Production of seedless watermelons (Vol. 1424). US Agricultural Research Service

Aremu AO, Bairu MW, Doležal K, Finnie JF, Van Staden J (2012) Topolins: a panacea to plant tissue culture challenges? Plant Cell Tiss Org 108(1):1-16

Badenes ML, Lin S, Yang X, Liu C, Huang X (2009) Loquat (Eriobotrya japonica Lind1.). In Genetics and Genomics of Rosaceae, Springer New York. pp 525-538

Badenes ML, Janick J, Lin S, Zhang Z, Liang GL, Wang W (2013) Breeding loquat. In: Janick J (ed) Plant Breeding Reviews, Volume 37, John Wiley \& Sons, Inc., Hoboken, NJ, USA. pp 259-296

Baenziger PS, Russell WK, Graef GL, Campbell BT (2006) Improving lives: 50 years of crop breeding, genetics, and cytology (C-1). Crop Sci 46:2230-2244

Barkley NA, Roose ML, Krueger RR, Federici CT (2006) Assessing genetic diversity and population structure in a citrus germplasm collection utilizing simple sequence repeat markers (SSRs). Theor. Appl. Genet. 112:1519-1531

Bartolozzi F, Warburton ML, Arulsekar S, Gradziel TM (1998) Genetic characterization and relatedness among California almond cultivars and breeding lines detected by 
randomly amplified polymorphic DNA (RAPD) analysis. J. Amer. Soc. Hort. Sci. $123: 381-387$

Bhat JG and Murthy HN (2007) Factors affecting in-vitro gynogenic haploid production in niger (Guizotia abyssinica (L. f.) Cass.). Plant Growth Regulation 52(3):241-248

Binarova P, Hause G, Cenklová V, Cordewener JH, Campagne ML (1997) A short severe heat shock is required to induce embryogenesis in late bicellular pollen of Brassica napus L. Sex Plant Reprod 10:200-208

Blakeslee AF, Belling J, Farnham ME, Bergner AD (1922) A haploid mutant in the Jimson weed, Datura stramonium. Science, Vol. 55:646-647

Blakeslee AF, Avery AG (1937) Methods of inducing chromosome doubling in plants by treatment with colchicine. Science $86: 408$

Blasco M, Naval MM, Zuriaga E, Badenes ML (2014) Genetic variation and diversity among loquat accessions. Tree Genetics \& Genomes. Doi:10.1007/s11295-014-0768-3

Blasco M, Badenes ML, Naval MM (2015a) Colchicine-induced polyploidy in loquat (Eriobotrya japonica (Thunb.) Lindl.). Plant Cell Tiss Org. Doi:10.1007/s11240-0140612-3

Blasco M, Badenes ML, Naval MM (2015b) Embryogenic response from anther culture of cultivars of loquat (Eriobotrya japonica (Thunb.) Lindl.) from different origins. Euphytica, 205(2):337-348

Bohanec B (2003) Ploidy determination using flow cytometry. In: Maluszynski M, Kasha KJ, Forster BP, Szarejko I (eds) Doubled Haploid Production in Crop Plants: A Manual. Kluwer Academic Publishers. pp 397-403

Bohanec B (2009) Doubled Haploids via Gynogenesis. In: Advances in Haploid Production in Higher Plants, Touraev A, Forster BP, Jain SM, Springer Science Business Media B.V. pp 35-46

Bouvier L, Zhang YX, Lespinasse Y (1993) Two methods of haploidization in pear, Pyrus communis L.: greenhouse seedling selection and in situ parthenogenesis induced by irradiated pollen. Theoretical and Applied Genetics, Vol. 87, No. 1-2:229-232

Bowman KD (2000) New hybrid citrus rootstocks developed by US Department of Agriculture. In Proc. Intl. Soc. Citricult. IX Congr. pp 51

Broertjes C (1976) Mutation breeding of autotetraploid Achimenes cultivars. Euphytica 25:297-304

Byrne DH (2012) Trends in fruit breeding. In Badenes ML and Byrne DH (eds) Fruit breeding. Handbook of Plant Breeding. Springer, New York. pp 3-36 
Cai LH, Yan FH, Luo ZR, Huang HW (2007) Allozyme análisis of interspecific relationships and cultivar identification in Eriobotrya. Acta Hort 750:215-220

Cao H, Kumar Biswas M, Lu Y, Hamdy Amar M, Tong Z, Xu Q (2011) Doubled haploid callus lines of Valencia sweet orange recovered from anther culture. Plant Cell Tiss Org 104:415-423

Cañete ML, Pinillos V, Cuevas J, Hueso JJ (2007) Sensory evaluation of the main loquat cultivars in Spain. Acta Hort 750:159-164

Cardone S, Pérez G, Picca A (2010) Polinización y fertilización in vitro. En: Levitus G, Echenique V, Rubinstein C, Hopp E, Mroginski L (eds) Biotecnología y Mejoramiento Vegetal II. Instituto Nacional de Tecnología Agropecuaria. Argentina. pp 185-196

Cardoso JC, Martinelli AP, Germanà MA, Latado RR (2014) In vitro anther culture of sweet orange (Citrus sinensis L. Osbeck) genotypes and of a C. clementina $\times$ C. sinensis 'Hamlin' hybrid. Plant Cell Tiss Org 117(3):455-464

Cardoso JC, Abdelgalel AM, Chiancone B, Latado RR, Lain O, Testolin R, Germanà MA (2016) Gametic and somatic embryogenesis through in vitro anther culture of different Citrus genotypes. Plant Biosyst 150:304-312. Doi: $10.1080 / 11263504.2014 .987847$

Carrera L, Sanzul J, Herrero M, Hormaza JI (2009) Genomic characterization of selfincompatibility ribonucleases (S-RNases) in loquat (Eriobotrya japonica Lindl.) (Rosaceae, Pyrinae). Molecular breeding, 23(4):539-551

Channuntapipat C, Wirthensohn M, Ramesh SA, Batlle I, Arús P, Sedgley M, Collins G (2003) Identification of incompatibility genotypes in almond (Prunus dulcis Mill.) using specific primers based on the introns of the $S$-alleles. Plant Breeding 122:164-168. Doi: 10.1046/j.1439-0523.2003.00842.x

Chen C, Lyon MT, O’Malley D, Federici CT, Gmitter J, Grosser JW, Chaparro JX, Roose ML, Gmitter FGJ (2008) Origin and frequency of 2 n gametes in Citrus sinensis $\times$ Poncirus trifoliata and their reciprocal crosses. Plant Sci 174:1-8

Chen L, Lou Q, Zhuang Y, Chen J, Zhang X, Wolukau JN (2007) Cytological diploidization and rapid genome changes of the newly synthesized allotetraploids Cucumis $\times$ hytivus. Planta 225:603-614

Chen Z (1986) Induction of androgenesis in woody plants. In: $\mathrm{Hu} \mathrm{H}$, Yang $\mathrm{H}$ (eds) Haploids of Higher Plants In Vitro, Springer-Verlag, Berlin, pp 42-66

Chen Z (2010) Molecular mechanisms of polyploidy and hybrid vigor. Trends in plant science 15:57-71

Chen Z, Wang H, Liao H (1980) The induction of Citrus pollen plants in artificial media. Acta Gen Sin 7:189-192 
Chen JF, Cui L, Malik AA, Mbira KG (2011) In vitro haploid and dihaploid production via unfertilized ovule culture. Plant Cell Tiss Org 104(3):311-319

Chhuneja P, Kaur S, Goel RK, Aghaee-Sarbarzeh M, Dhaliwal HS (2007) Introgression of leaf rust and stripe rust resistance genes from Aegilops umbellulata to hexaploid wheat through induced homoeologous pairing. In: Buck HT, Nisi JE, Salomón N (eds) Wheat production in stressed environments. Springer, Netherlands. pp 83-90

Chiancone $\mathrm{B}$ and Germanà $\mathrm{M}$ (2016) Microspore embryogenesis through anther culture in Citrus clementina Hort. ex Tan. In: Germanà MA, Lambardi M (eds) In Vitro Embryogenesis In Higher Plants. Methods in Molecular Biology, Springer-Humana Press pp 475-487

Chiancone B, Karasawa MMG, Gianguzzi V, Abdelgalel AM, Bárány I, Testillano PS, Germanà MA (2015) Early embryo achievement through isolated microspore culture in Citrus clementina Hort. ex Tan., cvs. 'Monreal Rosso' and 'Nules'. Frontiers in Plant Science 6:413. Doi: 10.3389/fpls.2015.00413

Chu C (1978) The N6 medium and its applications to anther culture of cereal crops. In: Proceedings of Symposium on Plant Tissue Culture. Science Press, Peking, pp 43-50

Cimò G, Marchese A, Germanà MA (2016) Microspore embryogenesis induced through in vitro anther culture of almond (Prunus dulcis Mill.). Plant Cell Tiss Org 128(1):8595. Doi: $10.1007 / \mathrm{s} 11240-016-1086-2$

Clarkson JJ, Lim KY, Kovarik A, Chase MW, Knapp S, Leitch AR (2005) Long term genome diploidization in allopolyploid Nicotiana section Repandae (Solanaceae). New phytologist 168:241-252

Collard BC, Mackill DJ (2008) Marker-assisted selection: an approach for precision plant breeding in the twenty-first century. Philosophical Transactions of the Royal Society B: Biological Sciences, 363(1491):557-572

Comai L (2005) The advantages and disadvantages of being polyploid. Nature Reviews Genetics 6(11):836-846

Contreras RN, Ruter JM, Schwartz BM (2010) Oryzalin-induced tetraploidy in Cryptomeria japonica (Cupressaceae). Hort Sci 45(2):316-319

Cooper WC, Reece PC, Furr JR (1962) Citrus breeding in Florida - past, present and future. In Proc Florida State Hort Soc 75:5-13

Crisson LJR and Visser L (2014) Using genetic resources: Rules for international exchange. ISO 690

Cuenca J, Aleza P, Juárez J, Pina JA, Navarro L (2010) 'Safor' mandarin: a new citrus mid-late triploid hybrid. Hort Sci 45(6):977-980 
Cuevas J, Romero IM, Fernández MD, Hueso JJ (2007) Deficit irrigation schedules to promote early flowering in 'Algerie' loquat. Acta Hort 750:281-286

Custers JB, Cordewener JH, Nöllen Y, Dons HJ, Campagne MMVL (1994) Temperature controls both gametophytic and sporophytic development in microspore cultures of Brassica napus. Plant Cell Rep 133:267-271

Da Camara Machado A, Puschmann M, Puhringer H, Kremen R, Katinger H, Da Camara Machado ML (1995) Somatic embryogenesis of Prunus subhirtella autumno rosa and regeneration of transgenic plants after Agrobacterium-mediated transformation. Plant Cell Rep 14:335-340

Datta SK (2005) Androgenic haploids: factors controlling development and its application in crop improvement. Curr Sci 89:1870-1878

De March G, Grenier E, Miannay N, Sulmont G, David H, David A (1993) Potential of somatic embryogenesis in Prunus avium immature zygotic embryos. Plant Cell Tiss Org $34: 209-21$

De Vienne D (2003) Molecular markers in plant genetics and biotechnology. Science Publishers, Inc. Enfield, NH

De Wet JMJ (1980) Origins of polyploids. In: Lewis WH (ed) Polyploidy biological relevance. Plenum Press, New York. pp 3-7

Deng XX, Deng ZA, Xiao SY, Zhang WC (1992) Pollen derived plantlets from anther culture of Ichang papeda hybrids No.14 and trifoliate orange. In: Proceedings of the International Society of Citriculture, Acireale, Italy. pp 190-192

Dermen H (1954) Colchiploidy in grapes. J Hered 45:159-172

Dermen H (1965) Colchiploidy and histological imbalance in triploid apple and pear. American Journal of Botany. pp 353-359

Dewey DR (1980) Some applications and misapplications of induced polyploidy to plant breeding. In: Lewis WH (eds) Polyploidy: biological relevance. Plenum Press, New York. pp 445-470

Dhawan O, Lavania U (1996) Enhancing the productivity of secondary metabolites via induced polyploidy: a review. Euphytica 87:81-89

Dhooghe E, Van Laere K, Eeckhaut T, Leus L, Van Huylenbroeck J (2011) Mitotic chromosome doubling of plants tissue in vitro. Plant Cell Tiss Org 104:359-373. Doi: 10.1007/s11240-010-9786-5

Dirlewanger E, Cosson P, Tavaud M, Aranzana MJ, Poizat C, Zanetto A, Arús P, Laigret R (2002) Development of microsatellite markers in peach [Prunus persica (L.) 
Batsch] and their use in genetic diversity analysis in peach and sweet cherry (Prunus avium L.). Theor Appl Genet 105:127-138. Doi: 10.1007/s00122-002-0867-7

Dolešel J, Greilhuber J, Suda J (2007) Flow Cytometry with Plant Cells: Analysis of Genes, Chromosomes and Genomes. Chem. Listy, 101:923

Doyle JJ and Doyle JL (1987) A rapid DNA isolation procedure for small quantities of fresh leaf tissue. Phytochem Bull 19:11-15

Druart P (1981) Embryogenese somatique et obtention de plantules chez Prunus incisa x serrula (GM9) cultivé in vitro. Bull Rech Agron Gembloux 16:205-220

Druart P (1990) Improvement of the somatic embryogenesis of the cherry dwarf rootstock INMIL/GM9 by the use of different sugars. Acta Hort 280:125-129

Dunwell JM (2009) Patents and haploid plants. In: Touraev A, Forster BP, Jain SM (eds) Advances in haploid production in higher plants. Springer, Heidelberg. pp 97-113

Dunwell JM (2010) Haploids in flowering plants: origins and exploitation. Plant Biotechnol J 8:377-424. Doi: 10.1111/j.1467-7652.2009.00498.x

Eder J, Chalyk S (2002) In vivo haploid induction in maize. Theor Appl Genet 104:703708

Einset J and Imhofe B (1951) Chromosome numbers of apple varieties and sports, 3. Proc Am Soc Hort Sci 58:103-108

Einset J (1959) Spontaneous polyploidy in cultivated apples. Proc Am Soc Hort Soc 59:291-302

Ellul P, Lelivelt C, Naval MM, Noguera FJ, Sanchez S, Atarés A, Dirks R (2007) Watermelon. World, 3(26,454):91-790

Elyazid DMA and El-Shereif AR (2014) In vitro induction of polyploidy in Citrus reticulata Blanco. American Journal of Plant Sciences 5(11):1679-1685

Esteves P, Clermont I, Marchand S, Belzile F (2014) Improving the efficiency of isolated microspore culture in six-row spring barley: II-exploring novel growth regulators to maximize embryogenesis and reduce albinism. Plant Cell Rep 33:871-879. Doi: $10.1007 / \mathrm{s} 00299-014-1563-1$

Evans DA, Sharp WR, Medina-Filho HP (1984) Somaclonal and gametoclonal variation. Am J Bot 71:759-774

Everson RE, Golin D (2003) Assessing the impact of the Green Revolution, 1960 to 2000. Science 300:758-762

FAOSTAT (2014) http://faostat3.fao.org 
Fatokun CA (2002) Breeding cowpea for resistance to insect and pests: attempted crosses between cowpea and Vigna vexillata. In: Fatokun CA, Tarawali SA, Singh BB, Kormawa PM, Tamo M (eds) Challenges and opportunities for enhancing sustainable cowpea production. IITA, Ibadan. pp 52-61

Felipe AJ and Socias i Company R (1987) 'Aylés', 'Guara', and 'Moncayo' almonds. Hort Sci 22:961-962

Ferrie AMR (2009) Current status of doubled haploids in medicinal plants. In: Touraev A, Forster BP, Jain SM (eds) Advances in haploid production in higher plants. Springer, Heidelberg. pp 209-217

Ferrie AMR and Caswell KL (2011) Isolated microspore culture techniques and recent progress for haploid and doubled haploid plant production. Plant Cell Tiss Org 104:301309. Doi: 10.1007/s11240-010-9800-y

Forner JB, Forner-Giner MA, Alcaide A (2003) Forner-Alcaide 5 and Forner-Alcaide 13: Two new citrus rootstocks released in Spain. 38:629-630

Forster BP, Thomas WTB (2005) Doubled haploids in genetics and plant breeding. Plant Breed Rev 25:57-88

Forster BP, Herberle-Bors E, Kasha KJ, Touraev A (2007a) The resurgence of haploids in higher plants. Trends Plant Sci 12:368-375. Doi: 10.1016/j.tplants.2007.06.007

Forster BP, Tuvesson S, Weyen J (2007b) Foreword: gametic cells and molecular breeding for crop improvement. Euphytica 158:273-274

Froelicher Y, Bassene JB, Jedidi-Neji E, Dambier D, Morillon R, Bernardini G,Costantino G, Ollitrault P (2007) Induced parthenogenesis in mandarin for haploid production: induction procedures and genetic analysis of plantlets. Plant Cell Reports, Vol. 26, No. 7, pp 937-944

Froelicher Y, Dambier D, Bassene JB, Costantino G, Lotfy S, Didout C, Beaumont V, Brottier P, Risterucci AM, Luro F, Ollitrault P (2008) Characterization of microsatellite markers in mandarin orange (Citrus reticulata Blanco). Mol Ecol Resour 8:119-122

Frost HB (1935) Four new citrus varieties: the Kara, Kinnow, and Wilking mandarins and the Trovita orange (No. 04; USDA, FOLLETO 1698)

Garin E, Grenier E, Grenier-De March G (1997) Somatic embryogenesis in wild cherry (Prunus avium). Plant Cell Tiss Org 48:83-91

George L, Rao PS (1982) In vitro induction of pollen embryos and plantlets in Brassica juncea. Plant Sci Lett 26:111-116 
Germanà MA (2003) Haploids and doubled haploids in Citrus ssp. In: Maluszynski M, Kasha KJ, Forster BP, Szarejko I (eds) Doubled haploid production in crop plants: a manual. Kluwer Academic Publishers, Dordrecht, The Netherlands, pp 303-307

Germanà MA (2005) Protocol of somatic embryogenesis from Citrus spp. anther culture. In: Jain SM, Gupta PK (eds) Protocol of somatic embryogenesis in woody plants. Kluwer, Dordrecht, pp 191-207

Germanà MA (2006) Doubled haploid production in fruit crops. Plant Cell Tiss Org 86:131-146. Doi: 10.1007/s11240-006-9088-0

Germanà MA (2007) Haploidy. Citrus genetics, breeding and biotechnology. pp 167

Germanà MA (2009) Haploids and doubled haploids in fruit trees. In: Advances in Haploid Production in Higher Plants. Springer Netherlands. pp 241-263

Germanà MA (2011a). Anther culture for haploid and doubled haploid production. Plant Cell Tiss Org 104:283-300. Doi: 10.1007/s11240-010-9852-z

Germanà MA (2011b) Gametic embryogenesis and haploid technology as valuable support to plant breeding. Plant Cell Rep 30:839-857. Doi: 10.1007/s00299-011-1061-7

Germanà MA (2012) Use of irradiated pollen to induce Parthenogenesis and haploid production in fruit crops. In: Shu QY, Forster BP, Nakagawa H (eds) Plant Mutation Breeding and Biotechnology. CABI Publishing. pp 411-421

Germanà MA and Chiancone B (2001) Gynogenetic haploids of Citrus after in vitro pollination with triploid pollen grains. Plant Cell Tiss Org 66:59-66

Germanà MA and Chiancone B (2003) Improvement of Citrus clementina Hort. ex Tan. microspore-derived embryoid induction and regeneration. Plant cell reports 22(3):181187. Doi:10.1007/s00299-003-0669-7

Germanà MA, Aleza P, Carrera E, Chen C, Chiancone B, Costantino G, Guo W (2013) Cytological and molecular characterization of three gametoclones of Citrus clementina. BMC Plant Biol 13:129

Germanà MA, Chiancone B, Lain O, Testolin R (2005) Anther culture in Citrus clementina: a way to regenerate tri-haploids. Aust J Agr Res 56(8):839-845. Doi: 10.1071/AR05025

Germanà MA, Crescimanno FG, De Pasquale F, Wang YY (1991) Androgenesis in 5 cultivars of Citrus limon L. Burm. f. Acta Hort 300:315-324

Germanà MA, Crescimanno FG, Motisi A (2000) Factors affecting androgenesis in Citrus clementina Hort. ex Tan. Hort Sci 14: 43-51 
Germanà MA and Reforgiato G (1997) Haploid embryos regeneration from anther culture of 'Mapo' tangelo (Citrus deliciosa $\times$ C. paradisi). Adv Hort Sci 11:147-152

Germanà MA, Scarano MT, Crescimanno FG (1996) First results on isolated microspore culture of Citrus. Proc Int Soc Citriculture 2:882-885

Germanà MA, Wang YY, Barbagallo MG, Iannolino G, Crescimanno FG (1994) Recovery of haploid and diploid plantlets from anther culture of Citrus clementina Hort. ex Tan. and Citrus reticulata Blanco. J Hort Sci 69:473-480

Gisbert AD, Besoain X, Llácer G, Badenes ML (2006) Protección del cultivo II: enfermedades. En: Agustí M, Reig C, Undurraga P (eds). El cultivo del níspero japonés. UPV-UPCV de Chile. pp 227-250

Gisbert AD, Reig C, Martínez-Calvo J, Gariglio N, Badenes ML, Agustí M, Llácer G (2007a) Frutales menores. El níspero japonés como ejemplo: situación actual, problemas y perspectivas. Acta Hort 48:624-630

Gisbert AD, Guillem A, Martínez-Calvo J, Llácer G, Badenes, ML (2007b) Contribution of biotechnology in genetic studies and breeding of loquat at IVIA, Spain. Acta Hort 750:93-96

Gisbert AD, Romero C, Martínez-Calvo JM, Leida C, Llácer G, Badenes ML (2009) Genetic diversity evaluation of a loquat (Eriobotrya japonica (Thunb) Lindl) germplasm collection by SSRs and S-allele fragments. Euphytica 168(1):121-134. Doi: $10.1007 / \mathrm{s} 10681-009-9901-\mathrm{z}$

Godini A (2002) Almond fruitfulness and role of self-fertility. Acta Hort 591:191-203

Gradziel TM, Dicenta F, Kester DE (2001a) The utilization of related almond species for almond variety improvement. J. Amer. Pomol. Soc. 55:100-108

Gradziel TM, Martínez-Gómez P, Dandekar AM (2001b) The use of S-allele specific PCR analysis to improve breeding efficiency for self-fertility in almond. Hort Sci $36: 440-440$

Gradziel TM (2003) Interspecifi c hybridizations and subsequent gene introgression within Prunus subgenus Amygdalus. Acta Hort 622: 249-255

Gradziel TM (2008) Almond (Prunus dulcis). In: M. Priyadarshan and S.M. Jain (eds). Breeding of plantation crops. Springer Sci. Publ. Berlin. pp 1-33

Gradziel TM (2009) Almond (Prunus dulcis) breeding. In Breeding plantation tree crops: temperate species Springer New York. pp 1-31

Grant-Downton RT and Dickinson HG (2006) Epigenetics and its implications for plant biology 2. The 'Epigenetic Epiphany' epigenetics, evolution and beyond. Ann Bot 97:11-27 
Grosser JW, Mourao-Fo FAA, Gmitter JFG, Louzada ES, Jiang J, Baergen K, Quiros A, Cabasson C, Schell JL, Chandler JL (1996). Allotetraploid hybrids between citrus and seven related genera producted by somatic hybridization. Theor. Appl. Genet. 92:577582

Grosser JW, Ollitrault P, Olivares-Fuster O (2000) Somatic hybridization in Citrus: an effective tool to facilitate cultivar improvement. In Vitro Cellular and Development Biology - Plant 36:434-449

Gu XF, Yang AF, Meng H, Zhang JR (2005) In vitro induction of tetraploid plants from diploid Zizyphus jujuba Mill. cv. Zhanhua. Plant cell reports 24(11):671-676

Guha S and Maheshwari SC (1964) In vitro production of embryos from anthers of Datura. Nature, Vol. 204, No. 4957, pp 497

Guha S and Maheshwari SC (1966) Cell division and differentiation of embryos in the pollen grains of Datura in vitro. Nature 212:97-98

Guo QG, Li XL, Wang WX, He Q, Liang GL (2007) Occurrence of natural triploids in loquat. Proceedings of the second international Symposium on Loquat. ISBN 978-9066055-40-7, Guangzhou, China. pp 128-128

GutieÁrrez-Pesce P, Taylor K, Muleo R, Rugini E (1998) Somatic embryogenesis and shoot regeneration from transgenic roots of the cherry rootstock Colt (Prunus avium $\mathrm{x}$ P. pseudocreasus ) mediated by pRi 1855 T-DNA of Agrobacterium rhizogenes. Plant Cell Rep 17:574-580

Hahn SK, Bai KV, Asiedu R (1990) Tetraploids, triploids and 2n pollen from diploid interspecific crosses with cassava. Theor Appl Genet 79:433-439. Doi: $10.1007 /$ BF00226148

Hammerschlag FA, Bauchan G, Scorza R (1985) Regeneration of peach from callus derived from immature embryos. Theor Appl Genet 70:248-251

Harbard JL, Griffin AR, Foster S, Brooker C, Kha LD, Koutoulis A (2012) Production of colchicine induced autotetraploids as a basis for sterility breeding in A. mangium Willd. Forestry 85:427-36. Doi: 10.1093/forestry/cps041

Harlan JR (1992) Crops and Man. American Society of Agronomy and Crop Science Society of America, Madison, WI

Hartung F and Schiemann J (2014) Precise plant breeding using new genome editing techniques: opportunities, safety and regulation in the EU. The Plant Journal 78(5):742752

Hawkes JG, Maxted N, Ford-Lloyd BV (2012) The ex situ conservation of plant genetic resources. Springer Science \& Business Media. ISO 690 
Hayward MD, Bosemark NO, Romagosa T (2012) Plant breeding: principles and prospects. Springer Science \& Business Media

Hazarika RR, Mishra VK, Chaturvedi R (2013) In Vitro Haploid Production - A Fast and Reliable Approach for Crop Improvement. In Crop Improvement Under Adverse Conditions. Springer New York. pp 171-212

He XL, Lin SQ, Yang XH, Hu YL, Hu GB, Bu JH (2007a) Resources of Eriobotrya in Guangdong, China. Acta Hort 750:197-202

He Q, Zhao XC, Guo QG, Li XL, Liang GL (2007b) Molecular identification of 5 loquat cultivars. Acta Hort 750:155-158

He Q, Wang W, Guo Q, Xiang S, Li X, Liang G (2012) Genetic Diversity and Utilization of Triploid Loquats (E. japonica Lindl). In: Caliskan M (ed) Genetic Diversity in Plants, pp 197-208. ISBN 978-953-51-0185-7. Doi: 10.5772/34155

Heberle-Bors E (1982) On the time of embryogenic pollen grain induction during sexual development of Nicotiana tabacum L. plants. Planta 156:402-406

Heberle-Bors E (1985) In vitro haploid formation from pollen: a critical review. Theor Appl Genet 71:361-374

Hegarty MJ, Barker GL, Brennan AC, Edwards KJ, Abbott RJ, Hiscock SJ (2008) Changes to gene expression associated with hybrid speciation in plants: further insights from transcriptomic studies in Senecio. Phil Trans R Soc B 363:3055-3069. Doi:10. $1098 /$ rstb.2008.0080

Henry RJ (2014) Sequencing of wild crop relatives to support the conservation and utilization of plant genetic resources. Plant Genetic Resources, 12(S1):S9-S11

Hernández JE (1999) Diversidad biológica: nuevos horizontes para la agricultura. Pulso agrario/monografía

Hidaka T, Yamada Y, Shichijo T (1979) In vitro differentiation of haploid plants by anther culture in Poncirus trifoliata (L.) Raf. Jpn J Breed 29:248-254

Hoban S, Arntzen JW, Bertorelle G, Bryja J, Fernandes M, Frith K, Hoelzel AR (2013) Conservation Genetic Resources for Effective Species Survival (ConGRESS): Bridging the divide between conservation research and practice. Journal for nature conservation, 21(6):433-437

Hochholdinger F and Hoecker N (2007) Towards the molecular basis of heterosis. Trends Plant Sci 12:427-432

Höfer M (1999) In vitro androgenesis in apple: improvement of the induction phase. Plant Cell Rep 22:365-370 
Höfer M and Lespinasse Y (1996) Haploidy in apple. In: Jain SM, Sopory SK, Veilleux, RE (eds) In vitro haploid production in higher plants, vol 3. pp 261-276

Huang B (1996) Gametoclonal variation in crop improvement. In: Jain SM, Sopory SK, Veilleux, RE (eds) In vitro haploid production in higher plants, vol 2. pp 73-91

Huang B and Sunderland N (1982) Temperature stress pretreatment in barley anther culture. Ann Bot 49:77-88

Humphreys MW, Gasior D, Lesniewska-Bocianowska A, Zwierzykowski Z, Rapacz M (2007) Androgenesis as a means of dissecting complex genetic and physiological controls: selecting useful gene combinations for breeding freezing tolerant grasses. Euphytica 158:337-345

Igic B and Kohn JR (2001) Evolutionary relationships among self-incompatibility RNases. Proc Natl Acad Sci USA 98:13167-13171

Islam SMS, Bari MA, Amin MN, Schmid JE (2001) In vitro plant regeneration through anther culture of some Bangladeshi wheat varieties. Plant Cell Tiss Org 11:31-39

Islam SMS and Tuteja N (2012) Enhancement of androgenesis by abiotic stress and other pretreatments in major crop species. Plant Sci, 182, 134-144

Jauhar PP (2006) Modern biotechnology as an integral supplement to conventional plant breeding: the prospects and challenges. Crop Sci 46(4):1841-1859

Jones OP, Gayner A, Watkins R (1984) Plant regeneration from callus tissue cultures of the cherry rootstock Colt (Prunus avium $\mathrm{x}$ P. pseudocerasus) and the apple rootstock $\mathrm{M}$. 25 (Malus pumila). J Hort Sci 59:463-467

Juárez J, Aleza P, Olivares-Fuster O, Navarro L (2004) Recovery of tetraploid clementine plants (Citrus clementina hort. ex Tan.) by in vitro colchicine treatment of shoot tips. Proc Int Soc Citriculture 1:151-154

Kadota M and Niimi Y (2002) In vitro induction of tetraploid plants from a diploid Japanese pear cultivar (Pyrus pyrifolia N. cv. Hosui). Plant Cell Rep 21(3):282-286

Kadota M and Niimi Y (2004) Production of triploid plants of Japanese pear (Pyrus pyrifolia Nakai) by anther culture. Euphytica 138:141-147

Kagan-Zur V, Yaron-Miron D, Mizrahi Y (1991) A Study of Triploid Tomato Fruit Attributes. J Am Soc Hort Sci 116(2):228-231

Kameya T and Hinata K (1970) Test-tube fertilization of excised ovules in Brassica. Japan J. Breed. 20:253-260

Karadeniz T and Senyurt (2007) Pomological characterization of loquat selections of the Black Sea region of Turkey. Acta Hort 750:113-116 
Karasawa MMG, Chiancone B, Gianguzzi V, Abdelgalel AM, Botta R, Sartor C, Germanà MA (2016) Gametic embryogenesis through isolated microspore culture in Corylus avellana L. Plant Cell Tiss Org 124:635-647. Doi: 10.1007/s11240-015-09211

Kasha KJ (1974) Haploids in higher plants: advances and potential. The Office of Continuing Education, University of Guelph Press, Guelph

Kasha KJ, Kao KN (1970) High frequency haploid production in barley (Hordeum vulgare L.). Nature 225:874-876

Kasha KJ, Song LSP, Park SJ, Reinbergs E (1977) Fixation of heterosis: comparison of F1 hybrids with their respective homozygous lines developing using doubled haploid procedures. Cereal Res Commun 5(3):205-214

Kasha KJ and Seguin-Swartz G (1983) Haploidy in crop improvement. In: Cytogenetics of Crop Plants. Swaminathan MS, Gupta K, Sinha U (eds). Macmillan India United, New Delhi. p 591

Kasha KJ, Hu TC, Oro R, Simion E, Shim YS (2001) Nuclear fusion leads to chromosome doubling during mannitol pretreatment of barley (Hordeum vulgare L.) microspores. Journal of Experimental Botany, Vol. 52, No. 359. pp 1227-1238

Kasha KJ and Maluszynsky M (2003) Production of doubled haploids in crop plants. An introduction. In: Maluszynsky M, Kasha KJ, Forster BP, Szaejko I (eds) Doubled haploid production in crop plants. A manual. Kluwer/FAO-IAEA, Dordrecht/Vienna. pp $1-4$

Kester DE and Asay R (1975) Almonds. In: Janick J and Moore JN (eds): Advances in fruit breeding. Purdue Univ. Press, West Lafayette, IN, USA. pp 387-419

Kester DE, Hansche PE, Beres V, Asay RN (1977) Variance components and heritability of nut and kernel traits in almond. J Amer Soc Hort Soc 102:264-266

Kester DE, Gradziel TM, Grasselly C (1991) Almonds (Prunus). In: Moore JN and Ballington HJ (eds). Genetic Resources of Temperate Fruit and Nut Crops. International Society for Horticultural Science, The Netherlands. pp 701-758

Kester DE and Gradziel TM (1996) Almonds. In: Janick J and Moore JN (eds): Fruit breeding, vol 3, John Wiley \& Sons, New York, USA. pp 1-97

Kester DE, Shackel KA, Micke WC, Viveros M, Gradziel TM (2004) Noninfectious bud failure in 'Carmel' almond: I. Pattern of development in vegetative progeny trees. J Amer Soc Hort Sci 129:244-249

Kihara H (1951) Triploid watermelons. Proc Amer Soc Hort Sci 58:217-230 
Krueger RR and Navarro L (2007) Citrus Germplasm Resources. Citrus Genetics, Breeding and Biotechnology, 45

Krueger RR and Roose ML (2003) Use of molecular markers in the management of citrus germplasm resources. J Amer Soc Hort Sci 128:827-837

Kupper RS, Federici CT, Roose ML (2010) Citrus rootstock breeding and evaluation. Citrograph 1(6):30-36

Khush GS and Virmani SS (1996) Haploids in plant breeding. In: Jain SM, Sopory SK, Veilleux RE (eds) In vitro haploid production in higher plants, vol 1. Kluwer, Dordrecht. pp 11-33

Ladizinsky G (1999) On the origin of almond. Genet Resour Crop Evol 46:143-147

Ledbetter CA, Ramming DW (1989) Seedlessness in grapes. Horticultural Reviews 11:159-184. Doi:10.1002/9781118060841.ch5

Li S, Yang D, Wu J, Zhang Z, Li T, Yang G, Liang Q, Liu X (2004) A primary study on anther culture of almond. Journal of Gansu Agricultural University 40:617-620

Li J, Wang Y Lin L, Zhou L, Luo N, Deng Q, Xian J, Hou C, Qiu Y (2008) Embryogenesis and plant regeneration from anther culture in loquat (Eriobotrya japonica L.). Sci Hortic-Amsterdam 115:329-336. Doi:10.1016/j.scientia.2007.10.007

Lichou J, Edin M, Tronel C, Saunier R (1990) Le espèce. En: Lichou J, Edin M, Tronel C, Saunier R (eds) Le cerisier. Ed. Ctifl, Paris, France. pp 35-39

Lin SQ, Sharpe RH, Janick J (1999) Loquat: botany and horticulture. Hortic Rev Am Soc Hort Sci 23:233-276

Lin SQ (2004) Plant material of loquat in Asian countries. First International Symposium on loquat. Options Méditérr 58:41-44

Lin SQ, Yang XH, Liu CM, Youli H, Yehua H, Guibing H, Zhang H, Xiaolong H, Liu Y, Liu Z (2004) Natural geographical distribution of genus Eriobotrya plants in China. Acta Hort 31(5):569-573

Lin SQ (2007) Word loquat production and research with special referent to China. Acta Hort 750:37-43

Liu Z and Gao S (2007) Micropropagation and induction of autotetraploid plants of Chrysanthemum cinerariifolium (Trev.) Vis. In Vitro Cellular \& Developmental Biology-Plant 43:404-408

Liu P, Zhao ZH, Dai L, Liu XY, Peng JY, Peng SQ, Zhou ZJ (2009) Genetic variations of Ziziphus cultivar 'Zanhuangdazao' by using RAPD technique. Acta Hort 840:149154 
Llácer G, Martínez-Valero R, Melgarejo P, Romero M, Toribio F (1995) Present status and future prospects of underutilized fruit tree crops in Spain. Cahiers Options Méditerranéennes 13:69-78

Lopes MS, Sefc KM, Laimer M, Da Camara Machado A (2002) Identification of microsatellite loci in apricot. Mol Ecol Notes 2:24-26. Doi: 10.1046/j.14718286.2002.00132.x

López M, Mnejja M, Rovira M, Collins G, Vargas FJ, Arús P, Batlle I (2004) Selfincompatibility genotypes in almond re-evaluated by PCR, stylar ribonucleases, sequencing analysis and controlled pollinations. Theor Appl Genet 109:954-964. Doi: $10.1007 / \mathrm{s} 00122-004-1656-2$

Luro F, Rist D, Ollitrault P (2001) Evaluation of genetic relationships in Citrus genus by means of sequence tagged microsatellites. Acta Hort 546:237-242

Luro F, Maddy F, Jacquemond C, Froelicher Y, Morillon R, Rist D, Ollitrault P (2004) Identification and evaluation of diplogyny in clementine (Citrus clementina) for use in breeding. Acta Hort 663:841-847

Lusser M, Parisi C, Plan D, Rodríguez-Cerezo E (2012) Deployment of new biotechnologies in plant breeding. Nature biotechnology, 30(3):231-239

Maluszynska J (2003) Cytogenetic tests for ploidy level analyses - chromosome counting. In: Doubled Haploid Production in Crop Plants: A Manual. Kluwer Academic Publishers, ISBN 1-4020-1544-5, Dordrecht. pp 391-395

Maluszynski M, Szarejko I, Barriga P, Balcerzyk A (2001) Heterosis in crop mutant crosses and production of high yielding lines using doubled haploid systems. Euphytica $120: 387-398$

Maluszynski M, Kasha KJ, Forster BP, Szarejko I (2003) Published doubled haploid protocols in plant species. In: Doubled Haploid Production in Crop Plants: A Manual. Kluwer Academic Publishers, Dordrecht. pp 309-335

Martìnez-Gòmez P, Sozzi GO, Sánchez-Pérez R, Rubio M, Gradziel TM (2003) New approaches to Prunus tree crop breeding. J Food Agr Env 1:52-63

Martínez-Gómez P, Sánchez-Pérez R, Vaknin Y, Dicenta F, Gradziel TM (2005) Improved technique for counting chromosomes in almond. Sci HorticAmsterdam 105:139-143. Doi: 10.1016/j.scienta.2005.01.019

Martínez-Gómez P, Sánchez-Pérez R, Dicenta F, Howad W, Gradziel TM (2006) Almond. In: C. Kole (eds). Genome mapping and molecular breeding, vol. 4, Fruits and nuts. Springer-Verlag, Heidelberg, Berlin. pp 229-242

Mehra A and Mehra PN (1974) Organogenesis and plantlet formation in vitro in almond. Bot Gaz 135:61-73 
Mesejo C, Reig C, Martínez-Fuentes A, Agustí M (2010) Parthenocarpic fruit production in loquat (Eriobotrya japonica Lindl.) by using gibberellic acid. Hort Sci 126(1):37-41

Messina R, Lain O, Marrazzo MT, Cipriani G, Testolin R (2004) New set of microsatellite loci isolated in apricot. Mol Ecol Notes 4:432-43. Doi: $10.1111 / \mathrm{j} .1471-$ 8286.2004.00674.x

Michellon R, Hugard J, Jonard R (1974) Sur l'isolément de colonies tissulaires de pêcher (Prunus persica Batsch., cultivars Dixired and Nectared IV) et d'amandier (Prunus amygdalus Stokes, cultivar Ai) a partir d'anthères cultivées in vitro. CR Acad Sci Paris Ser D, 278:1719-1722

Moose SP, Mumm RH (2008) Molecular plant breeding as the foundation for 21st century crop improvement. Plant physiology 147(3):969-977

Murashige T and Skoog F (1962) A revised medium for rapid growth and bio assays with tobacco tissue cultures. Physiologia plantarum 15(3):473-497

Murovec J and Bohanec B (2011) Haploids and doubled haploids in plant breeding. Plant Breeding. Rijeka, Croatia: InTech. pp 87-106

Musial K and Przywara L (1998) Influence of irradiated pollen on embryo and endosperm development in kiwifruit. Annals of Botany, Vol. 82, No. 6, pp. 747-756

Musial K and Przywara L (1999) Endosperm response to pollen irradiation in kiwifruit. Sexual Plant Reproduction, Vol. 12, No. 2, pp. 110-117

Musial K, Bohanec B, Jakše M, Przywara L (2005) The development of onion (Allium cepa L.) embryo sacs in vitro and gynogenesis induction in relation to flower size. In Vitro Cellular and Developmental Biology-Plant, Vol. 41, No. 4, pp. 446-452

Naval MM, Badenes ML, Blasco M (2014) Loquat: Progress and Expectations. In IV International Symposium on Loquat 1092. pp 19-24

Navarro L, Juarez J, Aleza P, Cuenca J, Julve JM, Piña JA, Olivares-Fuster O (2006) Selección de nuevos mandarinos triploides. Agraria Comunitat Valenciana. $2^{\mathrm{a}}$ época, año 2, 7:23-26

Navarro L and Juarez J (2007) Shoot-tip grafting in vitro: impact in the citrus industry and research applications. In: I.A. Khan (eds) Citrus genetics, breeding and biotechnology. CAB International, Wallingford. pp 353-364

Nitsch JP and Nitsch C (1969) Haploid plants from pollen grains. Science 163:85-85

Notsuka K, Tsuru T, Shiraishi M (2000) Induced polyploid grapes via in vitro chromosome doubling. J Jpn Soc Hort Sci 69:543-551. Doi:10.2503/jjshs.69.543 
Novelli VM, Cristofani M, Souza AA, Machado MA (2006) Development and characterization of polymorphic microsatellite markers for the sweet orange (Citrus sinensis L. Osbeck). Genet Mol Biol 29(1):90-96

Ocampo B, Conicella C, Moss JP (2000) Wide crossing: opportunities and progress. In Linking research and marketing opportunities for pulses in the $21 \mathrm{st}$ century. Springer Netherlands. pp 411-419

Ochatt SJ (2008) Flow cytometry in plant breeding. Cytometry 73A:581-598

Ochatt SJ and Revilla MA (2016) From stress to embryos: some of the problems for induction and maturation of somatic embryos. In: Germanà MA, Lambardi M (eds) In vitro embryogenesis in higher plants. Methods in molecular biology, Springer, Berlin, pp 523-535

Oiyama II and Kobayashi S (1993) Haploid obtained from diploid X triploid crosses of Citrus. J Jpn Soc Hort Sci 62(1):89-93

Oleszczuk S, Sowa S, Zimny J (2004) Direct embryogenesis and green plant regeneration from isolated microspores of hexaploid triticale ( $\times$ Triticosecale Wittmack) cv. Bogo. Plant Cell Rep 22(12):885-893. Doi:10.1007/s00299-004-0796-9

Ollitrault P, Dambier D, Seker M, Froelicher Y (2000) Rootstock breeding by somatic hybridization for the Mediterranean citrus industry. Acta Hort 535:157-162

Ollitrault P, Dambier D, Froelicher Y, Luro F, Cottin R (2001) La diversité des agrumes; structuration et exploitation par hybridation somatique. Comptes rendus de l'Académie d'Agriculture. 86:197-221

Ollitrault P, Froelicher Y, Dambier D, Luro F, Yamamoto M (2007) Seedlessness and ploidy manipulations. In: Khan IA (eds) Citrus Genetics, Breeding and Biotechnology. CAB International, Wallingford, UK. pp 197-218

Ollitrault P, Dambier D, Luro F, Froelicher Y (2008) Ploidy manipulation for breeding seedless triploid citrus. Plant Breeding Reviews 20:323-354. Doi: 10.1002/9780470380130.ch7

Ollitrault P, Navarro L (2012) Citrus. In Badenes ML and Byrne DH (eds) Fruit breeding. Handbook of Plant Breeding. Springer, New York. pp 623-662

Osborn TC, Pires JC, Birchler JA, Donald L, Auger Z, Chen J, Lee HS, Comai L, Madlung A, Doerge RW, Colot V, Martienssen RA (2003) Understanding mechanisms of novel gene expression in polyploids. Trends Genet 19:141-147. Doi:10.1016/S01689525(03)00015-5

Osolnik B, Bohanec B, Jelaska S (1993) Stimulation of androgenesis in white cabbage (Brassica oleracea var. capitata) anthers by low temperature and anther dissection. Plant Cell Tiss Org 32:241-246 
Otto SP and Whitton J (2000) Polyploid incidence and evolution. Annu Rev Genet 34:401-437. Doi:10.1146/annurev.genet.34.1.401

Ozkan H and Feldman M (2009) Rapid cytological diploidization in newly formed allopolyploids of the wheat (Aegilops-Triticum) group. Genome 52:926-934

Pacini E (2012) Pollen and seed analogies. Plant Biosyst 146:738-748. Doi: $10.1080 / 11263504.2012 .716798$

Padoan D, Chiancone B, Germanà MA, Khan PSSV, Barany I, Risueño MC, Testillano PS (2010) First stages of microspore reprogramming to embryogenesis through isolated microspore culture in loquat. In: III International Symposium on Loquat 887. pp 285290

Pandey S, Tyagi RK, Devi C, Singh N, Yadav SK (2014) Conservation and exchange of genetic resources in major vegetable crops. Indian Journal of Horticulture 71(2):281283

Park SM, Wakana A, Kim JH, Jeong CS (2002) Male and female fertility in triploid grapes (Vitis complex) with special reference to the production of aneuploid plants. Vitis 41:11-20

Paterson AH (2005) Polyploidy, evolutionary opportunity, and crop adaptation. Genetica 123:191-196. Doi:10.1007/s10709-003-2742-0

Pauly A, Pareyt B, Fierens E, Delcour JA (2013) Wheat (Triticum aestivum L. and T. turgidum L. ssp. durum) kernel hardness: II. Implications for end-product quality and role of puroindolines therein. Compr Rev Food Sci F 12:427-438. Doi:10.1111/15414337.12018

Peixe A, Barroso J, Potes A, Pais MS (2004) Induction of haploid morphogenic calluses from in vitro cultured anthers of Prunus armeniaca cv. "Harcot". Plant Cell Tiss Org 77:35-41. Doi: 10.1023/B:TICU.0000016498.95516.e6

Peña L, Cervera M, Ghorbel R, Dominguez A, Fagoaga C, Juarez J, Piña JA, Navarro L (2007) In: Khan IA (eds). Citrus genetics, breeding and biotechnology. CAB International, Wallingford. pp 329-344

Perera PIP, Yakandawala DMD, Hocher V, Verdeil JL, Weerakoon LK (2009) Effect of growth regulators on microspore embryogenesis in coconut anthers. Plant Cell Tiss Org 96(2):171-180. Doi:10.1007/s11240-008-9473-y

Pérez-Jiménez M, Carrillo-Navarro A, Cos-Terrer J (2012) Regeneration of peach (Prunus persica L. Batsch) cultivars and Prunus persica $\times$ Prunus dulcis rootstocks via organogenesis. Plant Cell Tiss Org 108(1):55-62 
Petersen KK, Hagberg P, Kristiansen K (2003) Colchicine and oryzalin mediated chromosome doubling in different genotypes of Miscanthus sinensis. Plant Cell Tiss Org 73:137-146

Pinillos V, Cañete ML, Sánchez, Cuevas J, Hueso JJ (2007) Fruit development and maturation phenological stages of 'Algerie' loquat. Acta Hort 750:331-336

Pintos B, Manzanera JA, Bueno MA (2007) Antimitotic agents increase the productivity of double-haploid embryos from cork oak anther culture. J Plant Physiol 164:1595-1604

Polat A (2007) Selection studies on loquat growing in Bakras (Turkey). Acta Hort 750:169-174

Polat A and Caliskan O (2007) Loquat Production in Turkey. Acta Hort 750:49-53

Powell W (1988) The influence of genotype and temperature pretreatment on anther culture response in barley (Hordeum vulgare L.). Plant Cell Tiss Org 12:291-297

Predieri S (2001) Mutation induction and tissue culture in improving fruits. Plant Cell Tiss Org 64:185-210. Doi:10.1023/A:1010623203554

Prescott-Allen R and Prescott-Allen C (2013) Genes from the wild: using wild genetic resources for food and raw materials. Routledge.

Raj Bhansali R, Driver JA, Durzan DJ (1990) Rapid multiplication of adventitious somatic embryos in peach and nectarine by secondary somatic embryogenesis. Plant Cell Rep 9:280-284

Ram M (2014) Polyploidy and distant hybridization in plant breeding. In: Ram M (ed) Plant breeding methods. PHI Learning Pvt Ltd., New Delhi. pp 423-445

Ramadugu C, Pfeil BE, Manjunath KL, Lee RF, Maureira-Butler IJ, Roose ML (2013) A six nuclear gene phylogeny of Citrus (Rutaceae) taking into account hybridization and lineage sorting. PLoS One 8(7):e68410

Ramsey J and Ramsey TS (2014) Ecological studies of polyploidy in the 100 years following its discovery. Phil Trans R Soc B 369:1-20. Doi:10.1098/rstb.2013.0352

Ramsey J and Schemske DW (1998) Pathways, mechanisms, and rates of polyploid formation in flowering plants. Annu Rev Ecol Syst 29:467-501. Doi: 10.1146/annurev.ecolsys.29.1.467

Rikhter AA (1969) Ways and methods of almond breeding. Tr Gos Nikit Bot Sad 43:81-94

Rimberia FK, Adaniya S, Ishimine Y, Etoh T (2007) Morphology of papaya plants derived via anther culture. Scientia Hort 111(3):213-219 
Roa C, Hamilton RS, Wenzl P, Powell W (2016) Plant Genetic Resources: Needs, Rights, and Opportunities. Trends in Plant Science 21(8):633-636

Rodríguez MC, Cuevas J, Hueso JJ (2007) Flower development in 'Algerie' loquat under scanning electron microscopy. Acta Hort 750:337-342

Roose ML (2007) Mapping and marker assisted selection in Citrus. In: Khan IA (eds), Citrus Genetics, Breeding and Biotechnology. CAB International, Wallingford, U.K. pp $275-286$

Roose ML and Williams TE (2007) Mutation breeding in Citrus. In: Khan IA (eds), Citrus Genetics, Breeding and Biotechnology. CAB International, Wallingford, U.K. pp 345-352

Roose ML and Close TJ (2008) Genomics of Citrus, a Major Fruit Crop of Tropical and Subtropical Regions. In: PIT. Moore and R. Ming (eds), Genomics of Tropical Crop Plants. Springer, p.187-200

Rowe PR and Rosales FE (1993) Breeding cooking bananas for areas with marginal growing conditions by using Cardaba (ABB) in cross-pollinations. Biotechnology Applications for Banana and Plantain Improvement, 128

Rubuluza T, Nikolova RV, Smith MT, Hannweg K (2007) In vitro induction of tetraploids in Colophospermum mopane by colchicine. S Afr J Bot 77:259-261

Rugini E, Pannelli G, Ceccarelli M, Muganu M (1996) Isolation of triploid and tetraploid olive (Olea europaea L.) plants from mixoploid cv. 'Frantoio' and 'Leccino' mutants by in vivo and in vitro selection. Plant Breeding 115(1):23-27. Doi: 10.1111/j.1439-0523.1996.tb00865.x

Russo G, Recupero S, Puglisi A, Recupero GR (2004) New triploid citrus hybrids by Italian genetic improvement.. Rivista di Frutticoltura e di Ortofloricoltura 66:14-18

Sajjad YASAR, Jaskani MJ, Mehmood A, Ahmad I, Abbas HAIDER (2013) Effect of colchicine on in vitro polyploidy induction in African marigold (Tagetes erecta). Pak J Bot 45:1255-1258

Sattler MC, Carvalho CR, Clarindo WR (2016) The polyploidy and its key role in plant breeding. Planta 243(2):281-296

Schuelke (2000) An economic method for the fluorescent labeling of PCR fragments. Nat Biotechnol 18:233-234. Doi: 10.1038/72708

Sedov EN (2014) Apple breeding programs and methods, their development and improvement. Russ J Genet 4:43-51. Doi:10.1134/S2079059714010092 
Sedov EN, Sedysheva GA, Serova ZM, Gorbacheva NG, Melnik SA (2014) Breeding assessment of heteroploid crosses in the development of triploid apple varieties. Russ J Genet 4:52-59. Doi:10.1134/S2079059714010109

Seguì-Simarro JM and Nuez F (2008a) How microspores transform into haploid embryos: Changes associated with embryogenesis induction and microspore derived embryogenesis. Physiol Plant 134:1-12. Doi: 10.1111/j.1399-3054.2008.01113.x

Seguí-Simarro JM and Nuez F (2008b) Pathways to doubled haploidy: chromosome doubling during androgenesis. Cytogenet Genome Res 120:358-369

Seguí-Simarro JM (2010) Androgenesis revisited. Bot Rev 76:377-404. Doi:10.1007/s12229-010-9056-6

Shao J, Chen C, Deng X (2003) In vitro induction of tetraploid in pomegranate (Punica granatum). Plant Cell Tiss Org 75:241-246. Doi: 10.1023/A:1025871810813

Sharma HC, Crouch JH, Sharma KK, Seetharama N, Hash CT (2002) Applications of biotechnology for crop improvement: prospects and constraints. Plant Sci 163:381-395

Sharp WR, Raskin RS, Sommer HE (1972) The use of nurse culture in the development of haploid clones in tomato. Planta 104:357-361

Shahvali-Kohshour R, Moieni A, Baghizadeh A (2013) Positive effects of cold pretreatment, iron source, and silver nitrate on anther culture of strawberry (Fragaria $\times$ ananassa Duch.). Plant Biotech Rep 7(4):481-488. Doi:10.1007/s11816-013-0286-Z

Simmonds NW and Sheperd K (1955) The taxonomy and origins of the cultivated bananas. Bot J Linn Soc 55:302-12. Doi: 10.1111/j.1095-8339.1955.tb00015.x

Smykal P (2000) Pollen embryogenesis - the stress mediated switch from gametophytic to sporophytic development. Current status and future prospects. Biol Plant 43:481-489

Smýkalová I, Šmirous Jr P, Kubošiová M, Gasmanová N, Griga M (2009) Doubled haploid production via anther culture in annual, winter type of caraway (Carum carvi L.). Acta Physiologiae Plantarum 31(1):21-31. Doi:10.1007/s11738-008-0195-x

Socias i Company R and Felipe AJ (1992) Self-compatibility and autogamy in 'Guara' almond. Journal of horticultural science 67(3):313-317

Socias i Company R (1998) Fruit tree genetics at a turning point: the almond example. Theor Appl Genet 96: 588-601. Doi: 10.1007/s001220050777

Socias i Company R (2002) Latest advances in almond self-compatibility. Acta Hort 591:205-212

Socias i Company R, Kodad O, Alonso JM, Gradziel JTM (2007) Almond Quality: A Breeding Perspective. In J. Janick (ed.). Horticultural Reviews 33:1-33 
Soltis DE, Albert VA, Leebens-Mack J, Bell CD, Paterson AH, Zheng C, Sankoff D, De Pamphilis CW, Wall PK, Soltis PS (2009) Polyploidy and angiosperm diversification. Am J Bot 96:336-348. Doi:10.3732/ ajb.0800079

Soltis PS and Soltis DE (2009) The role of hybridization in plant speciation. Annu Rev Plant Biol 60:561-588. Doi:10.1146/annurev.arplant.043008.092039

Sopory SK, Munshi M (1996) Anther culture. In: In vitro haploid production in higher plants. Springer Netherlands, pp 145-176

Soriano JM, Romero C, Vilanova S, Llácer G, Badenes ML (2005) Genetic diversity of loquat germplasm (Eriobotrya japonica (Thunb) Lindl) assessed by SSR markers. Genome 48(1):108-114

Soriano M, Li H, Boutilier K (2013) Microspore embryogenesis: establishment of embryo identity and pattern in culture. Plant Reproduction 26(3):181-196

Spiegel-Roy P and Kochba J (1981) Inheritance of nut and kernel traits in almond (Prunus amygdalus Batsch). Euphytica 30:167-174

Srivastava P and Chaturvedi R (2008) In vitro androgenesis in tree species: an update and prospect for further research. Biotech. Adv. 26:482-491

Starrantino A (1999) Tacle, a new triploid clementine x Tarocco hybrid. Rivista di Frutticoltura e di Ortofloricoltura 61(1): 45-47

Stebbins GL (1950) Variation and evolution in plants. Columbia University Press, New York

Sunderland N, Collins GB, Dunwell JM (1974) The role of nuclear fusion in pollen embryogenesis of Datura innoxia Mill. Planta 117:227-241

Szarejko I (2003) Doubled haploid mutant production. In: Maluszynsky M, Kasha KJ, Forster BP, Szaejko I (eds) FAO-IAEA. Doubled haploid production in crop plants. A manual. Kluwer, Dordrecht. pp 351-351

Szarejko I, Forster BP (2006) Doubled haploidy and induced mutation. Euphytica 158:359-37

Tamura M, Ushijima K, Sassa H, Hirano H, Tao R. Gradziel M, Dandekar AM (2000) Identification of self-incompatibility genotypes of almond by allele-specific PCR analysis. Theor Appl Genet 101:344-349. Doi: 10.1007/s001220051489

Tang H, Ren Z, Krczal G (2000) Somatic embryogenesis and organogenesis from immature embryo cotyledons of three sour cherry cultivars (Prunus cerasus L.). Sci Hortic-Amsterdam 83:109-126. Doi: 10.1016/S0304-4238(99)00073-4 
Tate JA, Soltis DE, Soltis PS (2005) Polyploidy in plants. In: Gregory TR (eds) The evolution of the genome. Elsevier, Academic Press, New York. pp 371-426

Tel-Zur N, Dudai M, Raveh E, Mizrahi Y (2011) In situ induction of chromosome doubling in vine cacti (Cactaceae). Hort Sci - Amsterdam 129:570-576. Doi: 10.1016/j.scienta.2011.04.027

Terai O (2002) Breeding loquat in Japan. First International Symposium on Loquat, Valencia, Spain, April 2002.

Tian S, Li B, Ding Z (2007) Physiological properties and storage technologies of loquat fruit. Fresh Prod 1(1):76-81

Touraev A, Pfosser M, Heberle-Bors E (2001) The microspore: A haploid multipurpose cell. Adv Bot Res 35:53-109

Tsay HS, Su CY (1985) Anther culture of papaya (Carica papaya L.). Plant Cell Rep 4:28-30

Tuvesson S, Dayteg C, Hagberg P, Manninen O, Tanhuanpaa P, Tenhola-Roininen T, Kiviharju E, Weyen J, Forster J, Schondelmaier J, Lafferty J, Marn M, Fleck A (2007) Molecular markers and doubled haploids in European plant breeding. Euphytica 158:305-312. Doi: 10.1007/s10681-006-9239-8

Udensi OU and Ontui V (2013) Determination by flow cytometry polyploidy inducingcapacity of colchicine in Cajanus cajan (L.) Mill sp. Pakistan Journal of Biological Sciences 16(13):630

Vacante V (2010) Citrus mites: identification, bionomy and control. CABI.

Van de Peer Y, Maere S, Meyer A (2009) The evolutionary significance of ancient genome duplications. Nat Rev Genet 10:725-732. Doi:10.1038/nrg2600

Väinölä A (2000) Polyploidization and early screening of Rhododendron hybrids. Euphytica 112:239-244. Doi: 10.1023/A:1003994800440

Varshney RK, Graner A, Sorrells ME (2005) Genomics assisted breeding for crop improvement. Trends Plant Sci 10:621-630

Varshney RV, Hoisington DA, Tyagi AK (2006) Advances in cereal genomics and applications in crop breeding. Trends Biotechnol 24:490-499

Wang YY, Sun CS, Wang CC, Chien NF (1973) The induction of the pollen plantlets of triticale and Capsicum annuum from anther culture. Scientia Sinica 16:147-151

Wang M, Van Bergen S, Van Duijn B (2000) Insights into a key developmental switch and its importance for efficient plant breeding. Plant Physiol 124:523-530 
Wedzony M, Forster BP, Zur I, Golemiec E, Szechynska-Hebda M, Dubas E, Gotebiowska (2009) Progress in doubled haploid technology in higher plants. In: Touraev A, Forster BP, Jain SM (eds) Advances in haploid production in higher plants. Springer. United Kingdom. pp 1-33

Wehner TC (2008) Watermelon. In: Prohens J, Nuez F (eds) Vegetables I. Handbook of Plant Breeding Volume 1. Springer New York. pp 381-418

Winarto B, Rachmawati F, Da Silva JAT (2011) New basal media for half-anther culture of Anthurium andreanum Linden ex André cv. Tropical. Plant Growth Regulation 65(3):513-529

Wolfe KH (2001) Yesterday's polyploids and the mystery of diploidization. Nat Rev Genet 2:333-341. Doi:10.1038/35072009

Wu JC, Yang XH, Lin SQ (2007) Optimization of the Inter-Simple Sequence Repeats reaction system in loquat germplasm. Acta Hort 750:135-139

Wu JH, Ferguson AR, Murray BG (2011) Manipulation of ploidy for kiwifruit breeding: in vitro chromosome doubling in diploid Actinidia chinensis Planch. Plant Cell Tiss Org 106(3):503-511

Wu JH, Ferguson AR, Murray BG, Jia Y, Datson PM, Zhang J (2012) Induced polyploidy dramatically increases the size and alters the shape of fruit in Actinidia chinensis. Ann Bot 109:169-179

Wu J, Ferguson AR, Murray BG, Duffy AM, Jia Y, Cheng C, Martin PJ (2013) Fruit quality in induced polyploids of Actinidia chinensis. Hort Sci 48(6):701-707

Wu GA, Prochnik S, Jenkins J, Salse J, Hellsten U, Murat F, et al. (2014) Sequencing of diverse mandarin, pummelo and orange genomes reveals complex history of admixture during citrus domestication. Nature biotechnology 32(7):656-662

Wutscher HK and Hill LL (1995) Performance of 'Hamlin' Orange on 16 Rootstocks in East-central Florida. Hort Sci 30(1):41-43

Xie JH, Wang W, Yang XH, Lin SQ (2007) Analysis of genetic relationships among Eriobotrya germplasm in China using ISSR markers. Acta Hort 750:203-208

Xu CM, Liu D, Zhang Z, Shen ZJ (2007) Genetic relationship of loquat analyzed by ISSR. Acta Hort 750:175-181

Xu Q, Chen LL, Ruan X, Chen D, Zhu A, Chen C, et al. (2013) The draft genome of sweet orange (Citrus sinensis). Nature genetics 45(1):59-66

Xing SH, Sun XF, Tang KX et al (2011) Induction and flow cytometry identification of tetraploids from seed-derived explants through colchicine treatments in Catharanthus roseus (L.) G. Don. J Biomed Biotechnol 2011:793198. Doi: 10.1155/2011/793198 
Yahata S, Sato S, Ohara H, Matsui H (2004) Induction of tetraploid in loquat (Eriobotrya japonica) with amiprofos-methyl and colchicine. Horticultural Research (Japan)

Yamamoto T, Mochida K, Imai T, Shi YZ, Ogiwara I, Hayashi T (2002) Microsatellite markers in peach (Prunus persica (L.) Batsch) derived from an enriched genomic and cDNA libraries. Mol Ecol Notes 2:298-301. Doi: 10.1046/j.1471-8286.2002.00242.x

Yang XH, Glakpe K, Lin SQ, Hu YL, He YH, Yuanshi JR, Liu YX, Hu GB, Liu CM (2005) Taxa of plants of genus Eriobotrya around the world and native of Southeastern Asia. J Fruit Sci 22(1):55-60

Yang XM, Cao ZY, An LZ, Wang YM, Fang XW (2006) In vitro tetraploid induction via colchicine treatment from diploid somatic embryos in grapevine (Vitis vinifera L.). Euphytica 152(2):217-224. Doi:10.1007/s10681-006-9203-7

Yang X, Ye CY, Cheng ZM, Tschaplinski TJ, Wullschleger SD, Yin W, Xia X, Tuskan GA (2011) Genomic aspects of research involving polyploid plants. Plant Cell Tiss Org 104(3):387-397. Doi:10.1007/s11240-010-9826-1

Yuan S, Liu Y, Fang Z, Yang L, Zhuang M, Zhang Y, Sun P (2009) Study on the relationship between the ploidy level of microspore-derived plants and the number of chloroplast in stomatal guard cells in Brassica oleracea. Agric Sci Chin 8:939-946

Zatapa-Arias FJ (2003) Laboratory protocol for anther culture technique in rice. In: Maluszynski M, Kasha KJ, Forster BP, Szarejko I (eds) Doubled haploid production in crop plant: a manual. Kluwer Academic Publishers, Boston/London, pp 109-116

Zhang YX, Lespinasse Y, Chevreu E (1990) Induction of haploidy in fruit trees. Acta Hort 280: 293-305

Zhang C, Tsukumi T, Ikeda M, Sato M, Okada H, Ohashi Y, Matsuno H, Yamamoto T, Wada M, Yoshikawa N, Matsumoto S, Li J, Mimida N, Watanabe M, Suzuki A, Komori S (2013) Effects of the microspore development stage and cold pre-treatment of flower buds on embryo induction in Apple (Malus $\times$ domestica Borkh.) anther culture. Journal of the Japanese Society for Horticultural Science 82(2):114-124

Zheng SQ (2007) Achievement and prospect of loquat breeding in China. Acta Hort 750: 85-91. Doi: 10.17660/ActaHortic.2007.750.10 



\section{LIST OF PAPERS AND WORKS}

\section{Scientific articles}

- Cimò G, Marchese A, Germanà MA (2016) Microspore embryogenesis induced through in vitro anther culture of almond (Prunus dulcis Mill.). Plant Cell Tiss Org 128(1):85-95. Doi: 10.1007/s11240-016-1086-2

- Germanà MA, Casamento D, Torello Marinoni D, Botta R, Cimò G (2016) Gametic embryogenesis through isolated microspore culture in mandarin (Citrus Reticulata Blanco), 'Mandarino Tardivo Di Ciaculli'. Citrus Research \& Technology (submitted)

\section{Poster presentation}

- Blasco M, Cimò G, Badenes ML, Naval MM (2016) Tools for increasing the loquat diversity. VIII Congreso de Mejora Genética de Plantas, $12^{\text {th }}-14^{\text {th }}$ July 2016, Vitoria-Gasteiz (Spain)

- Germanà MA, Casamento D, Torello Marinoni D, Botta R, Cimò G (2016) Gametic embryogenesis through isolated microspore culture in mandarin (Citrus Reticulata Blanco), cv 'Mandarino Tardivo Di Ciaculli'. 13th International Citrus Congress, Mabu Thermas \& Resort, $18^{\text {th }}-23^{\text {rd }}$ September 2016, Foz do Iguaçu (Brazil) 